INVESTIGATING APPROACHES TO ADVANCING KNOWLEDGE ON THE EFFECTS OF ROAD SAFETY TREATMENTS: AN APPLICATION TO ONTARIO RURAL TWO-LANE HIGHWAYS

By

Ian Lindley

BEng, Ryerson University, Toronto, Ontario, Canada, 2017

\author{
A thesis \\ presented to Ryerson University \\ in partial fulfillment of the \\ requirements for the degree of \\ Master of Applied Science \\ in the program of \\ Civil Engineering \\ Toronto, Ontario, Canada, 2019 \\ (C) Ian Lindley, 2019
}




\section{Author's Declaration}

I hereby declare that I am the sole author of this thesis. This is a true copy of the thesis, including any required final revisions, as accepted by my examiners.

I authorize Ryerson University to lend this thesis to other institutions or individuals for the purpose of scholarly research

I further authorize Ryerson University to reproduce this thesis by photocopying or by other means, in total or in part, at the request of other institutions or individuals for the purpose of scholarly research.

I understand that my thesis may be made electronically available to the public. 


\title{
INVESTIGATING APPROACHES TO ADVANCING KNOWLEDGE ON THE EFFECTS OF ROAD SAFETY TREATMENTS: AN APPLICATION TO ONTARIO RURAL TWO-LANE HIGHWAYS
}

\author{
By \\ Ian Lindley \\ Department of Civil Engineering \\ Ryerson University \\ Master of Applied Science, 2019
}

\begin{abstract}
Crash modification factors (CMFs) are important tools for understanding the safety benefits of treatment options. However, CMFs typically lack variability as they apply a single factor to all the sites that are treated by these road safety measures. Crash modification functions (CMFunctions) are one way to capture the variability of CMFs as a function of independent variables. This research conducted a case study on the application of edgeline, centreline and dual rumble strip treatments on Ontario provincial highways and investigated CMF variability by developing CMFunctions as well as separate CMFs for tangent and curved sections. Curved sections experienced greater benefits from the application of the rumble strips. In conducting the study, the Highway Safety Manual's application of rumble strip CMFs to Ontario roadways was also explored.
\end{abstract}




\section{Acknowledgements}

I would like to thank my partner, Catherine, for her love and understanding as I

conducted this research. This would not have been possible without you.

I would also like to thank my father Trevor, mother Joan and brothers Chris and Andrew.

The love and support they gave was instrumental and I cannot thank them enough for being there.

I would like to express my gratitude to Dr. Bhagwant Persaud for his guidance and support. His leadership played a critical role in this research.

My fellow graduate students under Dr. Persaud's supervision, Thanushan Rajeswaren and Alireza Jafari, helped with different aspects of the research and I would like to thank them.

Mr. Justin White deserves all the thanks that can be given as he provided his professional opinions on the work as well as access to the data used.

I would like to thank Mr. Craig Lyon for his help in developing the research and achieving the goals outlined in this thesis.

I would also like to thank Dr. Taha Saleem for providing access to resources that aided with the work done.

I would like to express my thanks to the Natural Sciences and Engineering Research Council of Canada (NSERC) and the Ministry of Transportation of Ontario (MTO) for their financial support through the Discovery Grant and Highway Infrastructure Innovation Funding Program (HIIFP) respectively. 


\section{Table of Contents}

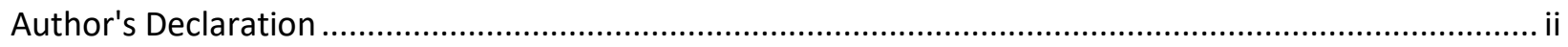

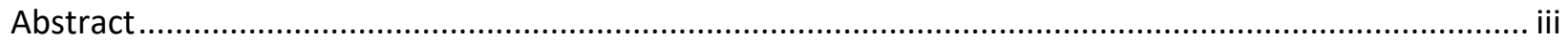

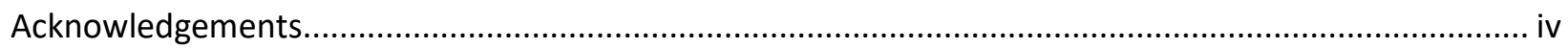

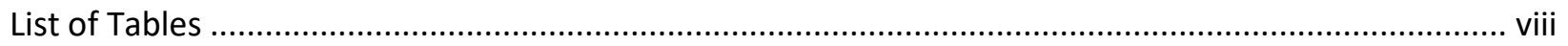

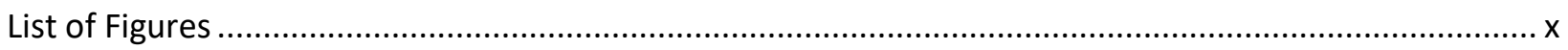

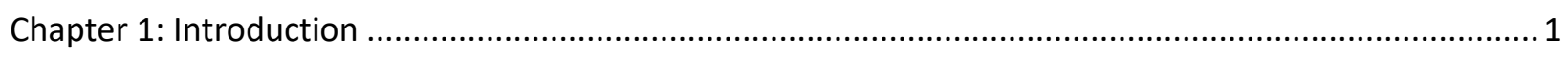

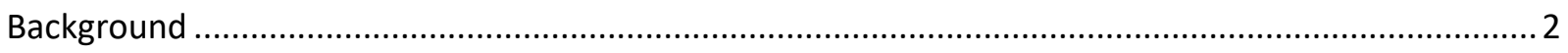

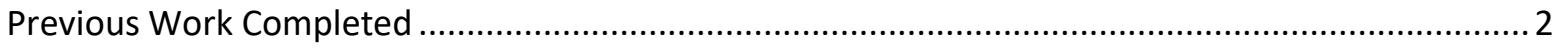

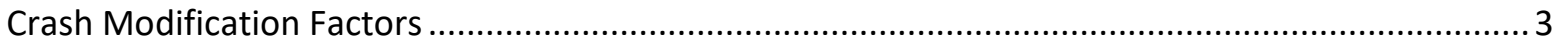

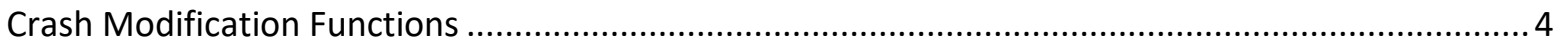

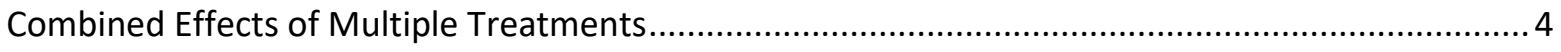

Highway Safety Manual Safety Crash Prediction Algorithm ....................................................... 4

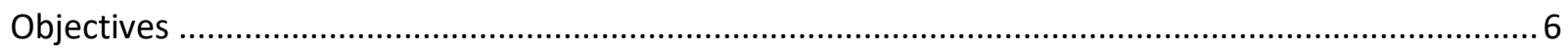

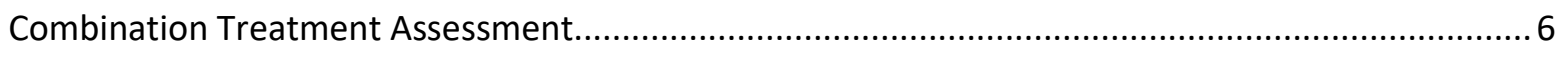

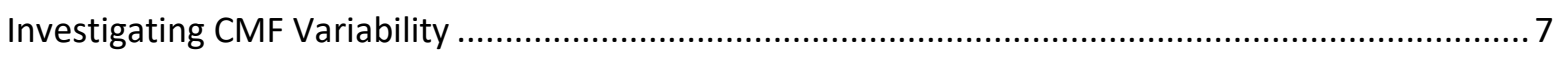

Assessing the Applicability of the Highway Safety Manual Crash Prediction Methodology for

Evaluating the Effects of Rumble Strip Application .............................................................. 8

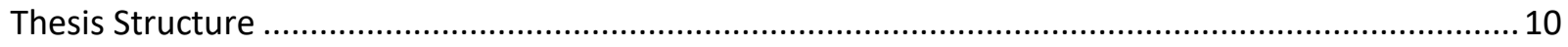

Chapter 2: Case Study of Centreline, Edgeline and Dual Rumble Strips: Development of Ontario Specific

CMFs and CMFunctions 
Rumble Strips

Combining Safety Treatments

Crash Modification Functions

Case Study Data

Case Study Locations

Tangent and Curved Sections

Traffic Volumes and Collsion Counts

Methodology.

Empirical Bayes Estimation.

Safety Performance Functions (SPFs)

Crash Modification Factors Variation

Ontario-Specific Results .

CMF Results for Aggregated Segments.

CMF Results for Tangent and Curved Sections

CMFunction Results

Discussion of Results.

Chapter 3: Assessing the Applicability of the Highway Safety Manual Crash Prediction Algorithm to Ontario Two-Lane Highways

Literature Review for the Highway Safety Manual Crash Prediction Algorithm 
Methodology

Investigating CMF Combination Methods 50

Validation of the Highway Safety Manual Crash Prediction Algorithm .53

Results from Investigating CMF Estimates using CMF Combination Methods... .56

CMF Estimates for Dual Rumble Strips using CMF Combination Methods .56

CMF Estimates for Dual Rumble Strips on Tangent and Curved Sections using CMF Combination

Methods

Results from Validation of the Highway Safety Manual Crash Prediction Algorithm.

Assessment through CMF Generation for Rumble Strips

Assessment Through CMF Generation for Shoulder Width 63

Discussion of Results 64

Chapter 4: Summary and Conclusions.

Appendix. 70

References .82 


\section{List of Tables}

Table 1: Summary of Rumble Strip CMFs (Eskandar, 2018) .......................................................... 2

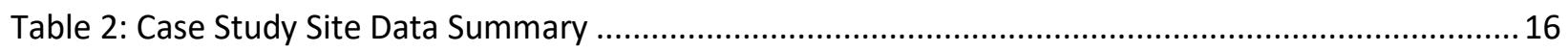

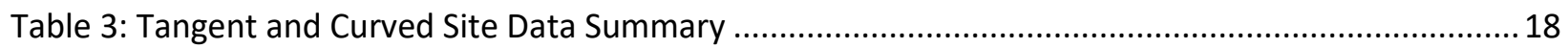

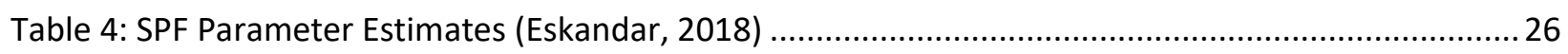

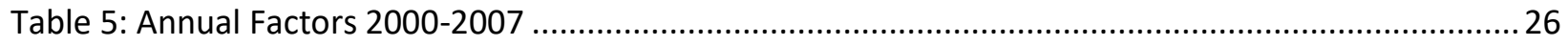

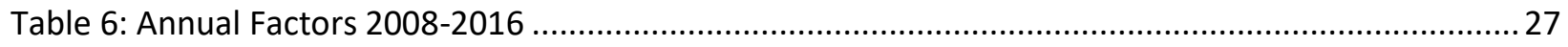

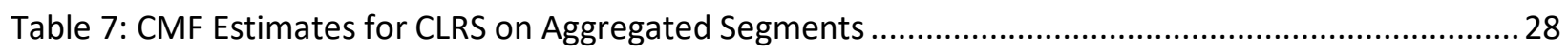

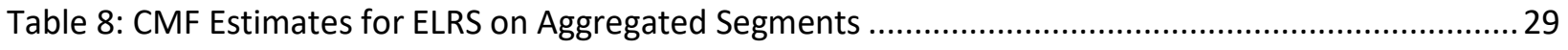

Table 9: CMF Estimates for Dual Rumble Strips on Aggregated Segments ............................................30

Table 10: CMF Estimates for CLRS using Tangent and Curved Sections ............................................. 31

Table 11: CLRS t-statistic Values for Tangent and Curved Sections ..................................................... 32

Table 12: CMF Estimates for ELRS on Tangent and Curved Sections..................................................... 33

Table 13: ELRS t-statistic Values for Tangent and Curved Sections ...................................................... 33

Table 14: CMF Estimates for Dual Rumble Strips on Tangent and Curved Sections ................................ 34

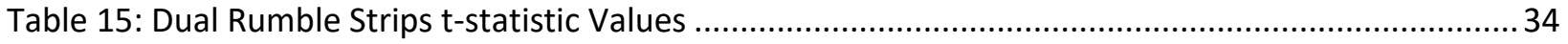

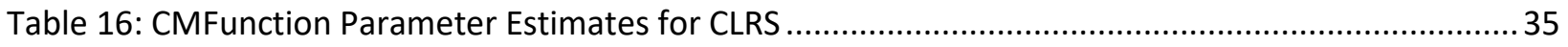

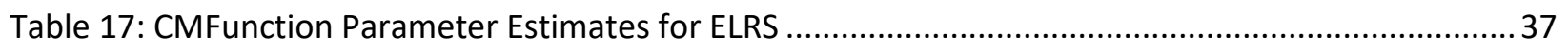

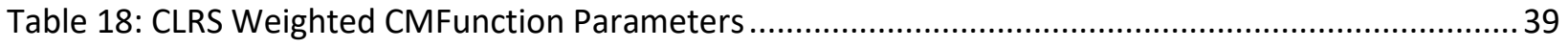

Table 19: ELRS Weighted CMFunction Parameter Results .................................................................. 40

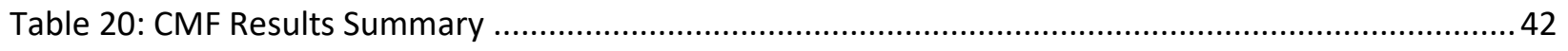

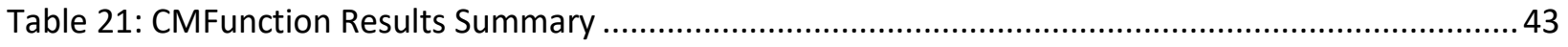


Table 22: Defining the Overlap of Individual Treatment Effects (Carter, et al., 2017)

Table 23: Method Selection for Same Type and Severity (Carter, et al., 2017) ...................................... 52

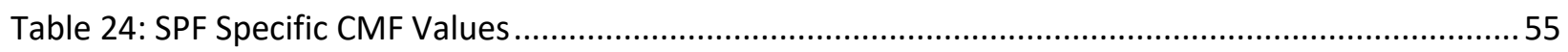

Table 25: CMF Estimates for Dual Rumble Strips using CMF Combination Methods...............................56

Table 26: Comparison of EB Results to Combination Methods using Aggregate Segments ..................... 57

Table 27: CMF Estimates for Dual Rumble Strips using Combination Methods.....................................5 58

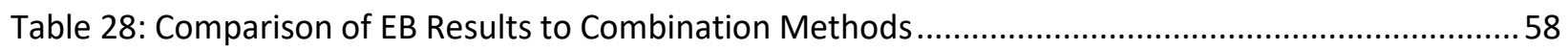

Table 29: CMF Estimates for Dual Rumble Strips on Tangent and Curved Sections using CMF Combination

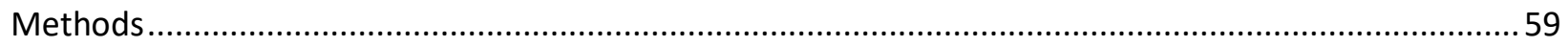

Table 30: Comparison of EB Results to Combination Methods on Tangent and Curved Sections ..............60

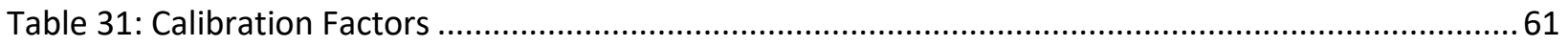

Table 32: CMFs Generated Through Predictive Model on Tangent Sections ........................................ 62

Table 33: Empirical-Bayes CMF Comparison with Highway Safety Manual Prediction Methods on Tangent

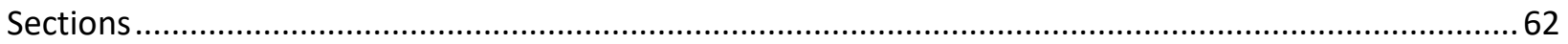

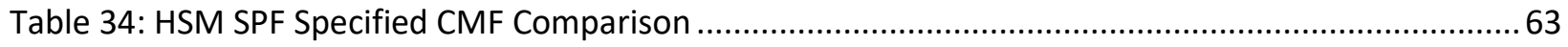




\section{List of Figures}

Figure 1: Rates of road traffic deaths per 100,000 population by WHO regions: 2013,2016 (World Health

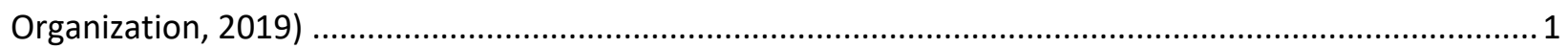

Figure 2: Centreline Rumble Strips CMFunction Values ................................................................ 36

Figure 3: Edgeline Rumble Strips CMFunction Values ................................................................... 37

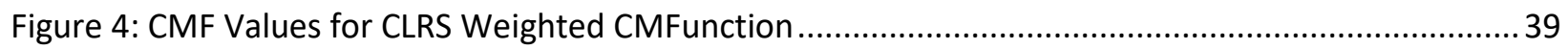

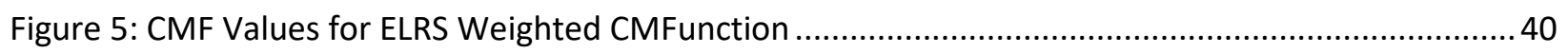

Figure 6: CLRS Total Crashes CMFunction to CMF Comparison......................................................... 45

Figure 7: CLRS PDO Crashes CMFunction to CMF Comparison......................................................... 45

Figure 8: CLRS Single Vehicle Crashes CMFunction to CMF Comparison ............................................. 46

Figure 9: ELRS Total Crashes CMFunction to CMF Comparison ....................................................... 46

Figure 10: ELRS PDO Crashes CMFunction to CMF Comparison....................................................... 47

Figure 11: ELRS Single Vehicle Crashes CMFunction to CMF Comparison ............................................ 47 


\section{Chapter 1: Introduction}

Major organizations across the world are aiming to reduce vehicle crashes. The World Health Organization (WHO) found that there were 1.35 million road traffic deaths globally in 2016 (World Health Organization, 2019). Figure 1 below shows the different road traffic death rates per 100,000 population in WHO Regions. To combat these numbers, organizations use road safety treatments that aim to increase safety. Treatments can reduce or eliminate the crashes through a variety of different manners depending on their design and application. In Canada alone, there were over 160,000 injury victims resulting from crashes across the country. (Transport Canada, 2019). These numbers will not decline without improvements to the driving environment and road safety measures affect this environment. With organizations looking to these measures, the effect that they have needs to be examined and quantified. This is the reasoning which governs this research work.

In this chapter, the research work is introduced by providing background information for the work done in this thesis. This background information includes information on the key topics discussed throughout the work, the objectives of this research and the structure of this thesis.

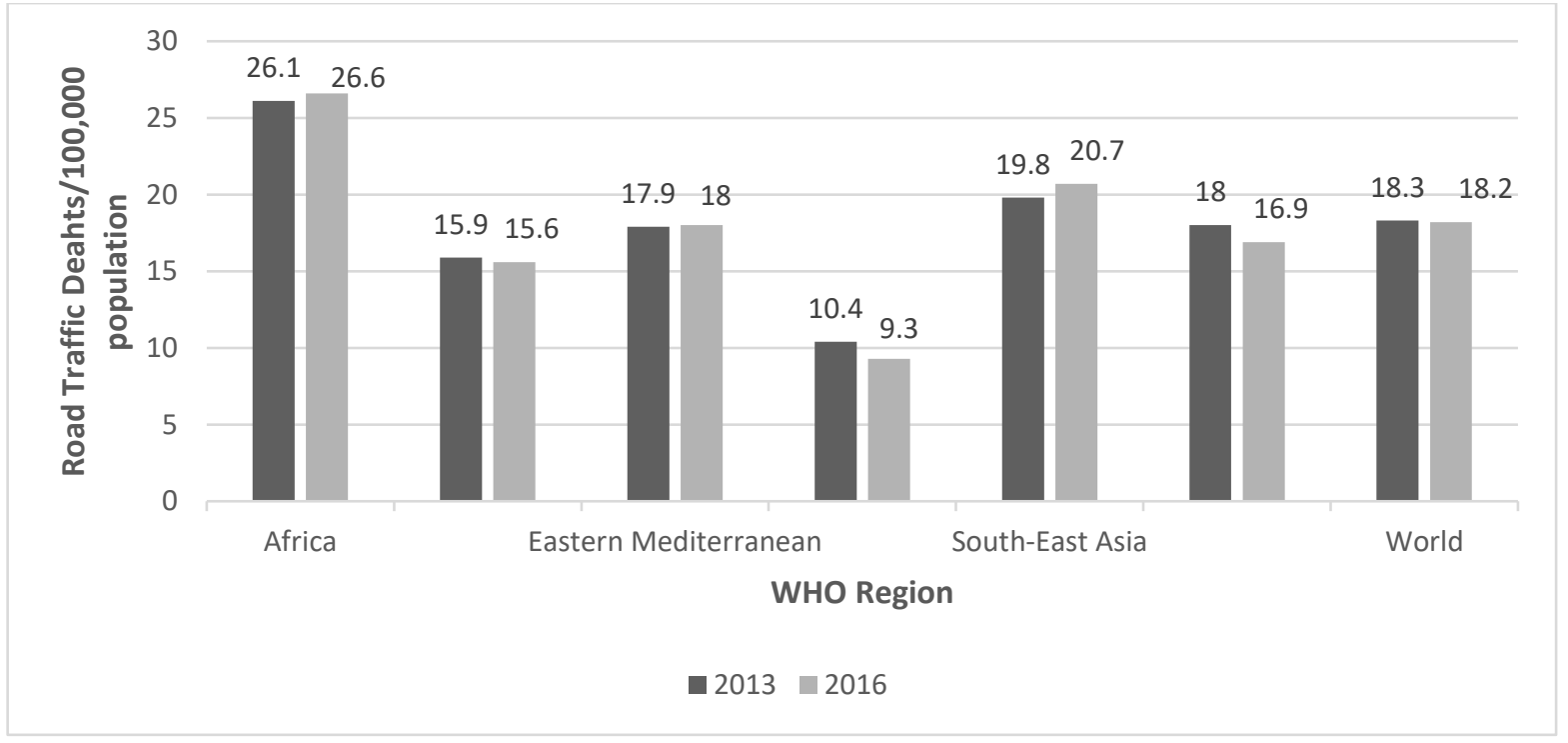

Figure 1: Rates of road traffic deaths per 100,000 population by WHO regions: 2013,2016 (World Health Organization, 2019) 


\section{Background}

The reasoning for studies on the effects of road safety treatments is to provide tools for organizations as they aim to reduce crashes and increase safety for all road users. Researching these treatments provides insight to their effects and justification for their implementation. It is also important to refine the research methods in order to ensure the accuracy of the CMFs that are generated.

This section of the thesis will provide insight into the work done in this study by supplying background information on the key topics examined. As well, this section outlines the objectives for this study and the structure of the work.

\section{Previous Work Completed}

This research builds on a recent thesis by Mark Eskandar titled Case Studies on Estimating Crash Modification Factors for Treatment Combinations with Empirical Investigation of Dual Rumble Strip Application in Ontario. A primary goal of Eskandar's work was to determine the Crash Modification Factors (CMFs) for dual rumble strips as they were applied to Ontario. An Empirical-Bayes (EB) study (Hauer, 1997) was conducted to develop the CMFs for the dual rumble strip treatment. However, dual rumble strip construction did not occur on the examined highways until after the study's time period. Without the real-world data to provide an accurate EB study, the CMFs for the dual rumble strips could only be estimated through the combination of the CMFs for both the CLRS and ELRS treatments (Eskandar, 2018). These individual CMFs and the results for the combined CMFs are found in Table 1 below.

Table 1: Summary of Rumble Strip CMFs (Eskandar, 2018)

\begin{tabular}{l|c|c|c|c|c|}
\multicolumn{1}{c}{ Crash Type } & \multicolumn{1}{c}{ Total } & \multicolumn{1}{c}{ Injury } & PDO & \multicolumn{1}{c}{ Single Vehicle } & Approach + Sideswipe \\
\hline CLRS CMF & 0.996 & 1.085 & 0.988 & 0.982 & 0.942 \\
\cline { 2 - 6 } ELRS CMF & 0.753 & 0.790 & 0.743 & 0.757 & 0.689 \\
\cline { 2 - 6 } Combined CMF & 0.805 & 0.790 & 0.743 & 0.799 & 0.689
\end{tabular}


These combined CMFs only provide estimates of the actual effectiveness of the dual rumble strips. A study of the real-world locations that the dual rumble strips are applied to is required in order to properly understand the benefits of this treatment option.

This previous study also had limited information for the CLRS and ELRS sites which hindered their CMF development and prevented the development of Crash Modification Functions. The datasets for the years 2014-2017 were unavailable at the time of the previous work but have been included in this study. This new data allowed for work to be done to capture CMF variability. The data also allowed for the investigation into whether the newly developed CMFs can be applied in the Highway Safety Manual crash prediction algorithm.

\section{Crash Modification Factors}

CMFs are representative values that are applied multiplicatively to the expected crashes to estimate the effect of a potential treatment (Gross, Persaud, \& Lyon, 2010). For example, a CMF of 0.5 would lead to the expectation that there would be a reduction in the expected frequency of crashes by $50 \%$. Conversely, a CMF value of 1.1 would lead to the belief that implementing the feature would cause an increase in the expected frequency of crashes by $10 \%$. Having these CMF values will allow organizations to understand and justify the implications of applying road safety treatments. Some CMFs for road safety treatments are available through previous research, but these are specific to the regions and treatments that were studied. CMFs for road treatments need to be studied so they can be developed and/or calibrated for the locations that they are to be applied to, such as Ontario highways, in order to provide accurate information that can lead on the safety effects of the decisions being made. 


\section{Crash Modification Functions}

A Crash Modification Function (CMFunction) is a further development of the CMF that provides CMF values depending on the values for the independent variables. These variables can be data variables such as crashes, length of road, traffic volumes or any combination of independent data variables. The CMFunctions better represent the actual conditions as a single CMF value cannot apply to all instances of the application of the treatment option. The functions can take many forms, including linear functions, that vary with the application circumstances.

\section{Combined Effects of Multiple Treatments}

The CMFs of individual treatments allow the justification of that treatment alone, but many scenarios involve more than one safety measure on the same road. These measures are acting at the same time and can result in unique situations that may not be understood by the CMFs of each one acting on their own. There are different ways to combine the effects of multiple treatments. The Highway Safety Manual (HSM) provides its own methodology that is used to combine the effect of the two or more treatments working together by taking the products of the CMFs (AASHTO, 2010). The differences between this methodology and the real-world data that pertains to treatments working together need to be understood so the methodology can be properly assessed. This research assesses the specific combination of centreline and edgeline rumble strips.

Highway Safety Manual Safety Crash Prediction Algorithm

The HSM includes Safety Performance Functions (SPFs) that allow for the prediction of the crashes on the different road types, including two-lane highways. These SPFs estimate the average crash rate for sites with the base conditions (AASHTO, 2010). For sites with conditions that differ from the base conditions, there are crash modification factors specific to the SPFs that account for the differences between the site conditions and base conditions. The crash prediction model also includes a calibration 
factor that accounts for the differences in time and location between the application of these models and the development of the predictive models. Newer predictive models have been developed that aim to provide more accuracy for the predicted crashe rates. 


\section{Objectives}

The effects of safety treatments can be examined through a variety of methodologies. In this study, different methodologies were compared using data provided by the Ministry of Transportation of Ontario (MTO), with a focus on the centreline, edgeline and dual rumble strip treatment options.

The objectives outlined in this section are broken down by the key topics so that information pertaining to each topic can be discussed and the objectives of each one understood. These topics include the assessment of the combination of multiple treatments, the investigation of CMF variability, and the assessment of the Highway Safety Manual's (HSM's) crash prediction methodology.

\section{Combination Treatment Assessment}

Combining treatment options can include several road safety measures. In this case study, the combined effect of centreline rumble strips (CLRS) and edgeline rumble strips (ELRS) is examined as the dual rumble strip treatment. As noted earlier, this effect has been estimated in the past by multiplying the individual CMFs together to generate a single combined CMF (AASHTO, 2010). Previous researchers have cast doubt on this method as it may overestimate the safety benefit from the application of multiple treatments and alternative methods have been proposed (Carter, et al., 2017). With information on sites in Ontario that feature the combination of ELRS and CLRS, the CMFs for these combined treatments can be evaluated. As such, the thesis will address the following objectives as they pertain to the combination of CMFs:

1. Determine the Ontario specific CMFs for combined rumble strip treatment based on the Empirical-Bayes method.

2. Estimate the CMF for the dual application of ELRS and CLRS based upon the Highway Safety Manual method of multiplication using Ontario specific results. 
3. Evaluate the alternative methods for combining the CMFs of multiple treatment options by comparing the CMFs from these methods to the observed dual rumble strip CMFs.

\section{Investigating CMF Variability}

The CMFs for the road safety treatments are given as averages that represent the different road conditions present when the treatment is applied. These values do not account for the changing conditions on the road such as the transition from tangent sections to curved sections or segments with different crash rates. Exploring the effects of the treatments on these varying conditions provides information on the conditions that the treatment should be applied to.

Investigating Difference between Tangent and Curved Road Sections

The MTO defines their road segments by the start and end points along the entirety of the provincial road network. These road segments contain smaller sections that can be defined as tangent or curved. The variability of rumble strip CMFs by horizontal alignment (i.e. tangent or curved) on these types of roads is not well understood but should be examined as different rumble strip types target different crash types. For example, edgeline rumble strips (ELRS) may be more effective at preventing crashes that occur due to vehicles running off the road whereas centreline rumble strips tend to be aimed at preventing vehicles from crossing over to the oncoming traffic. Based on their targeted crashes, the CMF for each treatment type could be different based on the alignment of the road section (i.e., tangent or curved). While there are different targets for each of the rumble strips, there exists some overlap due to the ability of both rumble strips to prevent crashes caused by inattentive drivers. For this thesis the objectives in exploring the safety effects of rumble strips for tangent and curved road sections are:

1. Investigate and develop more robust Ontario specific CMFs for tangent and curved road sections with ELRS, CLRS and dual rumble strips treatment options. 
2. Evaluate the effectiveness of each treatment type on the different crash types and severities examined including total, property-damage only (PDO) and single vehicle (SV) crashes.

3. Compare the results of the CMFs developed for the three treatment options and all crash types and severities.

Investigating the Development of Crash Modification Functions

With the CMFs defined for the three treatment options, CMFunctions can also be developed using the CMF estimates and characteristics for the individual road sections. These functions provide more accuracy as they allow the CMF value to vary depending on the independent variable(s) values. This means that the CMF value can be found for varying road conditions that are grouped together in the CMF calculation. For example, variations in the expected crashes $/ \mathrm{km} /$ year would lead to different CMF values when using the CMFunctions. The objectives for this thesis as they pertain to the development of CMFunctions are:

1. Develop the Ontario specific CMFunctions for all three treatment types and all crash types and severities.

2. Compare the single value CMFs to those given by the CMFunctions.

Assessing the Applicability of the Highway Safety Manual Crash Prediction Methodology for Evaluating the Effects of Rumble Strip Application

As stated earlier, the HSM includes predictive models for the different road and crash types. These models include a function for the base conditions, factors for the difference between the site and base conditions and a calibration factor that accounts for the changes between the predictive model's development and application. This factor can be developed using the Calibrator software (Lyon, Persaud, \& Gross, 2016) developed in Excel worksheets (Microsoft) and the road data provided by the MTO. The objectives related to assessing the HSM crash prediction methodology are: 
1. Find calibration factors for rural two-lane highways in Ontario by using the Calibrator software and the base condition sites.

2. Compare the results of the expected crashes from the calibrated safety performance functions to the observed crashes on the rumble strip sites in order to estimate the implied CMFs.

3. Compare the implied CMFs developed using the HSM method to those developed from the EB before-after analysis. 


\section{Thesis Structure}

This thesis is organized into the following chapters from this point onwards:

Chapter 2, Case Study of Centreline, Edgeline and Dual Rumble Strips: Development of Ontario Specific CMFs and CMFunctions: This chapter contains the development of the CMFs for ELRS, CLRS and combination treatments. These CMFs lead to the CMFunction generation for each of the treatment types.

Chapter 3, Assessing the Applicability of the Highway Safety Manual Crash Prediction Algorithm to Ontario Two-Lane Highways: In this chapter, the Highway Safety Manual method is examined for its applicability to Ontario rural two-lane highways.

Chapter 4, Summary and Conclusions: This chapter uses the results from the Case Study and Highway Safety Manual assessment to make relevant conclusions. 


\section{Chapter 2: Case Study of Centreline, Edgeline and Dual Rumble Strips: Development of Ontario Specific CMFs and CMFunctions}

This chapter of the thesis examines the work done for the development of the crash modification factors (CMFs) and the crash modification functions (CMFunctions) in Ontario. These CMFs and CMFunctions were developed for the centreline rumble strips (CLRS), edgeline rumble strips (ELRS) and dual rumble strips treatment options. For this development, data was used that focused on rural two-lane highways in the province of Ontario, Canada. The road and crash information datasets were provided by the Ministry of Transportation of Ontario (MTO). The road datasets were combined with geospatial data, provided by the MTO, to get the tangent and curved road sections of the MTO-defined segments. The various methods used in this study aim to provide definitive results for these specific types of road safety measures. 


\section{Literature Review for Rumble Strip Applications}

This thesis examines the use of three different rumble strip treatments: centreline rumble strips, edgeline rumble strips and dual rumble strips. Understanding the effects of the first two treatments options provides insights into the third as the dual rumble strip treatment consists of the other two working in combination.

\section{Rumble Strips}

Rumble strips are road features that alert drivers to departures from normal operation by giving both auditory and tactile feedback to the drivers when the vehicles' wheels travel over them. Two common locations for the rumble strips are the centreline and edgeline of the roadway. Edgeline rumble strips (ELRS) are targeted towards vehicles that run off the road due to driver inattention (Torbic, et al., 2009). Centreline rumble strips can prevent similar run-off-road crashes, but mainly aim to reduce crashes with vehicles traveling in the opposite direction, such as head-on and sideswipe crashes (Torbic, et al., 2009).

ELRS studies have focused primarily on run-off-the-road crashes on highway segments. Some studies have examined two-lane rural roads and how the ELRS impact this crash type on these types of roads. A study of two-lane rural roads in British Columbia found a $26.1 \%$ reduction for these crashes on these two-lane rural roads due to the implementation of the ELRS (Sayed, DeLeur, \& Pump, 2010). The same study also examined the effects of applying CLRS to these same roads in British Columbia and found reductions of $14 \%$ for all injury crashes and $25 \%$ reduction in all frontal and sideswipe injury crashes.

The studies on the CLRS were conducted mostly on two-lane rural roads with a focus on the head-on and sideswipe crashes (Torbic, et al., 2009). According to the studies, there was an average reduction of $65 \%$ in head-on crashes due to the implementation of the CLRS (Torbic, et al., 2009). In 
British Columbia, the same study as the ELRS on the two-lane rural roads found a $29.3 \%$ in the run-offroad and head-on crashes.

The effects of combining these rumble strips is limited as there are limited samples of this dual rumble strip treatment (Persaud, Lyon, Eccles, \& Soika, 2016). There was a study of this dual rumble strip conducted in British Columbia where the dual rumble strip safety treatment was found to cause a 21.4\% reduction in total run-off-road crashes and head-on crashes (Sayed, DeLeur, \& Pump, 2010).

The Transportation Association of Canada (TAC) outlines guidelines for the application of shoulder (edgeline) and centreline rumble strips (Bahar, Wales, \& Longtin-Nobel, 2001). The report made recommendations for the locations where the different rumble strip treatments should be applied. For edgeline rumble strips, the locations for their application included two-lane and multi-lane roadways that did not travel through urban areas. Centreline rumble strips were said to be applicable to two-lane, four-lane undivided roads and climbing or passing lanes with no-passing zones. They were also appropriate for horizontal curves with higher crash history or low radii.

\section{Combining Safety Treatments}

There are situations where the application of a single treatment option is not sufficient to achieve the level of safety that the designers desire. In these circumstances, more than one treatment option may be combined and applied to the road sections. An example of this would be the construction of left turn lanes while also increasing the shoulder width. There are times when there is a CMF value already developed for the effect of this combined treatment so designers can use this value to predict the changes in crashes due to the implementation of this combination, but this is an ideal scenario (Carter, et al., 2017).

Without this ideal scenario, studies have looked at providing formulas for the combination of the CMFs. The Highway Safety Manual (HSM) provides its own methodology, but the National 
Cooperative Highway Research Program (NCHRP) Project 17-63 looked into the potential tendency of the HSM method to overestimate the safety benefits of the combined treatment (Carter, et al., 2017). The difference between the two methodologies is explored later in the thesis as there is still discussion on how to combine CMFs.

\section{Crash Modification Functions}

Crash modification functions (CMFunctions) are developed as an improvement over CMFs as there are errors in using CMFs. One of the biggest issues of using CMFs is the lack of variability of the CMF to different scenarios within the same treatment type (Chen \& Persaud, 2014). For example, if a safety treatment had a CMF of 0.6 then one would expect to see a $40 \%$ reduction in crashes regardless of whether there were 20 crashes or 200 . This lack of variation means that planners may overestimate the safety benefits.

CMFunctions work by modifying the value based upon the independent variables selected. These independent variables may be single data variables, such as left turn lane length, or combinations of multiple variables, such as crashes/km/year. The inclusion of the independent variables means that the CMFunctions can better account for the treatment location characteristics (Osama, Sayed, \& Sacchi, 2016). 


\section{Case Study Data}

The work done in this thesis covers provincial highway segments in Ontario that feature centreline, edgeline and dual rumble strip treatments. The datasets for these segments were provided by the Ministry of Transportation of Ontario (MTO) and had to include information that would lead to the determination of the safety effects of these treatment options, such information includes:

- Location and year of rumble strip installation;

- Road characteristics, including tangent or curved, of segments containing rumble strip applications;

- Traffic volumes for provincial highways; and

- Crash related data for provincial highways.

\section{Case Study Locations}

The highways that were examined were rural two-lane undivided provincial highways in Ontario. The datasets on the highways that fit into this category and had rumble strip treatments applied were provided by the MTO. The three treatment options, ELRS, CLRS and dual rumble strips, were applied on sites varying in quantity and length. In total, there were 15 sites totaling $174.0 \mathrm{~km}$ of CLRS treated roadway, 6 sites totaling $43.6 \mathrm{~km}$ of ELRS treated roadway and 5 sites totaling $42.8 \mathrm{~km}$ of dual rumble strip treated roadway.

Reference sites required for use in the evaluation methodology are sites that are not treated by any of the treatment options but are similar to the treated sites in the other road characteristics. Reference sites from the previous study were updated with new crash data to provide new annual factors for the safety performance functions. Some of the reference sites from the previous work were treated with one of the rumble strip treatments and were no longer included in the reference group. These reference sites formed a combined $213.2 \mathrm{~km}$ over 12 unique sites. Appendix: Table 1 through Appendix: Table 4 
summarize the data collected for CLRS, ELRS, dual rumble strips and reference sites including the highway identification, location and length. Table 2 below summarizes some of the data for the MTO defined sites used in the case study.

Table 2: Case Study Site Data Summary

\begin{tabular}{|l|c|c|c|c|}
\hline & Reference Sites & CLRS Sites & ELRS Sites & Dual Rumble Strips Sites \\
\hline \# of km & 213.2 & 174.0 & 43.6 & $42 / 8$ \\
\hline \# of years & 16 & 16 & 16 & 16 \\
\hline km*years after & 3411 & 493 & 233 & 598 \\
\hline km*years before & - & 2291 & 464 & 8617 \\
\hline Average AADT before & 5158 & 4590 & 7180 & 13500 \\
\hline Max AADT before & 8200 & 12500 & 12700 & 5700 \\
\hline Min AADT before & 2350 & 1700 & 3650 & 9950 \\
\hline Average AADT after & - & 4958 & 9275 & 14200 \\
\hline Max AADT after & - & 12800 & 16700 & 6650 \\
\hline Min AADT after & - & 1700 & 4550 & \\
\hline
\end{tabular}

Tangent and Curved Sections

The MTO defined segments can be broken down into smaller tangent and curved segments that allow for the exploration of the effect of the rumble strip treatments on these types of roads and for developing CMFunctions. At the time this study was conducted, neither the CMF Clearinghouse Database (FHWA, 2019) nor the HSM (AASHTO, 2010) contained CMFs for these unique scenarios. It is important to know which type of road sections would see the greatest benefit from the rumble strip treatments. These curved and tangent sections were determined and categorized based on their treatment types (Eskandar, 2018). 
There are $16.4 \mathrm{~km}$ of CLRS, $19.0 \mathrm{~km}$ of ELRS and $26.9 \mathrm{~km}$ of dual rumble strip treatment that are tangent sections while $62.2 \mathrm{~km}$ of CLRS, $13.1 \mathrm{~km}$ of ELRS and $14.7 \mathrm{~km}$ of dual rumble strip treatment are curved sections. Summaries of the tangent and curved sections that have been treated with the CLRS, ELRS and dual rumble strip treatments are available in Appendix: Table 5, Appendix: Table 6 and Appendix: Table 7 respectively.

\section{Traffic Volumes and Collsion Counts}

The traffic volume data is important for the development of CMFs. Appendix: Table 8 and Appendix: Table 9 show the AADT for the years 2000-2016 which were used in this study. The MTO has provided this data, along with the crash data from their motor vehicle accident database in the form of Excel (Microsoft) spreadsheets. The data was sorted by a number of variables including location, location type, crash severity and initial impact. For the study, the following crash severities and types were examined:

- Total Crashes (Total);

- Fatal + Injury Severity Crashes (Injury);

- Property Damage Only Severity Crashes (PDO);

- Approach and Sideswipe Crashes (App + SS); and

- $\quad$ Single vehicle crashes (SV).

The tangent and curved sections were only examined separately for total, PDO and SV crashes due to data restrictions that carried over from the previous study (Eskandar, 2018). Appendix: Table 10 through Appendix: Table 17 outline the site crashes for the CLRS, ELRS and dual rumble strips for the road sections and the tangent and curved segments. Table 3 on the next page summarizes some of the data that is used in this study for the tangent and curved sections. 
Table 3: Tangent and Curved Site Data Summary

\begin{tabular}{|l|c|c|c|c|c|c|c|c|}
\hline \multirow{2}{*}{} & \multicolumn{2}{|l|}{ Reference Sites } & \multicolumn{2}{c|}{ CLRS Sites } & \multicolumn{2}{c|}{ ELRS Sites } & \multicolumn{2}{c|}{$\begin{array}{c}\text { Dual Rumble Strips } \\
\text { Sites }\end{array}$} \\
\cline { 2 - 10 } & Tan & Cur & Tan & Cur & Tan & Cur & Tan & Cur \\
\hline \# of km & 262 & 169 & 16 & 62 & 19 & 13 & 27 & 15 \\
\hline \# of years & 14 & 14 & 16 & 16 & 16 & 16 & 16 & 16 \\
\hline km*years after & 3448 & 2095 & 174 & 701 & 177 & 127 & 274 & 160 \\
\hline $\begin{array}{l}\text { km*years } \\
\text { before }\end{array}$ & - & - & 72 & 232 & 108 & 69 & 129 & 61 \\
\hline $\begin{array}{l}\text { Crashes/km } \\
\text { before }\end{array}$ & 1.00 & 1.02 & 1.12 & 1.16 & 1.48 & 1.96 & 1.35 & 1.45 \\
\hline $\begin{array}{l}\text { Crashes/km } \\
\text { after }\end{array}$ & - & - & 2.22 & 4.59 & 2.68 & 5.59 & 1.46 & 2.33 \\
\hline PDO crashes & 0.79 & 0.78 & 0.81 & 0.88 & 1.07 & 1.48 & 1.07 & 1.16 \\
\hline PDO crashes & - & - & 1.71 & 3.90 & 2.04 & 4.54 & 1.15 & 1.83 \\
\hline SV crashes/km & 0.79 & 0.81 & 0.91 & 0.91 & 1.12 & 1.42 & 1.08 & 1.15 \\
\hline SV crashes/km & - & - & 1.66 & 3.67 & 1.89 & 3.96 & 1.05 & 1.701 \\
\hline Average AADT & 5428 & 5814 & 5219 & 5152 & 8871 & 9981 & 8713 & 8105 \\
\hline Max AADT & 12600 & 12700 & 6800 & 5800 & 12700 & 12700 & 13200 & 12700 \\
\hline Min AADT & 1700 & 1700 & 3700 & 3700 & 5000 & 6600 & 5700 & 5700 \\
\hline Average AADT & - & - & 6587 & 6837 & 9922 & 11125 & 9783 & 9068 \\
\hline Max AADT after & - & - & 12800 & 12800 & 16700 & 16700 & 14200 & 14200 \\
\hline Min AADT after & - & - & 3600 & 3600 & 4550 & 7750 & 6400 & 6600 \\
\hline
\end{tabular}




\section{Methodology}

This thesis used the Empirical Bayes (EB) methodology for before-after studies in order to conduct this rumble strip evaluation (Hauer, 1997). A before-after study involves the investigation of the safety performance of sites before and after the treatment is applied. The EB before-after method was selected as it is designed to remove the concerns of regression to the mean (Hauer, 2015). Regression to the mean, as it pertains to road safety, is the phenomenon that roads may have high crashes in one time period and lower in the next without any safety measures applied. Without accounting for the regression to the mean, studies may overestimate the safety benefits of the treatment by attributing this fluctuation in crashes to the treatment.

\section{Empirical Bayes Estimation}

The changes in safety caused by the treatment are important for understanding the effects of the treatment. In an EB study, the change in safety caused by a treatment is given by the following formula:

$$
\Delta=\lambda-\pi
$$

Where,

$\lambda=$ the expected number of crashes that would have occurred at the site if the treatment had not been implemented

$\pi=$ the observed number of crashes that occurred at the specific treatment site after implementation of the treatment

$\lambda$ is determined in the EB methodology using the SPF specific to the crash type or severity under investigation. The first step to finding $\lambda$ is the estimation of the number of crashes in the before period using the SPFs for sites without treatment. These predictions are then summed per site per year to create the summed SPF predictions (P). This value is compared to the annual crash observations for each 
site $(x)$ in the same before period. Using these values, an approximation of the number of crashes $(\mathrm{m})$ can be found using the following equation:

$$
m=w(P)+(1-w) x
$$

This $w$ represents the weight that is given to the accidents and is calculated with the dispersion factor $(k)$ and the predictions $(P)$ as seen in the following equation:

$$
w=\frac{1}{1+k P}
$$

While this combination of predictions and observations helps deal with the regression to the mean effects, there needs to be a factor (f) to account for differences in traffic volumes, weather, crash reporting and the time periods before and after the treatment. This factor is applied to the previously calculated $m$ and is equal to the predicted after period crashes over the before period predictions. The result of this calculation is the expected number of crashes if there had not been a treatment applied, $\lambda$, and these equations can be seen below:

$$
\begin{gathered}
\qquad \lambda=f \times m \\
f=\frac{\text { predicted collisions after safety treatment }}{P}
\end{gathered}
$$

The CMF for a group of sites is estimated as an index of effectiveness $(\theta)$ and from summing $\lambda, \pi$, and their variances, using the following equation:

$$
\theta=\frac{\pi_{\text {sum }} / \lambda_{\text {sum }}}{1+\left(\operatorname{Var} \lambda_{\text {sum }} / \lambda^{2}{ }_{\text {sum }}\right)}
$$


The index of effectiveness may be used to determine the change cause by the safety treatment, as a percent change, by the following equation:

$$
\text { percent change }=100 \times(1-\theta)
$$

The standard deviation of $\theta$ is determined using the following equation:

$$
S D(\theta)=\sqrt{\frac{\theta^{2}\left[\frac{\text { Var } \pi_{\text {sum }}}{\pi^{2}{ }_{\text {sum }}}+\frac{\text { Var } \lambda_{\text {sum }}}{\lambda^{2}{ }_{\text {sum }}}\right]}{\left[1+\frac{\operatorname{Var} \lambda_{\text {sum }}}{\lambda^{2}{ }_{\text {sum }}}\right]^{2}}}
$$

Safety Performance Functions (SPFs)

SPFs are vital to the EB study as they provide the estimates for the expected crash frequency without treatment that the observed counts with the treatment are compared to. The SPFs can depend on a variety of independent variables and the selection of these variables is vital to the accuracy of the SPFs. For this study, the independent variables were selected as AADT and length of the segments as there is limited variation in the other road characteristics. Some of the characteristics that remained largely the same were posted speed, shoulder width and lane width. The statistical significance of these variables, as well the values for the coefficients for the variables, was completed using the SAS statistical software (SAS Institute, 2014). These SPFs provide an estimate for the number of crashes per year and took the form of the following equation:

$$
\frac{\text { Crashes }}{\text { year }}=e^{\alpha} A A D T^{b} \text { Length }^{c}
$$

In this formula, the values a, b and c, are the SPF parameters that vary for the different crash types and severities. Annual factors help account for the variations that occur between each reported year of data by acting as multipliers to the yearly safety performance functions (SPFs). These variations 
occur because of changes outside the study's control such as weather and reporting practices. The annual factors are determined by the following equation:

$$
\text { Annual Factor }=\frac{\text { Observed Crashes }}{\text { SPF Predicted Crashes }}
$$

These annual factors vary by year as well as by crash type and severity based upon the data from the reference sites. With the annual factors determined, the SPFs can then provide accurate estimates for the crash counts by accounting for the normal yearly variations outside of the study's control. The SPFs are multiplied by these annual factors in order to get the accurate estimates.

\section{Crash Modification Factors Variation}

CMFs are usually given as average values that apply to all sites that are treated with the safety feature. However, this is not accurate as the treatment may have different effects when applied to different conditions. These conditions can include different horizontal road alignments, such as tangent or curved, or different crash rates.

\section{Crash Modification Factors for Tangent and Curved Sections}

The CMFs for tangent and curved sections use the same methodology as the EB before-after study but use the data for the tangent and curved sections rather than the MTO-defined segments. As such, there are different SPFs that pertain to the tangent and curve sections. These unique SPFs lead to the calculation of the CMFs for the different alignment types.

When comparing the results for the tangent and curved sections, the t-test is performed in order to determine if the results are significantly different. This is done by comparing the critical tstatistic value and the observed t-statistic value. The critical t-statistic value is calculated using Excel's (Microsoft) two-tailed inverse formula, the probability that is being tested and the degree of freedom in the scenarios. If the difference between the tangent and curved sections is significant, the critical t- 
statistic value will be less than the observed t-statistic value which is found through the following formula:

$$
\begin{gathered}
\text { Observed } t-\text { test }=\frac{(\overline{x 2}-\overline{x 1)}}{\text { Spooled } * \sqrt{\frac{1}{n 1}+\frac{1}{n 2}}} \\
\text { Spooled }=\sqrt{\frac{\left(S E_{1}^{2} \times D F_{1}\right)+\left(S E_{2}^{2} \times D F_{2}\right)}{D F_{1}+D F_{2}}}
\end{gathered}
$$

where,

$\overline{x 1}$ and $\overline{x 2}=$ the absolute value of the CMFs

$n 1$ and $n 2=$ the number of sites used for $\mathrm{x} 1$ and $\mathrm{x} 2$

$S E_{n}=$ the standard error for $\mathrm{CMF}_{\mathrm{n}}$

$D F_{\mathrm{n}}=$ the degree of freedom for $\mathrm{CMF}_{\mathrm{n}}$

\section{Crash Modification Functions}

Crash Modification Functions (CMFunctions) are developed using the CMFs that are obtained by other methods. In this study, the method selected was the Empirical-Bayes before-after study using the Ontario road data. In particular, the tangent and curved sections' CMFs were used to develop the CMFs in this study. CMFunctions can take a variety of forms, but this study used a linear model with the form (Lyon, Persaud, \& Donnell, 2018):

$$
C M F=\text { Intercept }+ \text { Coefficient } \times \text { Independent Variable }
$$

This independent variable can be a single value, such as the AADT, or a combination of a few, such as crashes $/ \mathrm{km} /$ year. Selecting the independent variable is the second step, after the development of the CMFs, in the development of the CMFunctions. 
Using Excel (Microsoft) software, a regression analysis can be performed to determine the CMFunction values for the intercept and coefficient of the independent variable based on the CMF estimation for individual sites. This analysis used the crashes $/ \mathrm{km} /$ year of the sites as the independent variable, following the method outlined in previous studies (Lyon, Persaud, \& Donnell, 2018). The function that is generated by this comparison outputs CMF values for different crashes $/ \mathrm{km} /$ year. The minimum and maximum values of the crashes $/ \mathrm{km} /$ year provide the boundaries of where the CMFunction values can be applied. 


\section{Ontario-Specific Results}

The results for the case study of CLRS, ELRS and dual rumble strip treatments can be grouped together in specific subsections. The SPF parameters and annual factors are results that are used throughout these subsections. The subsections consist of the overall CMF results, the CMF results on the tangent and curved sections and the CMFunction results.

For the reasons outlined earlier, the SPFs used in this study follow the form seen in the equation below:

$$
\frac{\text { Crashes }}{\text { year }}=e^{\alpha} A A D T^{b} \text { Length }^{c}
$$

where,

$A A D T=$ the average annual daily traffic of the site

Length $=$ the length of the site

$\mathrm{a}, \mathrm{b}$ and $\mathrm{c}=$ SPF parameters that vary based on road type, crash type and severity

As stated earlier, the parameters for the SPF need to be determined in order to calculate the expected number of crashes in the absence of treatment. These values are determined using the SAS statistical software (SAS Institute, 2014) with negative binomial error structure and include a value for the over dispersion value ( $\mathrm{k}$ ) which is used in the empirical Bayes methodology and indicates if the variance is different than the mean as is the case for a negative binomial distribution. The smaller the $\mathrm{k}$ value, the less dispersed the variance value is from the mean (Hauer, 2015). The values for the parameters, as well as $k$, can be found in Table 4 on the next page. 
Table 4: SPF Parameter Estimates (Eskandar, 2018)

\begin{tabular}{|c|c|c|c|c|}
\hline Crash Type & $a$ & $b$ & $c$ & $\mathrm{k}$ \\
\hline \multicolumn{5}{|c|}{ MTO-Defined Segments } \\
\hline \multirow{5}{*}{$\begin{array}{l}\text { Total } \\
\text { Injury } \\
\text { PDO } \\
\text { Single Vehicle } \\
\text { Approach + Sideswipe }\end{array}$} & -5.4619 & 0.6469 & 0.9677 & 0.0345 \\
\hline & -6.1696 & 0.5878 & 0.8633 & 0.0694 \\
\hline & -5.9628 & 0.6606 & 1.0174 & 0.0366 \\
\hline & -4.943 & 0.5652 & 0.9527 & 0.0429 \\
\hline & -10.1432 & 0.9203 & 1.0218 & 0.0705 \\
\hline \multicolumn{5}{|c|}{ Curved Sections } \\
\hline Total & -6.1609 & 0.736 & 0.9052 & 0.1427 \\
\hline PDO & -6.6589 & 0.7623 & 0.9006 & 0.1190 \\
\hline Single Vehicle & -5.663 & 0.6488 & 0.9272 & 0.1147 \\
\hline \multicolumn{5}{|c|}{ Tangent Sections } \\
\hline Total & -4.801 & 0.5675 & 0.9646 & 0.1198 \\
\hline PDO & -4.909 & 0.5436 & 1.0019 & 0.1044 \\
\hline Single Vehicle & -3.9975 & 0.4491 & 0.9510 & 0.1188 \\
\hline
\end{tabular}

With the SPF parameters determined, the annual factors can be found using the reference sites.

These annual factors increase the accuracy of the predictions and are found in Tables 5 and 6 below. The reason these annual factors are based upon the reference sites is because they provide insights to the variations that occur on the sites throughout the years without the impact of the rumble strip treatments.

Table 5: Annual Factors 2000-2007

\begin{tabular}{|c|c|c|c|c|c|c|c|c|}
\hline Year & 2000 & 2001 & 2002 & 2003 & 2004 & 2005 & 2006 & 2007 \\
\hline Total & 0.942 & 1.052 & 1.029 & 1.129 & 1.122 & 1.079 & 1.050 & 1.196 \\
\hline Injury & 1.139 & 1.159 & 1.060 & 1.177 & 1.088 & 1.088 & 1.105 & 1.160 \\
\hline PDO & 0.880 & 1.016 & 1.017 & 1.111 & 1.128 & 1.072 & 1.030 & 1.203 \\
\hline$A p p+S S$ & 0.523 & 0.880 & 1.156 & 0.851 & 0.617 & 0.832 & 0.762 & 0.934 \\
\hline SV & 0.945 & 0.993 & 1.005 & 1.127 & 1.141 & 1.102 & 1.052 & 1.175 \\
\hline
\end{tabular}


Table 6: Annual Factors 2008-2016

\begin{tabular}{|c|c|c|c|c|c|c|c|c|c|}
\hline Year & 2008 & 2009 & 2010 & 2011 & 2012 & 2013 & 2014 & 2015 & 2016 \\
\hline Total & 1.037 & 1.072 & 0.867 & 0.613 & 0.916 & 1.108 & 1.042 & 1.055 & 1.016 \\
\hline Injury & 1.007 & 0.880 & 0.858 & 0.498 & 0.689 & 0.962 & 0.947 & 0.852 & 0.779 \\
\hline PDO & 1.041 & 1.122 & 0.865 & 0.642 & 0.972 & 1.140 & 1.139 & 1.096 & 1.067 \\
\hline$A p p+S S$ & 0.941 & 1.104 & 0.959 & 2.121 & 0.626 & 0.773 & 0.887 & 1.014 & 0.999 \\
\hline SV & 1.049 & 1.107 & 0.860 & 0.593 & 0.879 & 1.048 & 1.014 & 0.992 & 0.951 \\
\hline
\end{tabular}

Using the SPFs and the annual factors above, the CMFs for each of the treatment options can be calculated. CMFs were first calculated for aggregated segments that included tangents and curves. Then CMFs were calculated separately for tangents and curve sections before aggregating those individual effects to get an overall CMF that could be compared to the first set of CMFs. The results for the aggregated segments' CMFs can be found in Tables 7, 8, and 9 for the CLRS, ELRS and dual rumble strip treatments respectively. Included in these tables are the estimates for the expected number of crashes if no treatment had occurred and the observed number of crashes after treatment.

\section{CMF Results for Aggregated Segments}

CMF Results for Centreline Rumble Strips on Aggregated Segments

Table 7 on the next page shows the results for the CLRS CMF calculations. The CMFs show that implementing CLRS has virtually the same effect on the injury crashes and the approach and sideswipe crashes. All the crash types show reductions due to application of the CLRS treatment and, other than the PDO crashes, are significant at the $95 \%$ confidence level. These values indicate that applying the CLRS treatment can be an effective method for reducing crashes on the road sections. These rumble strips primarily target the approach and sideswipe crashes as they alert drivers when they encroach upon the oncoming lane. This can be seen with the CMF result of 0.702 , but the standard deviation was the highest due to the presence of only 36 crashes in the dataset. These approach and sideswipe crashes 
can lead to a higher number of injury crashes than the single vehicle crashes due to the nature of the crashes. As such, it can be expected that there will be a similar reduction in injury crashes with a drop in the approach and sideswipe crashes. This expectation is reflected in the results for the injury crashes as the $\mathrm{CMF}$ is 0.705 for these types of crashes. While they may not be the primary targets, the single vehicle crashes are still impacted due to the ability of the rumble strips to alert the driver that they are deviating from normal road operations. With the impacts on the different types of crashes, it should also be expected that there will be a reduction in the total crashes despite these crashes including types not specifically targeted by the rumble strip treatments. The overall reduction in crashes show that the CLRS can be used as an effective safety treatment for road sections.

Table 7: CMF Estimates for CLRS on Aggregated Segments

\begin{tabular}{|l|c|c|c|c|c|}
\cline { 2 - 6 } \multicolumn{1}{c|}{ Crash Type } & Total & Injury & PDO & SV & App + SS \\
\hline Observed "After" Crashes & 416 & 71 & 342 & 296 & 36 \\
\hline Expected “After" Crashes & 472 & 101 & 365 & 351 & 51 \\
\hline CMF & 0.882 & 0.705 & 0.938 & 0.844 & 0.702 \\
\hline SE & 0.045 & 0.087 & 0.053 & 0.050 & 0.126 \\
\hline CMF 95\% Upper Limit & 0.971 & 0.878 & 1.043 & 0.945 & 0.945 \\
\hline
\end{tabular}

CMF Results for Edgeline Rumble Strips on Aggregated Segments

The results for the ELRS CMF calculations are found in Table 8 on the next page. The effects of the ELRS are considerably different for each of the crash types. However, the total and injury crashes CMFs are not significant at the $95 \%$ confidence level. There are significant standard errors due to the low number of crashes on the ELRS treated sites. However, the single vehicle crashes experience a significant crash reduction with a CMF at 0.689 . This crash type is the closest MTO defined crash type to the run-off-road crashes that the ELRS treatment targets. These crashes are the target due to the location of the ELRS between the roadway and the edge of the road. PDO crashes are expected to change in a similar fashion as the single vehicle crashes due to the nature of the single vehicle crashes. As seen, the PDO crash CMF is calculated as 0.818 which follows this expectation as the single vehicle 
crashes CMF is 0.689 . The approach and sideswipe crashes were omitted in this section due to a lack of data causing unreliability in the result for the CMF. Unlike the CLRS, the ELRS does not target this type of crash and the treatment may not have been applied to roads with higher counts for this crash type. Despite some CMFs lacking statistical significance, the results indicate considerable improvements for the targeted crash types and severities.

Table 8: CMF Estimates for ELRS on Aggregated Segments

\begin{tabular}{|l|c|c|c|c|c|}
\cline { 2 - 6 } \multicolumn{1}{c|}{ Crash Type } & Total & Injury & PDO & SV & App + SS \\
\hline Observed "After" Crashes & 177 & 45 & 132 & 95 & 13 \\
\hline Expected "After" Crashes & 201 & 46 & 161 & 138 & 3 \\
\hline CMF & 0.878 & 0.980 & 0.818 & 0.689 & 0.410 \\
\hline SE & 0.072 & 0.162 & 0.078 & 0.075 & 0.125 \\
\hline CMF 95\% Upper Limit & 1.021 & 1.304 & 0.974 & 0.839 & 0.660 \\
\hline
\end{tabular}

CMF Results for Dual Rumble Strips on Aggregated Segments

Table 9 on the next page contains the results for the dual rumble strip treatment CMF estimates. All the CMFs indicate a reduction in crashes, but only the CMFs for total and PDO crashes are significant at the $95 \%$ confidence level. These two crash types have CMFs showing an almost $30 \%$ reduction in crashes due to the implementation of the dual rumble strips. While the other CMFs should be taken with the understanding that there is a lack of statistical significance, the results showing reductions for all crash types and severities is expected as the dual rumble strips target all the types of crashes studied in this thesis. The lack of significance could have been caused by the low number of crashes as seen in the injury crashes. The approach and sideswipe crashes had a high standard error due to a lack of data. The injury and single vehicle crashes are significant at the $90 \%$ confidence level, but the approach and sideswipe are still not significant. While there is a lack of significance for some of the CMFs, the values of the CMFs indicate a reduction in the expected crashes. 
Table 9: CMF Estimates for Dual Rumble Strips on Aggregated Segments

\begin{tabular}{|c|c|c|c|c|c|}
\hline Crash Type & Total & Injury & PDO & SV & $A p p+S S$ \\
\hline Observed "After" Crashes & 100 & 20 & 80 & 81 & 13 \\
\hline Expected "After" Crashes & 140 & 26 & 111 & 94 & 15 \\
\hline CMF & 0.712 & 0.755 & 0.723 & 0.864 & 0.884 \\
\hline SE & 0.072 & 0.172 & 0.082 & 0.098 & 0.255 \\
\hline CMF 95\% Upper Limit & 0.856 & 1.098 & 0.888 & 1.059 & 1.394 \\
\hline
\end{tabular}

CMF Results for Tangent and Curved Sections

Dividing the MTO-defined segments into smaller sections defined as tangent or curved allows for the separate effects on these sections to be observed. The results from these observations are available in Tables 10, 12, and 14 for the CLRS, ELRS and dual rumble strips respectively. The results include the CMFs, expected number of crashes if no treatment had occurred and the observed number of crashes after treatment. Aggregate results are provided for each treatment option that combine the separate effects for tangents and curves into an overall CMF. Tables 11,13 and 15 demonstrate the tstatistic results for significance of the CMF difference between the tangent and curved sections.

\section{CMF Results for Centreline Rumble Strips on Tangent and Curved Sections}

The results for the CLRS effects on tangent and curved sections are found in Table 10 on the next page. The CMFs on the tangent sections indicate that the CLRS has a similar effect on the different crash types and severities. All the results for CLRS, for both tangent and curved sections, are significant at the $95 \%$ confidence level. The CMFs on the curved sections indicate that the CLRS has more impact on these sections when compared to the tangent but have a similar effect on the different crash types and severities. With these CMF values, it can be seen that the CLRS treatment causes a significant reduction in crashes on both the tangent and curved sections. However, the effect is greater on the curved sections of the road with CLRS treatment than the tangent sections with the same treatment. As can be 
seen in Table 11 on the next page, the results for the tangent and curved sections are significantly different for all crash types other than the single vehicle crashes.

All the overall CMF values determined were below 1.0, indicating improvements to the sites treated by the CLRS, and were significant at the $95 \%$ confidence level. There is a considerable gap between the total crashes CMF and the other two CMFs. This indicates that the total crashes consist of higher amounts of crash types that were not included in the calculation of the CMFs. Results were not found for the injury and approach and sideswipe crashes that were included in the CMF calculations for the MTO-defined segments. These omissions are due to the fact that these CMFs are based upon the tangent and curved sections, which did not include the calculations required for CMF calculation for these crash types. Despite these omissions, these micro focused CMFs provide an increased accuracy for the CMF values by using SPFs that developed for the tangent and curved sections rather than the overall segments which had both. These specific SPFs were tailored to the differences between the tangent and curved sections rather than as an average for both.

Table 10: CMF Estimates for CLRS using Tangent and Curved Sections

\begin{tabular}{|l|c|c|c|c|c|c|c|c|c|}
\cline { 2 - 9 } \multicolumn{1}{c|}{} & \multicolumn{3}{c|}{ Tangent Sections } & \multicolumn{3}{c|}{ Curved Sections } & \multicolumn{3}{c|}{ Overall } \\
\cline { 2 - 9 } \multicolumn{1}{l|}{ Crash Type } & Total & PDO & SV & Total & PDO & SV & Total & PDO & SV \\
\hline $\begin{array}{l}\text { Observed } \\
\text { "After" } \\
\text { Crashes }\end{array}$ & 81 & 60 & 62 & 221 & 165 & 171 & 302 & 225 & 233 \\
\hline $\begin{array}{l}\text { Expected } \\
\text { "After" } \\
\text { Crashes }\end{array}$ & 103 & 77 & 80 & 260 & 204 & 205 & 363 & 281 & 285 \\
\hline CMF & 0.787 & 0.780 & 0.773 & 0.735 & 0.704 & 0.720 & 0.832 & 0.835 & 0.817 \\
\hline SE & 0.094 & 0.110 & 0.106 & 0.051 & 0.057 & 0.057 & 0.050 & 0.058 & 0.056 \\
\hline $\begin{array}{l}\text { CMF 95\% } \\
\text { Upper Limit }\end{array}$ & 0.975 & 0.996 & 0.985 & 0.837 & 0.818 & 0.834 & 0.933 & 0.951 & 0.930 \\
\hline
\end{tabular}


Table 11: CLRS t-statistic Values for Tangent and Curved Sections

\begin{tabular}{|l|c|c|c|}
\hline \multicolumn{1}{|r|}{ Crash Type } & Total & PDO & SV \\
\hline Critical t-statistic & 2.035 & 2.035 & 2.035 \\
\hline Observed t-statistic & 2.158 & 2.729 & 1.955 \\
\hline
\end{tabular}

CMF Results for Edgeline Rumble Strips on Tangent and Curved Section

Table 12 on the next page shows the results of the CMF calculations for the ELRS treated tangent and curved sections. The CMFs on the tangent sections indicate that the ELRS has a similar effect on the PDO and single vehicle crashes and the total crashes CMF is not significant at the $95 \%$ confidence level. The CMFs on the curved sections indicate that the ELRS has a similar effect on the PDO and single vehicle crash types and severities and all the CMFs are significant at the $95 \%$ confidence level. The CMF for total crashes on the tangent and curved sections are drastically different as it goes from 1.013 to 0.524 respectively. This difference, along with the overall lower values for the CMFs on the curved sections, indicates that the ELRS treatment is considerably more effective on the curved sections. This can be attributed to the fact that this treatment targets single vehicle crashes with a higher percentage of single vehicle crashes making up the total crashes on the curved sections. Table 13 on the next page shows the results for the t-test for significance which found that all the results were significantly different when comparing tangent and curved sections.

All the overall CMF values determined were below 1.0, indicating improvements to the sites treated by the ELRS, and were significant at the $95 \%$ confidence level. The three CMFs were relatively close together as the greatest difference between the CMFs corresponded to a $2 \%$ difference in the crash reduction. This indicates that the ELRS treatment has the same effect regardless of the examined crash type or severity. 
Table 12: CMF Estimates for ELRS on Tangent and Curved Sections

\begin{tabular}{|l|c|c|c|c|c|c|c|c|c|}
\cline { 2 - 9 } \multicolumn{1}{c|}{} & \multicolumn{3}{c|}{ Tangent Sections } & \multicolumn{3}{c|}{ Curved Sections } & \multicolumn{3}{c|}{ Overall } \\
\cline { 2 - 10 } \multicolumn{1}{c|}{ Crash Type } & Total & PDO & SV & Total & PDO & SV & Total & PDO & SV \\
\hline $\begin{array}{l}\text { Observed } \\
\text { "After" } \\
\text { Crashes }\end{array}$ & 180 & 101 & 98 & 61 & 63 & 54 & 241 & 164 & 152 \\
\hline $\begin{array}{l}\text { Expected } \\
\text { "After" } \\
\text { Crashes }\end{array}$ & 178 & 138 & 128 & 116 & 94 & 108 & 294 & 246 & 222 \\
\hline CMF & 1.013 & 0.730 & 0.765 & 0.524 & 0.584 & 0.570 & 0.819 & 0.667 & 0.683 \\
\hline SE & 0.084 & 0.080 & 0.084 & 0.068 & 0.080 & 0.084 & 0.056 & 0.057 & 0.060 \\
\hline $\begin{array}{l}\text { CMF 95\% } \\
\text { Upper Limit }\end{array}$ & 1.181 & 0.890 & 0.933 & 0.660 & 0.744 & 0.738 & 0.931 & 0.781 & 0.804 \\
\hline
\end{tabular}

Table 13: ELRS t-statistic Values for Tangent and Curved Sections

\begin{tabular}{|l|c|c|c|}
\hline \multicolumn{1}{|c|}{ Crash Type } & Total & PDO & SV \\
\hline Critical t-statistic & 2.145 & 2.145 & 2.145 \\
\hline Observed t-statistic & 13.318 & 3.847 & 4.894 \\
\hline
\end{tabular}

CMF Results for Dual Rumble Strips on Tangent and Curved Sections

Table 14 on the next page shows the results of the CMF calculation for the tangent and curved sections with the dual rumble strips treatment. The CMFs for the dual rumble strips are significantly lower than either the CLRS or ELRS as expected due to the combined benefits of each. The CMFs on the tangent sections indicate the dual rumble strips have a similar effect for the total and PDO crashes and all the CMFs are significant at the $95 \%$ confidence level. The CMFs on the curved sections indicate that the dual rumble treatment has almost the same effect on all types and severities and all the CMFs are significant at the $95 \%$ confidence level. These CMF results demonstrate that the dual rumble strip treatment option is effective for all crash types on tangent and curved sections. As can be seen in table 15 on the next page, only the results for the single vehicle were significantly different at the $95 \%$ confidence level between the tangent and curved sections. 
All the CMF values determined were below 1.0, indicating improvements to the sites treated by the CLRS, and were significant at the $95 \%$ confidence level. The CMFs for dual rumble strips have similar weights and are lower than the values for each of the CLRS and ELRS individually. The similarity indicates that the treatment is affecting all the crash types and severities similarly. The dual rumble strips' CMFs being lower than the individual CMF values for each of the rumble strip treatments that make up the dual rumble strips treatment is the expected result that has been found in the previous methods that were examined in this study.

Table 14: CMF Estimates for Dual Rumble Strips on Tangent and Curved Sections

\begin{tabular}{|l|c|c|c|c|c|c|c|c|c|}
\cline { 2 - 9 } \multicolumn{1}{c|}{} & \multicolumn{3}{c|}{ Tangent Sections } & \multicolumn{3}{c|}{ Curved Sections } & \multicolumn{3}{c|}{ Overall } \\
\cline { 2 - 10 } \multicolumn{1}{c|}{ Crash Type } & Total & PDO & SV & Total & PDO & SV & Total & PDO & SV \\
\hline $\begin{array}{l}\text { Observed } \\
\text { "After" } \\
\text { Crashes }\end{array}$ & 49 & 36 & 35 & 63 & 50 & 47 & 112 & 86 & 82 \\
\hline $\begin{array}{l}\text { Expected } \\
\text { "After" } \\
\text { Crashes }\end{array}$ & 82 & 61 & 52 & 120 & 91 & 88 & 202 & 152 & 139 \\
\hline CMF & 0.596 & 0.586 & 0.677 & 0.526 & 0.550 & 0.536 & 0.554 & 0.565 & 0.588 \\
\hline SE & 0.086 & 0.099 & 0.116 & 0.067 & 0.079 & 0.079 & 0.053 & 0.062 & 0.066 \\
\hline $\begin{array}{l}\text { CMF 95\% } \\
\text { Upper Limit }\end{array}$ & 0.768 & 0.784 & 0.909 & 0.660 & 0.708 & 0.694 & 0.660 & 0.688 & 0.720 \\
\hline
\end{tabular}

Table 15: Dual Rumble Strips t-statistic Values

\begin{tabular}{|l|c|c|c|}
\hline \multicolumn{1}{|r|}{ Crash Type } & Total & PDO & Single Vehicle \\
\hline Critical t-statistic & 2.262 & 2.262 & 2.262 \\
\hline Observed t-statistic & 1.614 & 0.715 & 2.512 \\
\hline
\end{tabular}

\section{CMFunction Results}

The CMFs developed for the smaller tangent and curved sections allow for a sufficient sample size for the development of CMFunctions. These functions provide CMF values for the different road conditions that were grouped together based on the treatment types. The CMFunctions were developed using the CMFs from both the tangent and curved sections together. This was done as the differences between the tangent and curved sections for the CMFunction were not statistically significant and using 
all the sites provided an increased sample size for the development of the CMFunction. As stated earlier, the CMFunction takes a linear function form with the estimated crashes/km/year before treatment as the independent variable as seen in the equation below:

$$
C M F=\text { Intercept }+ \text { Coefficient } \times\left(\frac{\frac{\text { Crashes }}{\mathrm{km}}}{\text { year }}\right)
$$

The values for the intercept and coefficient can be found in Tables 15 and 16 for the CLRS and the ELRS respectively. These tables also include the minimum and maximum estimated crashes/ $\mathrm{km} /$ year that the CMFunction is applied for. Figures 2 and 3 demonstrate the CMF values achieved at various estimated crashes/km/year values for the CLRS and ELRS respectively. The CMFunction for dual rumble strip treatment was also examined.

\section{CMFunction Results for Centreline Rumble Strips}

The CMFunction parameters for the CLRS can be found in Table 16 below. The values for the CMF from this CMFunction, as shown in Figure 2 on the next page, are all below 1.00. This indicates a reduction in crashes with the application of the CLRS treatment. All the values decrease with increases in the number of expected crashes/km/year which could be explained by the fact that with more crashes on the road section, there is more opportunity for reduction in the crash numbers. These results provide meaningful insights onto the variable effect of the rumble strip treatments.

Table 16: CMFunction Parameter Estimates for CLRS

\begin{tabular}{|l|l|l|l|l|}
\hline Crash Type & Intercept & Coefficient & $\begin{array}{l}\text { Minimum } \\
\text { Crashes/km/year }\end{array}$ & $\begin{array}{l}\text { Maximum } \\
\text { Crashes/km/year }\end{array}$ \\
\hline Total & 1.126 & -0.254 & 0.770 & 1.546 \\
\hline PDO & 1.060 & -0.281 & 0.571 & 1.179 \\
\hline SV & 1.240 & -0.484 & 0.648 & 1.158 \\
\hline
\end{tabular}




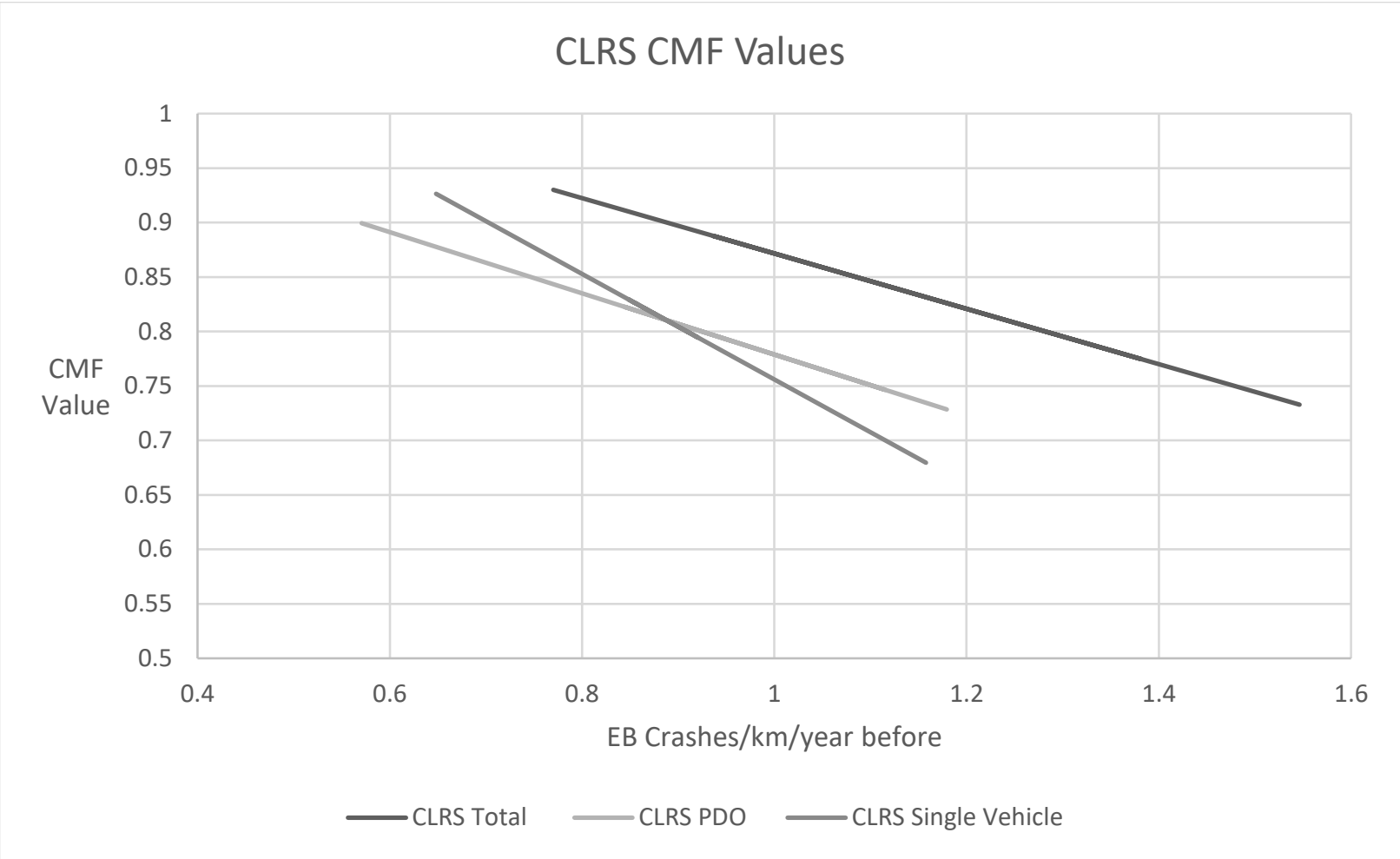

Figure 2: Centreline Rumble Strips CMFunction Values

CMFunction Results for Edgeline Rumble Strips

The CMFunction parameters for the ELRS on tangent and curved sections can be found in Table 17 on the next page. The values for the CMFs from these CMFunctions, as shown in Figure 3 on the next page, vary from situations where the rumble strips impact is negative at lower expected crashes $/ \mathrm{km} /$ year before to a reduction in the crashes of more than $50 \%$ at higher expected crashes $/ \mathrm{km} /$ year before. However, a significant portion of the CMF values, including all the values for the PDO and single vehicle crashes, can be found below the 1.00 mark indicating a reduction in the crashes. As with the CLRS, the values decrease as the value for the expected crashes $/ \mathrm{km} /$ year before treatment increase. 
Table 17: CMFunction Parameter Estimates for ELRS

\begin{tabular}{|l|l|l|l|l|}
\hline Crash Type & Intercept & Coefficient & $\begin{array}{l}\text { Minimum } \\
\text { Crashes/km/year }\end{array}$ & $\begin{array}{l}\text { Maximum } \\
\text { Crashes/km/year }\end{array}$ \\
\hline Total & 1.462 & -0.274 & 1.094 & 2.425 \\
\hline PDO & 0.865 & -0.154 & 0.744 & 1.869 \\
\hline SV & 1.245 & -0.429 & 0.774 & 1.746 \\
\hline
\end{tabular}

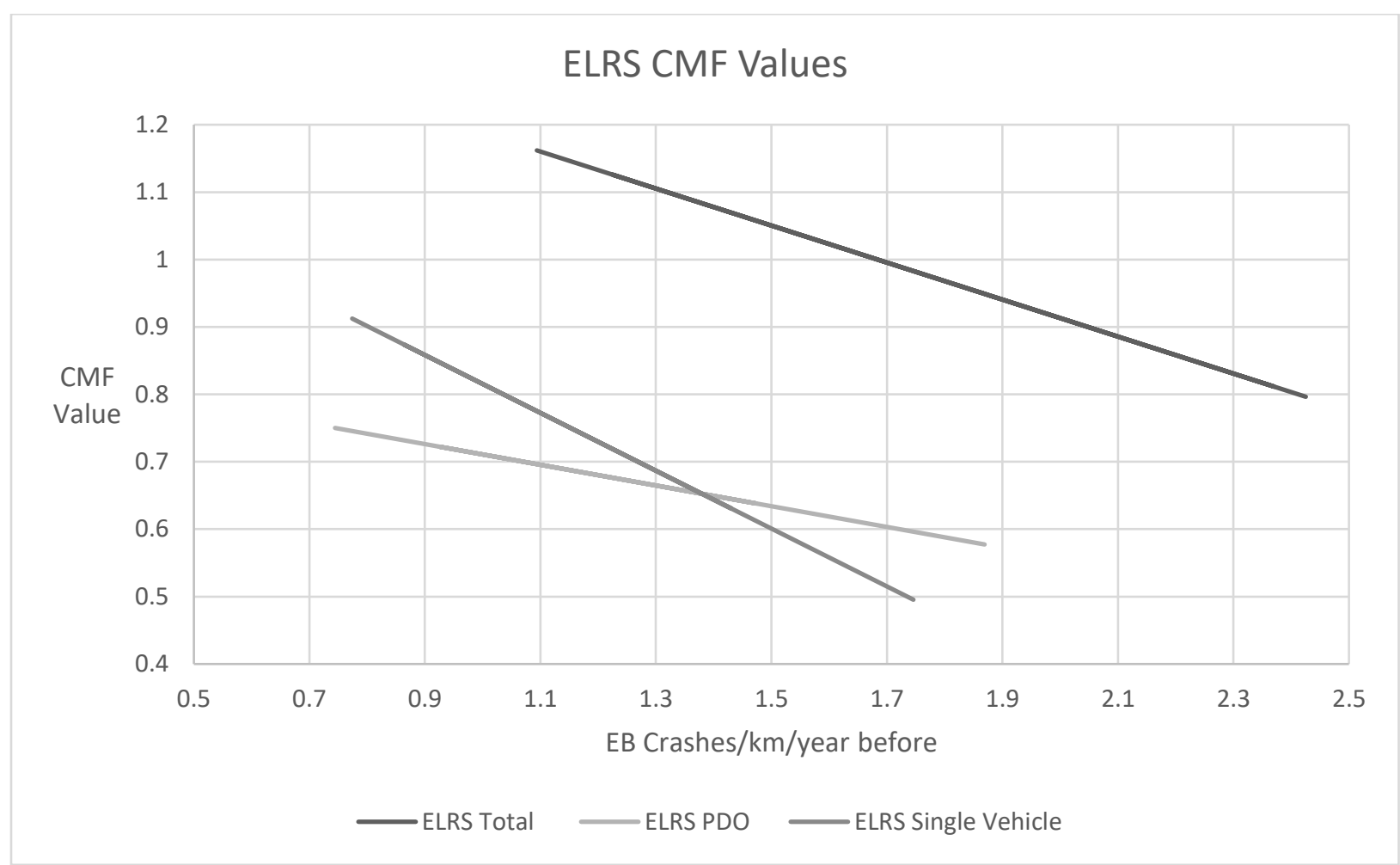

Figure 3: Edgeline Rumble Strips CMFunction Values

CMFunction Results for Dual Rumble Strips

There was an attempt to generate CMFunctions for the dual rumble strip treatment using the tangent and curved sections results. However, the lack of data lead to unreliable results that were not realistic. For example, at the highest crashes $/ \mathrm{km} /$ year value the CMF value dropped below 0 . CMFs are above zero as negative values for the CMFs would lead to a negative number for the number of crashes after the treatment is applied. With more data, the CMFunction for this treatment type could define the 
ability of the dual rumble strips to interact with the crashes in the varying situations that occur on the roads treated by the dual rumble strips and provide more insight on the treatment.

The CMFunction calculations involve all the CMFs for the tangent and curved sections and calculates the function based on these values. However, some of the sites in question had CMFs that were calculated as zero due to the absence of crashes in the after period. While these sites are a valuable source of information, they can skew the results. There are also a number of sites that had large standard errors that can affect the CMFunction calculations. In order to combat this, a weight is given to each of the sites related to the variance in their CMF. This variance is calculated through the following formula:

$$
\sigma_{x}=S E_{x}^{2}
$$

$$
\begin{aligned}
& \text { where, } \\
& \sigma_{x}=\text { the variance for site } \mathrm{x} \\
& S E_{x}=\text { the standard error for site } \mathrm{x}
\end{aligned}
$$

Since standard errors could not be calculated for sites with CMF values of 0 , an arbitrary high value was given for the variance. Those sites with high variance values were given low weights to help combat any errors in the calculation of the CMFunction. The information was then put into the IBM SPSS statistics software (IBM, 2017) and a weighted linear regression was performed in order to determine the values for the CMFunctions. Tables 18 and 19 on the following pages have the values that were determined for the functions while Figures 4 and 5 on the following pages show the values for the CMFs calculated using the CMFunctions. 
Weighted CMFunction Results for Centreline Rumble Strips

Table 18 below has the values for the parameters of the weighted CMFunction for the CLRS treatment. An interesting result is the coefficient values as they vary in both magnitude and direction. Both the total and single vehicle crash types have coefficients that are positive, indicating that the CMF value will increase with increases in the expected crashes $/ \mathrm{km} / \mathrm{year}$. This trend for the CMFs is visible in Figure 4 below. The value for the expected crashes $/ \mathrm{km} /$ year coefficient for total crashes is high, indicating that the CMF greatly increases as the crashes $/ \mathrm{km} / \mathrm{year}$ increases.

Table 18: CLRS Weighted CMFunction Parameters

\begin{tabular}{|l|l|l|l|l|}
\hline Crash Type & $\begin{array}{l}\text { Weighted } \\
\text { Intercept }\end{array}$ & $\begin{array}{l}\text { Weighted } \\
\text { Coefficient }\end{array}$ & $\begin{array}{l}\text { Minimum } \\
\text { Crashes/km/year }\end{array}$ & $\begin{array}{l}\text { Maximum } \\
\text { Crashes/km/year }\end{array}$ \\
\hline Total & 0.251 & 0.510 & 0.770 & 1.546 \\
\hline PDO & 0.446 & -0.130 & 0.571 & 1.179 \\
\hline SV & 0.254 & 0.103 & 0.648 & 1.158 \\
\hline
\end{tabular}

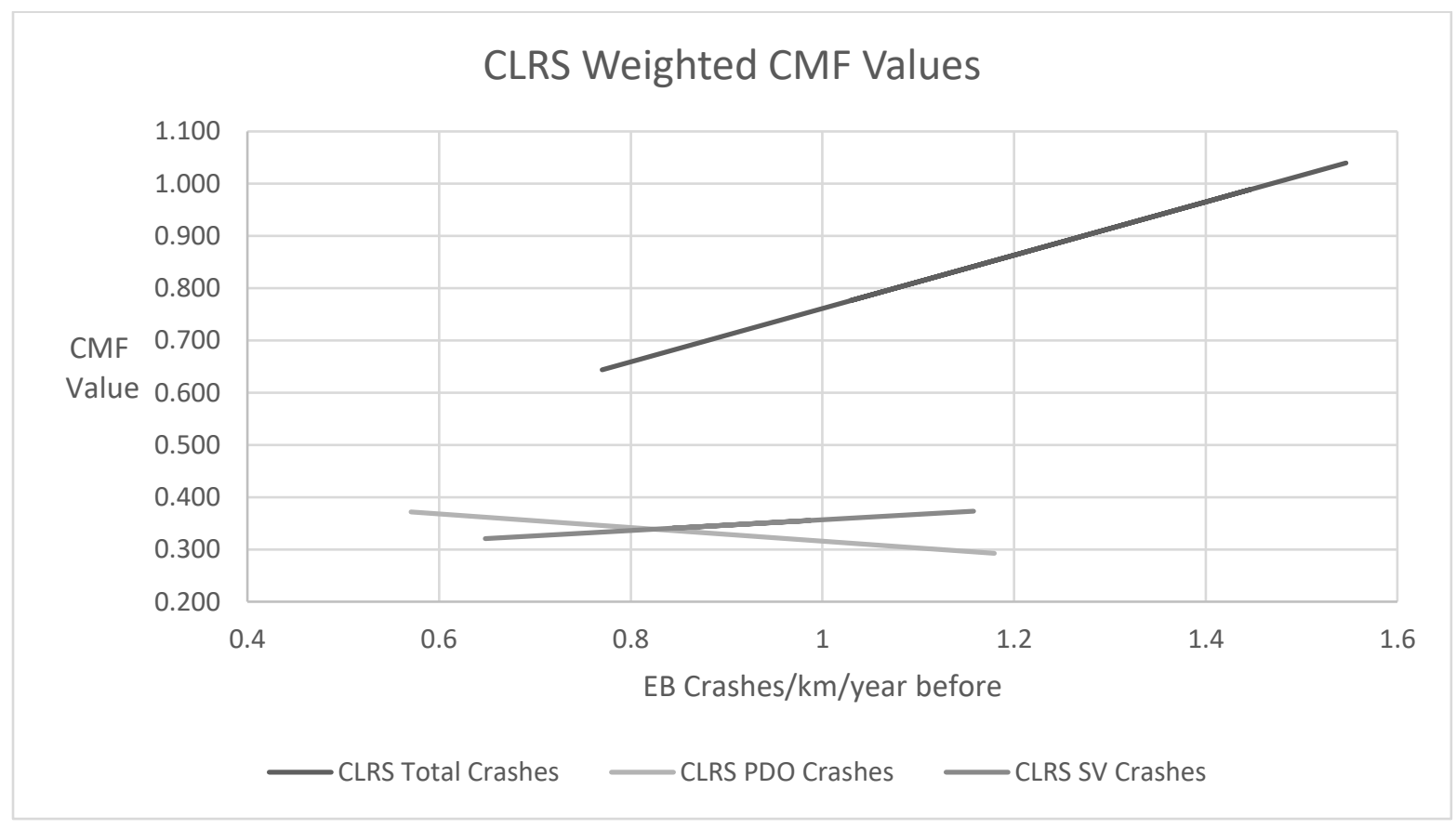

Figure 4: CMF Values for CLRS Weighted CMFunction 
Weighted CMFunction Results for Edgeline Rumble Strips

Table 19 below has the values for the parameters of the weighted CMFunction for the ELRS treatment. These values all follow the same trend as the intercept value is greater than 1.0 and the coefficient for the independent variable is negative. This negative indicates that CMF value will decrease with increases in the crashes $/ \mathrm{km} /$ year as seen in Figure 5 below. Due to the values for the expected crashes/km/year, the CMF values are all below 1.0. These values indicate that the ELRS has a positive impact on safety for all the crash types and severities.

Table 19: ELRS Weighted CMFunction Parameter Results

\begin{tabular}{|l|l|l|l|l|}
\hline Crash Type & $\begin{array}{l}\text { Weighted } \\
\text { Intercept }\end{array}$ & $\begin{array}{l}\text { Weighted } \\
\text { Coefficient }\end{array}$ & $\begin{array}{l}\text { Minimum } \\
\text { Crashes/km/year }\end{array}$ & $\begin{array}{l}\text { Maximum } \\
\text { Crashes/km/year }\end{array}$ \\
\hline Total & 1.015 & -0.304 & 1.094 & 2.425 \\
\hline PDO & 1.031 & -0.446 & 0.744 & 1.869 \\
\hline SV & 1.417 & -0.727 & 0.774 & 1.746 \\
\hline
\end{tabular}

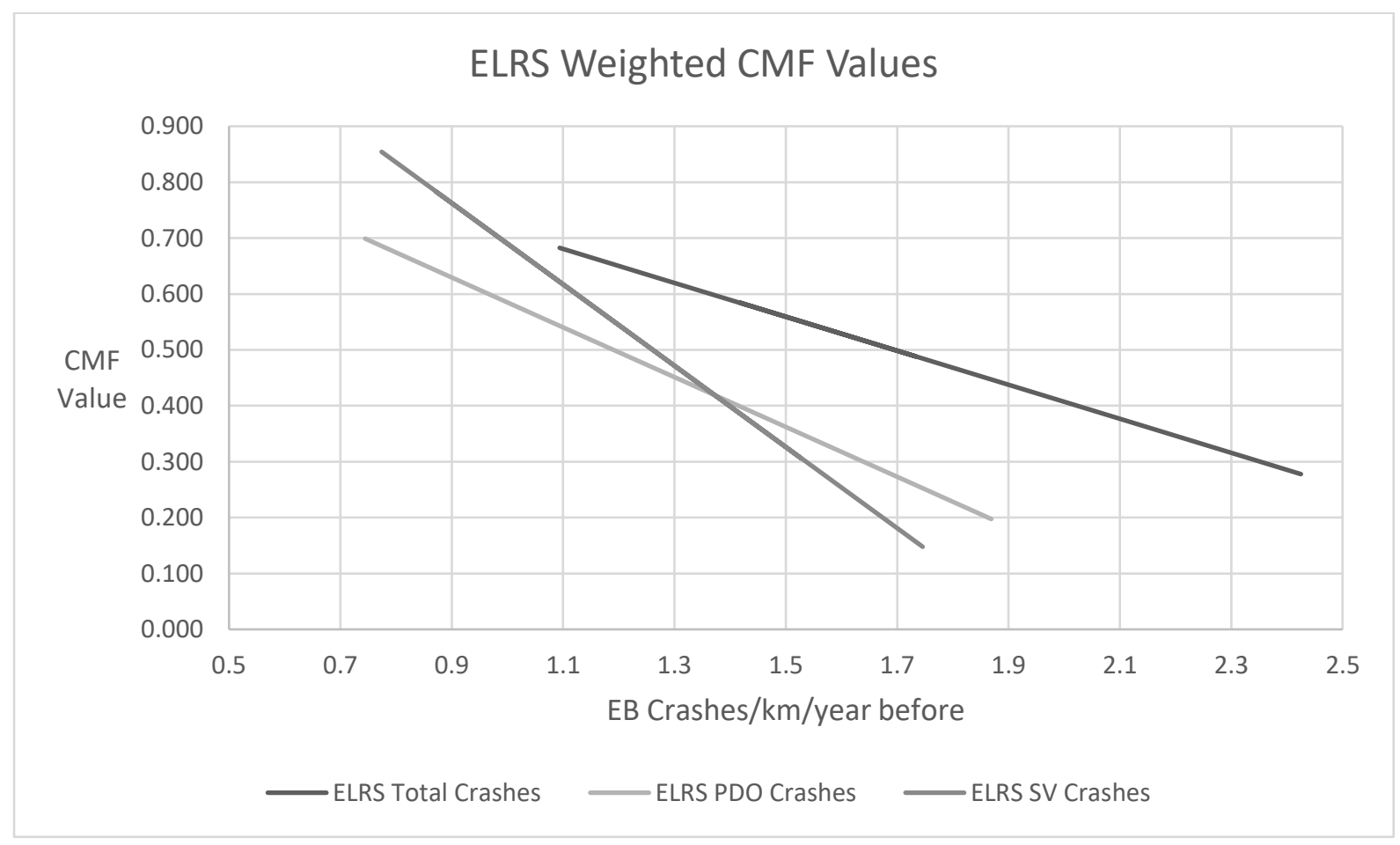

Figure 5: CMF Values for ELRS Weighted CMFunction 


\section{Discussion of Results}

The Empirical-Bayes before-after study provides insights into the effects of the application of rumble strip treatments. These effects, as seen by the CMFs in Table 20 below, demonstrate the effectiveness of these safety measures across the highway system in Ontario. These effects varied in both the reliability of their determination and the magnitude of the effect, but all showed improvement due to the treatment.

The centreline and edgeline rumble strip treatment options showed considerable improvements to the crash counts after implementation as can be seen in Table 20 on the next page. This can especially be seen in the values for their targeted approach and sideswipe crashes and single vehicle crashes respectively. These are the targeted crashes due to their location on the road surface. Outside of the single vehicle crash effects, which were statistically insignificant, the dual rumble strips treatment showed greater improvements than either rumble strip treatment applied individually. The CMFs developed using the aggregate segments for the dual rumble strips show an almost $30 \%$ reduction in the expected crashes due to their application. Logically, this fits expectation as applying both the CLRS and ELRS will target all the crashes covered by these individual rumble strip treatments. With the reduction in different types of crashes, the counts for the severities will also be affected as seen by all three of the rumble strip treatment options.

The CMF results from the previous work are included for comparison as the previous study's goal was to investigate the CMFs of dual rumble strip treatment. Due to a lack of available data, the previous research could only estimate the CMFs using the NCHRP Project 17-63 methodology (Eskandar, 2018). There are differences in the values between the estimations and the EB results, but some values are similar. This can especially be seen in the PDO crashes CMFs where the difference is 0.02 which relates to a $2 \%$ difference in the crash reduction the CMFs say will occur with the treatment. 
Table 20: CMF Results Summary

\begin{tabular}{|l|c|c|c|c|c|}
\cline { 2 - 6 } \multicolumn{1}{c|}{ Crash Type } & Total & Injury & PDO & SV & App + SS \\
\hline CLRS CMF using Aggregated Segments & 0.882 & 0.705 & 0.938 & 0.844 & 0.702 \\
\hline CLRS CMF using Tangent and Curved Sections & 0.819 & N/A & 0.667 & 0.683 & N/A \\
\hline ELRS CMF using Aggregated Segments & 0.878 & 0.980 & 0.818 & 0.689 & N/A \\
\hline ELRS CMF using Tangent and Curved Sections & 0.598 & N/A & 0.835 & 0.817 & N/A \\
\hline Dual Rumble Strips CMF using Aggregated Segments & 0.712 & 0.755 & 0.723 & 0.864 & N/A \\
\hline $\begin{array}{l}\text { Dual Rumble Strips CMF using Tangent and Curved } \\
\text { Sections }\end{array}$ & 0.554 & N/A & 0.565 & 0.588 & N/A \\
\hline $\begin{array}{l}\text { Previous Estimation of Dual Rumble Strips CMF } \\
\text { (Eskandar, 2018) }\end{array}$ & 0.805 & 0.790 & 0.743 & 0.799 & 0.689 \\
\hline
\end{tabular}

As can be seen in table above, the CMFs using the aggregated segments underestimated the safety benefits of each treatment. This comparison can be made for the total, PDO and single vehicle crashes as the other types, injury crashes and approach and sideswipe crashes, were not examined in this study. The differences between the values occur as the SPFs for the tangent and curved include two different functions for the tangent and curved sections whereas the aggregated segments have a single function that represents these segments that include both tangent and curved sections. For this reason, the CMFs developed using the tangent and curved SPFs are more accurate and thus, better representative of the effects of the rumble strip treatments.

Crash Modification Functions are tools that provide more comprehensive values for the effects of different safety treatment options. In this study, these functions took a linear model form with an intercept value and a coefficient for the independent variable selected. This variable was selected as the crashes/km/year in order to normalize the crash counts for the road sections that varied in length. The crash counts used were the expected values based on the EB estimated crashes for the before period. The road sections that were defined as tangent and curved sections formed the datasets that were used for the CMFunctions. 
The results for the intercept and coefficient values are found in Table 21 below for the CLRS and ELRS treatment options as well as for the three different crash types and severities studied in the focus on the tangent and curved sections. All the intercept values are positive which indicates a good result as the CMF value determined from these CMFunctions should never be below zero. It is because the CMF value should always be positive that the dual rumble strip treatments are not included in the CMFunction results. At the higher independent variable values, the dual rumble strip CMFs fell below zero for the total crashes. This could have been caused by the lack of available data for the dual rumble strip treatment option. The CMFunctions took the form:

$$
C M F=\text { Intercept }+ \text { Coefficient } \times\left(\frac{\frac{\text { Crashes }}{\mathrm{km}}}{\text { year }}\right)
$$

Table 21: CMFunction Results Summary

\begin{tabular}{|c|c|c|c|}
\hline Treatment Type & Crash Type & Intercept & Coefficient \\
\hline CLRS & Total & 1.126 & -0.254 \\
\hline CLRS & PDO & 1.060 & -0.281 \\
\hline CLRS & SV & 1.240 & -0.484 \\
\hline ELRS & Total & 1.462 & -0.274 \\
\hline ELRS & PDO & 0.865 & -0.154 \\
\hline ELRS & SV & 1.245 & -0.429 \\
\hline
\end{tabular}

The coefficient values are all negative which causes the CMF values generated by these CMFunctions to decrease with increases in the expected crashes $/ \mathrm{km} / \mathrm{year}$ the before period. This can be explained by the rumble strips having more opportunity to affect the crash rates if there is a higher crash rate before treatment on the road that the treatment is applied to. These coefficient values caused the CMF values generated by these CMFunctions to be mostly under the value of 1.00 indicating a reduction in crashes. This occurred for all the crash types and severities at almost the entire range of crashes/km/year values. The only exception to this was the ELRS effects on total crashes at the lower end of the crashes/ $\mathrm{km} / \mathrm{year}$ values. These values ranged between the minimum and maximum values of 
the sites studied. These maximum and minimum values demonstrate for which values these CMFunctions should be applied.

Figures 6 through 11 show the results of the CMFunction values compared to the overall CMFs determined through the EB study for the CLRS and ELRS treatment options for the total, PDO and single vehicle crashes respectively. These figures also include HSM CMF values for each rumble strip treatment. It should be noted the HSM does not include CMFs specific to PDO crashes for either treatment or for single vehicle crashes with the CLRS treatment. In these cases, the CMF for the total crashes is used. The figures also include the CMF values from the weighted CMFunctions.

The weighted CMFunctions parameters vary significantly from the other CMF values. This can especially be seen in the CLRS results as some of the CMFs from the weighted regression increase with increases in the expected crashes/km/year. This trend was not seen in any of the unweighted CMFunctions. Outside of the total crashes, the CMF values for the CLRS were significantly lower than any of the other CMFs determined by the other methods. The total crashes CMF value varied from significantly below the other CMFs to significantly above.

The ELRS weighted CMFunctions followed the same patterns as the unweighted CMFunctions as the CMF values decrease with increases in the expected crashes $/ \mathrm{km} /$ year before. These decreases in the CMF values indicate decreased numbers of crashes on the treated sites. Despite the similarities in the trends of the CMF values, the values from the weighted CMFunctions are considerably lower than the unweighted CMFunctions.

In summary, the CMFunctions based on weighted regression appear unrealistic and inconsistent. This is likely due to the fact that sites with relatively and randomly low variance can have an unrealistically dominant effect while, as indicated earlier no weight is given to sites with a CMF of zero, and sites with relatively high variance are assigned little weight. This issue could be resolved by 
grouping sites but the relatively small number of sites did not allow for this option to be explored in this study.

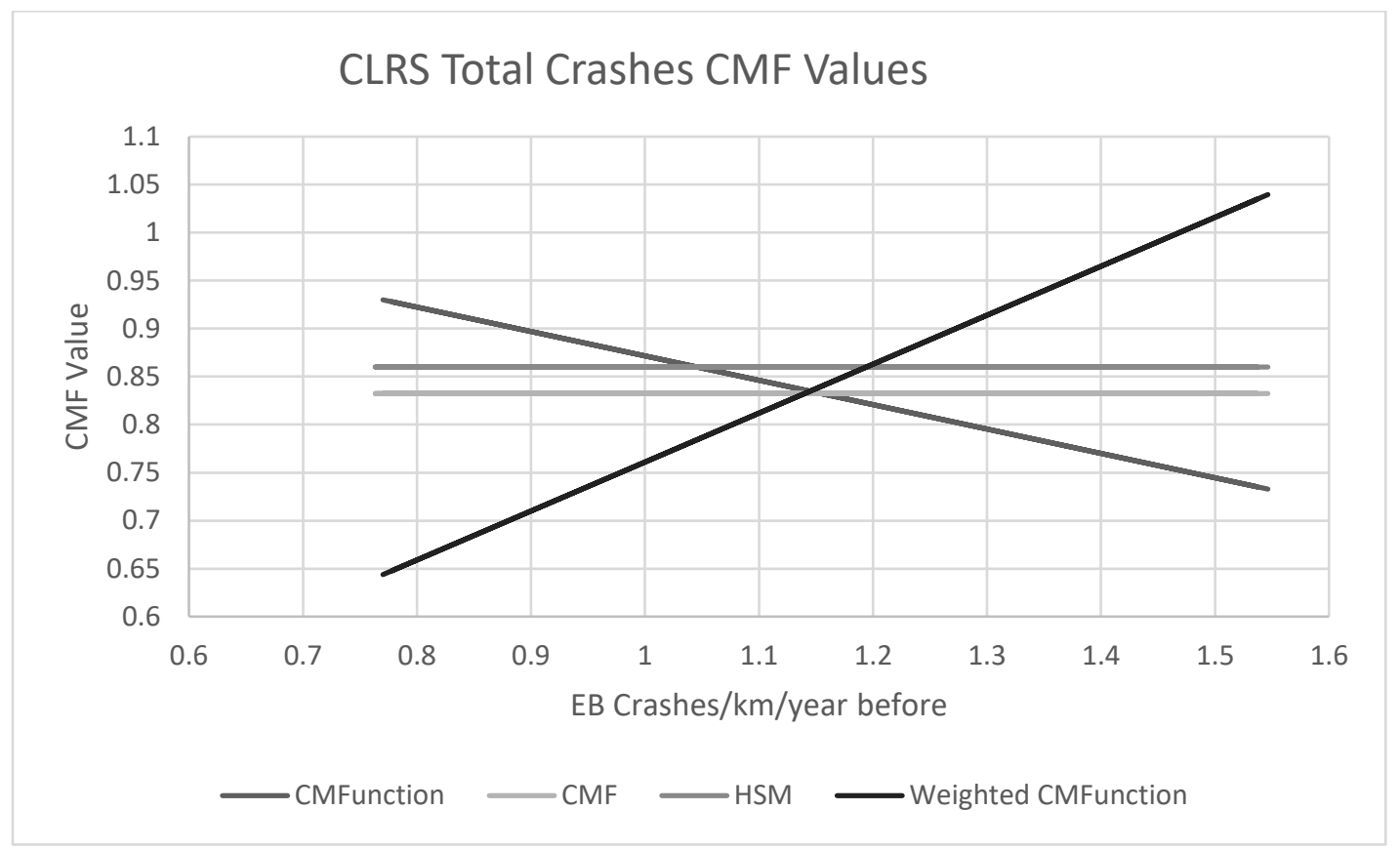

Figure 6: CLRS Total Crashes CMFunction to CMF Comparison

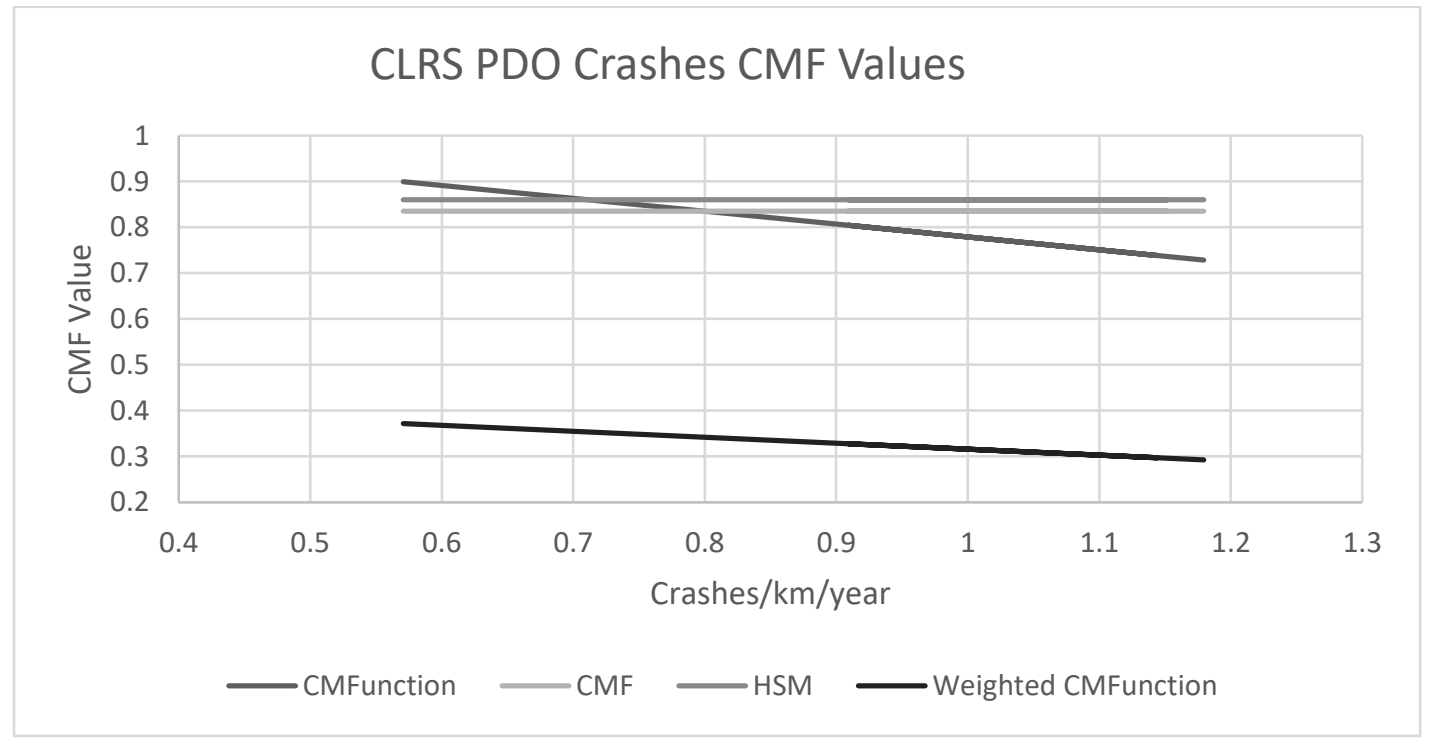

Figure 7: CLRS PDO Crashes CMFunction to CMF Comparison 


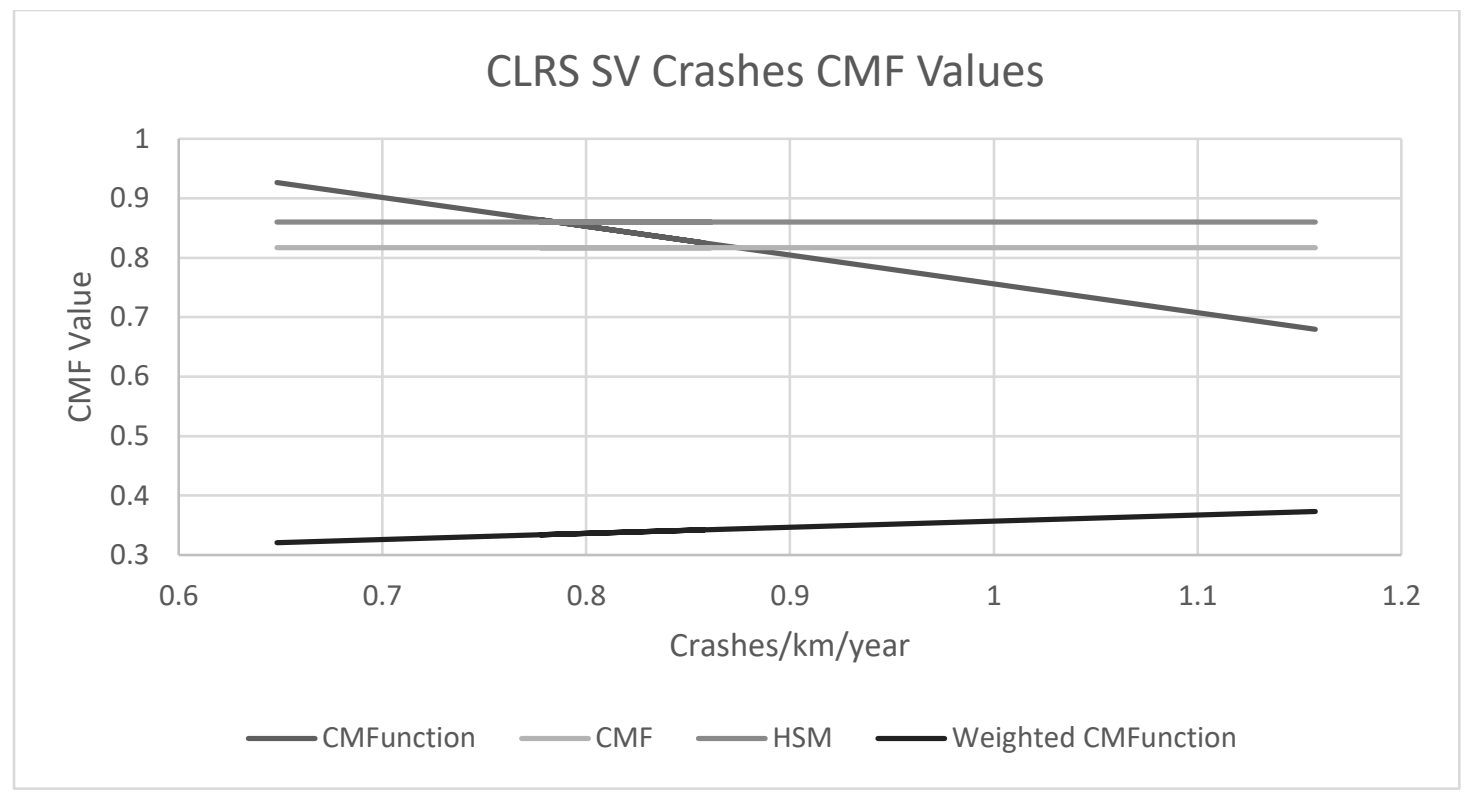

Figure 8: CLRS Single Vehicle Crashes CMFunction to CMF Comparison

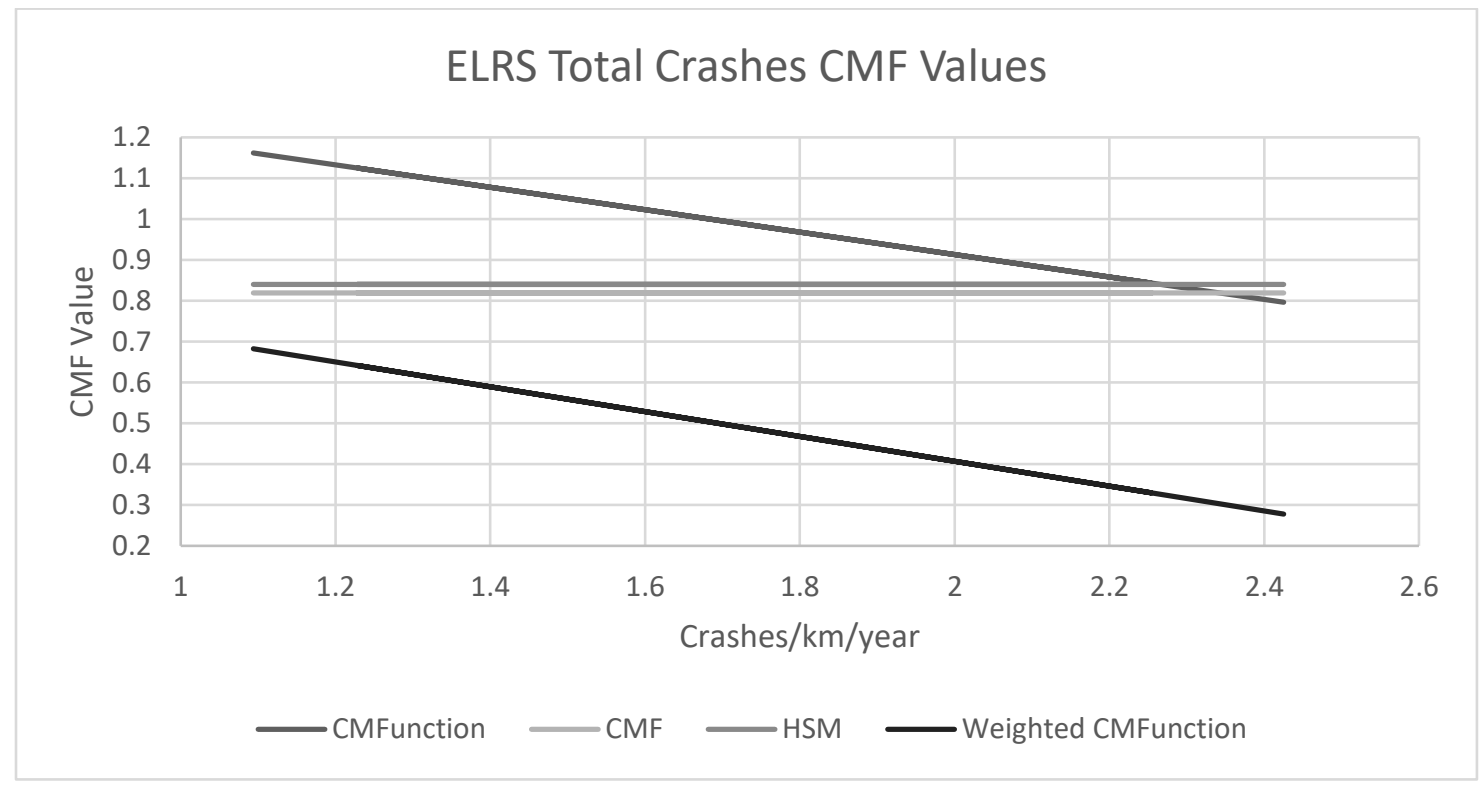

Figure 9: ELRS Total Crashes CMFunction to CMF Comparison 


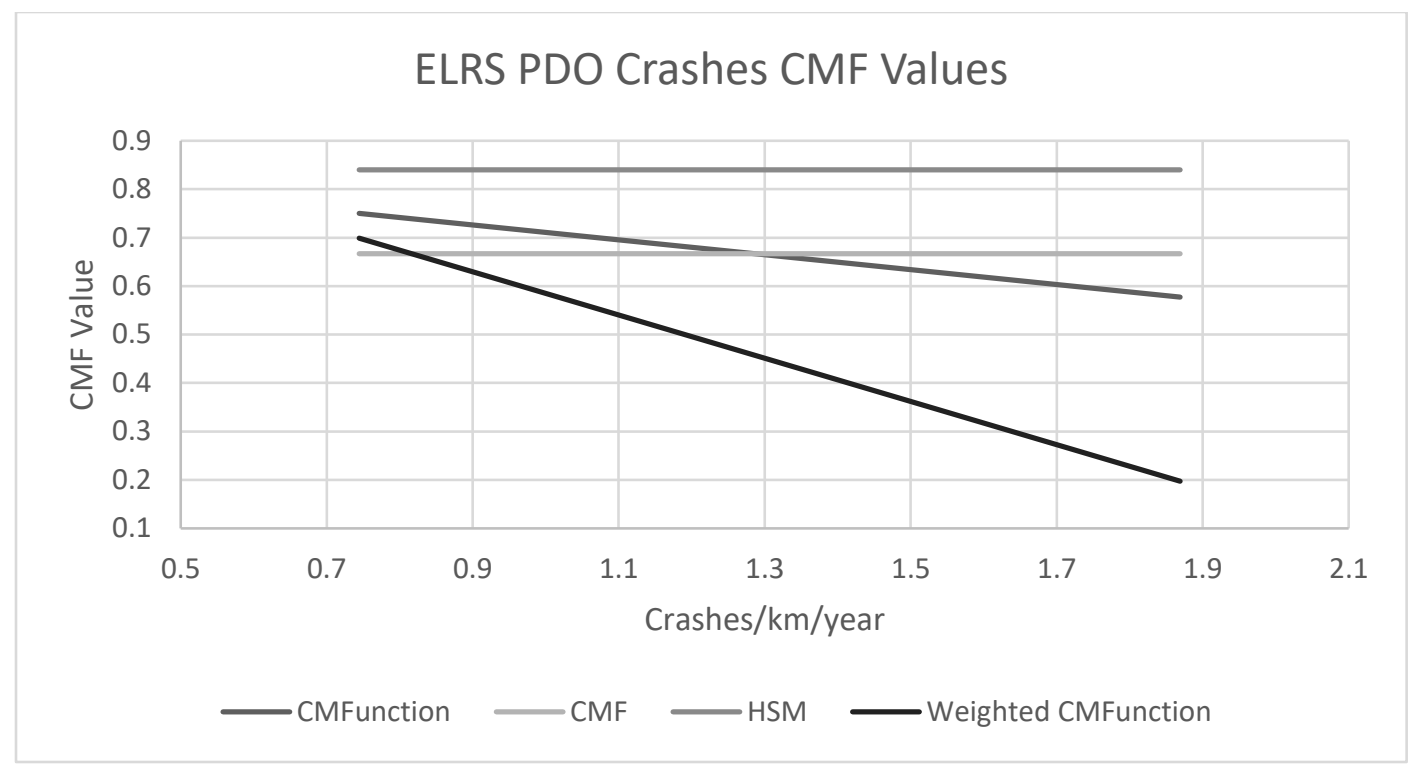

Figure 10: ELRS PDO Crashes CMFunction to CMF Comparison

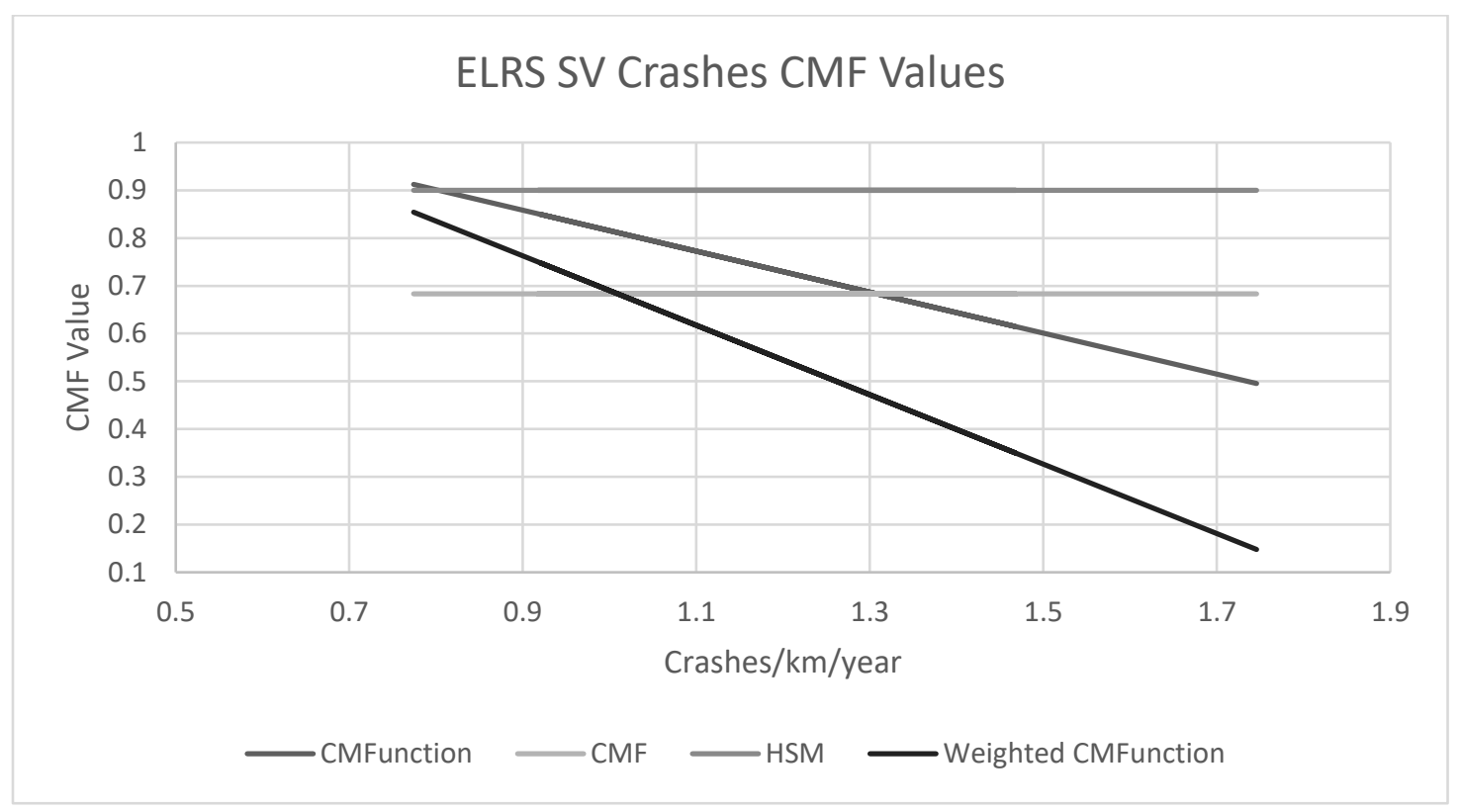

Figure 11: ELRS Single Vehicle Crashes CMFunction to CMF Comparison 


\section{Chapter 3: Assessing the Applicability of the Highway Safety Manual Crash Prediction Algorithm to Ontario Two-Lane Highways}

This chapter examines the Highway Safety Manual (HSM) crash prediction algorithm as it applies to Ontario two-lane highways. For this examination, the first step is to examine the relevant literature including the HSM itself and other studies that have looked at the HSM. With this step complete, the methodology for examining the HSM is understood and then completed as they pertain to the rumble strips in Ontario. The HSM algorithm for predicting the number of crashes takes the following form:

$$
N_{\text {predicted }}=N_{s p f x} \times\left(C M F_{1 x} \times C M F_{2 x} \times \ldots \times C M F_{y x}\right) \times C_{f x} \quad(\mathrm{AASHTO}, 2010)
$$

Where,

$N_{\text {predicted }}$ is the predicted number of crashes for site type $\mathrm{x}$

$N_{s p f x}$ is the number of predicted crashes for base conditions

$C M F_{y x}$ is the Crash Modification Factors specific to SPF for site type $\mathrm{x}$

$C_{f x}$ is the calibration factor to adjust the SPF for local conditions for site type $\mathrm{x}$

Literature Review for the Highway Safety Manual Crash Prediction Algorithm

As stated earlier, the relevant literature includes information on the HSM method of combining the CMFs of multiple treatments. It also includes the studies that have examined this method and explored alternative methods for combining the CMFs. Lastly, the use of the HSM's safety performance functions and CMFs for estimating crashes is examined.

\section{CMF Combination Methods}

There are times when multiple safety treatments are applied to the same site and it is important to understand the possible effects of having multiple treatments applied. The HSM recommends the 
multiplication method for the estimation of the combined effect of the safety treatments (AASHTO, 2010). However some recent studies have examined this method and come to conclusions regarding its ability to predict the combined effects of multiple treatments.

A study conducted in 2017 came to the conclusion that the multiplication method had the tendency to overestimate the safety benefits (Park \& Abdel-Aty, 2017). This study examined the strengths and weaknesses of the different proposed methods for the combination of the CMFs. These methods included the multiplication method that the HSM recommends, among others used in other studies. Some of these weaknesses in the combination methods included overestimation, common to the multiplication method, and the need for region-specific values for certain methods, such as the multiplication with adjustment function method.

NCHRP Project 17-63 examined new techniques for the prediction of the combined effects of multiple treatments (Carter, et al., 2017). This was done after the study determined that the multiplication method had a tendency to overestimate the safety benefits of combination treatments. Multiple combination methods were proposed to be applied in different situations due to varying factors such as the magnitude of the CMFs and the amount of overlap between the safety treatments. These methods are examined later in this chapter.

\section{Calibration Factors for the Crash Prediction Algorithm}

The HSM includes safety performance functions (SPFs) that have been developed to help with the prediction of crashes. These functions include a base condition model, modification factors for site conditions and a calibration factor that accounts for changes between the development of the model and the application of the model. These calibration factors need to be done for the different study locations and the different road types (Faisal, 2011). The SPFs, once calibrated, generate the predicted crashes on the road segments without additional road safety treatments. 


\section{Methodology}

The exploration of the Highway Safety Manual's (HSM's) crash prediction methods are done in a variety of different methods. The HSM includes methods for combining CMFs for multiple treatments which have been called to question by studies. The HSM also includes SPFs for the different road and crash types. Both of these scenarios are examined to see how the HSM can be applied in Ontario.

Investigating CMF Combination Methods

When combining two or more different treatment options there are a variety of different methods. One of these is the HSM's recommendation of multiplying the CMFs together to get the combined effect (AASHTO, 2010). The multiplication method estimates the combined CMF by multiplying the individual CMFs involved in the combination treatment as seen in the equation below:

$$
C M F_{t}=\left(C M F_{1} \times C M F_{2} \times \ldots \times C M F_{n}\right)
$$

Where

$C M F_{t}$ is the $\mathrm{CMF}$ for the combined treatments

$C M F_{1}$ is the first $\mathrm{CMF}$

$\mathrm{CMF}_{2}$ is the second $\mathrm{CMF}$

$C M F_{n}$ is the $\mathrm{n}^{\text {th }} \mathrm{CMF}$

As noted above, studies into this methodology have determined that this method can overestimate the effect of a combination treatment (Carter, et al., 2017). In the same study, there were new methods developed which aim to better represent what happens in the combined scenarios. In order to determine the correct method, there are a few steps that need to be done. The first is to 
determine the amount of overlap between the treatments applied in the combined treatment. There are five cases for the amount of overlap, as seen in Table 22 below.

Table 22: Defining the Overlap of Individual Treatment Effects (Carter, et al., 2017)

\begin{tabular}{|l|l|}
\hline Case & Description \\
\hline A: Zero overlap & $\begin{array}{l}\text { This case represents two truly independent effects where the complete } \\
\text { benefit of both treatments is realized. }\end{array}$ \\
\hline B: Some overlap & $\begin{array}{l}\text { This case represents two treatments that both provide some level of } \\
\text { benefit, but the second treatment has some overlap with the first. }\end{array}$ \\
\hline C: Complete overlap & $\begin{array}{l}\text { This case represents two non-independent effects where the second } \\
\text { treatment targets some or all of the same crash types/severities as the first. }\end{array}$ \\
\hline D: Enhancing effects & $\begin{array}{l}\text { This case represents a scenario where the combined effect of two } \\
\text { treatments is greater than the sum of their individual effects because one } \\
\text { treatment enhances the effectiveness of the other treatment. }\end{array}$ \\
\hline E: Counteracting effects & $\begin{array}{l}\text { This case represents a scenario where the combined effect of two } \\
\text { treatments is less than the effect of the most effective treatment because } \\
\text { one treatment counteracts the effect of the other treatment. }\end{array}$ \\
\hline
\end{tabular}

The second step is to determine the magnitudes of the changes to the crashes due to the treatment. Three levels were given for the magnitude of the effect based on the percent change in the crashes: small (less than 10\%), medium (10-25\%), and large (greater than 25\%) (Carter, et al., 2017). These magnitudes are absolute values regardless of whether the application of the treatment caused an increase in the crash counts, $\mathrm{CMF}>1.0$, or an improvement through the decrease in crash counts, $\mathrm{CMF}<1.0$. The third step involves using these magnitudes to determine the recommended method for the combination of the CMFs. The different recommended methods for each of the overlap cases and magnitude combinations can be found in Table 23 on the next page. As seen in the table, the magnitude of the CMFs are only taken into account for the Case B scenario as the other cases use one method for the combination of CMFs regardless of the magnitudes. 
Table 23: Method Selection for Same Type and Severity (Carter, et al., 2017)

\begin{tabular}{|l|l|l|}
\hline Overlap & Magnitude & Method \\
\hline $\begin{array}{l}\text { Case A } \\
\text { Case D }\end{array}$ & Not applicable & Additive effects with maximum reduction of $100 \%$ (i.e., CMF $=0$ ) \\
\hline & Small-Small & Dominant effect \\
\cline { 2 - 3 } & Small-Medium & Dominant common residuals (if CMFs < 1.0); Dominant effect otherwise \\
\cline { 2 - 3 } Case B & Small-Large & Dominant effect \\
\cline { 2 - 3 } & Medium-Medium & Dominant common residuals (if CMFs $<1.0$ ); Dominant effect otherwise \\
\cline { 2 - 3 } & Medium-Large & Dominant common residuals (if CMFs $<1.0$ ); Dominant effect otherwise \\
\cline { 2 - 3 } & Large-Large & Dominant common residuals (if CMFs $<1.0$ ); Dominant effect otherwise \\
\hline Case C & Not applicable & Dominant effect \\
\hline Case E & Not applicable & Multiplicative \\
\hline
\end{tabular}

Using the table above, it can be seen that there are multiple methods that can be used and that the amount of overlap is the first step in the selection of the methods. If the overlap was determined to be Case B, the two methods used for calculation of the combined safety benefits were the dominant effect method and the dominant common residuals method. The dominant effect method works by assuming the largest safety benefit, i.e. the smallest CMF, will dominate the effect of the combined treatment. In the dominant method, the CMF for the combined treatment is the same as the dominating $\mathrm{CMF}$ and can be seen in the equation below:

$$
C M F_{t}=\min \left(C M F_{1}, C M F_{2}, \ldots, C M F_{n}\right)
$$

Where

$C M F_{t}$ is the $\mathrm{CMF}$ for the combined treatments

$C M F_{1}$ is the most effective $\mathrm{CMF}$

$\mathrm{CMF}_{2}$ is the second most effective CMF

$C M F_{n}$ is the $\mathrm{n}^{\text {th }}$ most effective CMF 
The dominant common residuals method combines the CMFs in similar fashions to the multiplication method and the dominant effect method. The dominant CMF is applied as an exponent value to the multiplication of all the CMFs involved in the combination treatment. The dominant common residuals method can be seen in the equation below:

$$
C M F_{t}=\left(C M F_{1} \times C M F_{2} \times \ldots \times C M F_{n}\right)^{C M F_{1}}
$$

Where

$C M F_{t}$ is the $\mathrm{CMF}$ for the combined treatments

$C M F_{1}$ is the most effective $\mathrm{CMF}$

$C M F_{2}$ is the second most effective CMF

$C M F_{n}$ is the $\mathrm{n}^{\text {th }}$ most effective CMF

Validation of the Highway Safety Manual Crash Prediction Algorithm

The Highway Safety Manual (HSM) outlines a number of baseline safety performance functions (SPFs) for the prediction of crashes on the different types of roads (AASHTO, 2010). These predictive models have been developed for the same type of rural two-lane highways as were examined in this thesis. However, newer predictive base models have been developed in order to better predict the values for the different crash types and severities (Ivan, et al., 2018). The SPFs used in this study involve a number of parameters that change depending on the crash type and severity but take the general form seen in the equation below:

$$
N=\exp \left[b_{0}+b_{1} \times \ln (A A D T) \times \ln (L)\right]
$$


Where,

$\mathrm{N}$ is the number of predicted crashes

$b_{0}$ and $b_{1}$ are the parameters that depend upon the crash type and severity

AADT is the average annual daily traffic

$L$ is the length of the road section

In order to apply these models, a region-specific calibration factor needs to be developed for each type and severity. This is because the values for the parameters in the SPFs are found using general data for the United States rather than the specific data in the region. This calibration factor is determined by the following equation:

$$
C_{F}=\frac{\sum \text { Observed Collisions }}{\sum \text { Predicted Collisions }}
$$

These calibration factors are applied to the SPFs for each of the crash types and severities as a multiplier. The predictive models include any CMFs that apply to the sites that are being examined such as CMFs relating to lane width or shoulder width. As indicated at the start of this chapter these CMFs are multiplicatively applied for non-base conditions using the algorithm documented here:

$$
N_{\text {predicted }}=N_{s p f x} \times\left(C M F_{1 x} \times C M F_{2 x} \times \ldots \times C M F_{y x}\right) \times C_{f x} \quad(\text { AASHTO, 2010) }
$$

Where,

$N_{\text {predicted }}$ is the number of predicted crashes for site type $\mathrm{x}$

$N_{s p f x}$ is the number of predicted crashes for base conditions

$C M F_{y x}$ is the Crash Modification Factors specific to SPF for site type $\mathrm{x}$

$C_{f x}$ is the calibration factor to adjust the SPF for local conditions for site type $\mathrm{x}$ 
In validating this algorithm using Ontario data, predicted crash counts for sites with rumble strips are obtained without applying a rumble strip CMF and then compared to the observed counts in order to infer CMFs of the sites treated by the rumble strips. These CMFs are then compared to those obtained from the EB study to assess the validity of the HSM algorithm for Ontario roads. The CMFs used in the algorithm are shown in Table 24 below. These were specified in the HSM and pertained to shoulder width, shoulder type and lane width. The use of the tangent only sites meant that the CMFs for the curves are not included. Other CMFs, such as the CMFs for driveway density, were not included due to the lack of data so, in effect, base conditions were assumed for these variables, which, for Ontario roads, is a reasonable assumption.

A similar assessment was done to estimate CMFs for shoulder width, this time applying the EB CMFs for rumble strips and comparing the implied CMFs to those provided in the HSM as shown in Table 24. In this table, the acronym PTPV stands for partially paved.

Table 24: SPF Specific CMF Values

\begin{tabular}{|l|l|l|l|l|l|l|l|l|l|l|l|l|}
\hline $\begin{array}{l}\text { Road } \\
\text { Characteristic }\end{array}$ & \multicolumn{4}{|c|}{ Shoulder Width (ft) } & \multicolumn{3}{|c|}{ Shoulder Type (Width in ft) } & \multicolumn{3}{l|}{$\begin{array}{l}\text { Lane width } \\
\text { (ft) }\end{array}$} \\
\hline Value & 0 & 6 & 7 & 8 & 10 & $\begin{array}{l}\text { Gravel } \\
(8)\end{array}$ & $\begin{array}{l}\text { PTPV } \\
(0)\end{array}$ & $\begin{array}{l}\text { PTPV } \\
(6)\end{array}$ & $\begin{array}{l}\text { PTPV } \\
(8)\end{array}$ & $\begin{array}{l}\text { Paved } \\
(8)\end{array}$ & 11 & 12 \\
\hline CMF Value & 1.50 & 1.00 & 1.00 & 0.87 & 0.77 & 1.02 & 1.00 & 1.02 & 1.06 & 1.00 & 1.05 & 1.00 \\
\hline
\end{tabular}




\section{Results from Investigating CMF Estimates using CMF Combination Methods}

The HSM and NCHRP Project 17-63 methodologies differ from each other, but both aim to provide estimates of the safety benefits that occur when multiple treatments are applied. The ideal scenario is the study of the actual application of the multiple treatments and the effect that this combination has. Having the estimates and this real-world data provides an opportunity to see the effectiveness of the methods.

\section{CMF Estimates for Dual Rumble Strips using CMF Combination Methods}

The results for the combination methods are found in Table 25 below. Both the HSM and NCHRP Project 17-63 methods show the dual rumble strips treatment is expected to decrease crashes by a substantial amount such as the $40 \%$ and $30 \%$ reduction in crashes estimated by the HSM and NCHRP Project 17-63 methods respectively. As can be seen, the multiplication method from the HSM overestimates the safety benefit of the dual rumble strip treatment compared to the results from generated by the NCHRP Project 17-63 method. This overestimation can occur when the safety effects of the treatments are dependent. While the HSM does overestimate comparatively to the NCHRP Project 17-63 method, both of the results need to be compared to the real-world application of the dual rumble strip treatments in order to see how effective each methodology actually is.

Table 25: CMF Estimates for Dual Rumble Strips using CMF Combination Methods

\begin{tabular}{|c|l|l|l|l|}
\hline Crash Type & CLRS & ELRS & $\begin{array}{l}\text { Combined Estimate } \\
\text { (HSM) }\end{array}$ & $\begin{array}{l}\text { Combined Estimate } \\
\text { (NCHRP Project 17-63) }\end{array}$ \\
\hline Total & 0.882 & 0.878 & 0.774 & 0.799 \\
\hline Injury & 0.705 & 0.980 & 0.691 & 0.705 \\
\hline PDO & 0.938 & 0.818 & 0.767 & 0.805 \\
\hline SV & 0.844 & 0.689 & 0.582 & 0.688 \\
\hline
\end{tabular}

The differences between the HSM and NCHRP Project 17-63 methods are pronounced, but neither estimation approach is ideal. Ideally there is real-world data that demonstrates the effects of using the dual rumble strip treatment. For this study, there is real-world results for the dual rumble 
strip, consisting of ELRS and CLRS, application. As are found in Table 26 below, the CMFs determined by the EB method differ from both of the other estimates. The differences vary between overestimation and underestimations of the safety benefits. In all the crash types and severities, the estimates both either overestimate or underestimate for each of the crash types and severities. However, the HSM model had the higher magnitude of difference between the estimates and the results determined from the real-world application of this dual rumble strip treatment. This can be explained by the fact that the HSM recommends a single method for combining the CMFs whereas NCHRP Project 17-63 has a number of methods that are targeted to the specific circumstances surrounding the CMF combination.

Table 26: Comparison of EB Results to Combination Methods using Aggregate Segments

\begin{tabular}{|c|c|c|c|}
\hline Crash Type & $\begin{array}{c}\text { Empirical-Bayes Dual } \\
\text { Rumble Strips CMF }\end{array}$ & $\begin{array}{c}\text { Combined CMF } \\
\text { Estimate (HSM) }\end{array}$ & $\begin{array}{c}\text { Combined CMF Estimate (NCHRP } \\
\text { Project 17-63) }\end{array}$ \\
\hline Total & 0.712 & 0.774 & 0.799 \\
\hline Injury & 0.755 & 0.691 & 0.705 \\
\hline PDO & 0.723 & 0.767 & 0.805 \\
\hline SV & 0.864 & 0.582 & 0.688 \\
\hline
\end{tabular}

Earlier, the CMFs developed from the tangent and curved SPFs were determined to be better representatives of the safety effects of the treatment options. As such, they can also be used to estimate the values for the dual rumble strip treatment in both the HSM and NCHRP Project 17-63 methodologies. Comparing the results from the two different methodologies, the HSM method overestimates the safety benefits using the multiplication method. The results for the different combination methods can be found in Table 27 on the next page. Table 28 on the next page shows the comparison between these methodologies and the actual results for the dual rumble strips. In this table, the HSM method values are relatively close to the results from the EB calculation. The HSM method still overestimates the safety benefits of the treatment but the values are closer to the EB values when compared to the values from the NCHRP Project 17-63 method. 
Table 27: CMF Estimates for Dual Rumble Strips using Combination Methods

\begin{tabular}{|c|c|c|c|c|}
\hline Crash Type & CLRS & ELRS & $\begin{array}{c}\text { Combined Estimate } \\
\text { (HSM) }\end{array}$ & $\begin{array}{c}\text { Combined Estimate } \\
\text { (NCHRP Project 17-63) }\end{array}$ \\
\hline Total & 0.819 & 0.598 & 0.490 & 0.653 \\
\hline PDO & 0.667 & 0.835 & 0.557 & 0.613 \\
\hline SV & 0.683 & 0.817 & 0.558 & 0.621 \\
\hline
\end{tabular}

Table 28: Comparison of EB Results to Combination Methods

\begin{tabular}{|c|c|c|c|}
\hline Crash Type & $\begin{array}{c}\text { Empirical-Bayes Dual } \\
\text { Rumble Strips CMF }\end{array}$ & $\begin{array}{c}\text { Combined CMF } \\
\text { Estimate (HSM) }\end{array}$ & $\begin{array}{c}\text { Combined CMF Estimate (NCHRP } \\
\text { Project 17-63) }\end{array}$ \\
\hline Total & 0.554 & 0.490 & 0.653 \\
\hline PDO & 0.565 & 0.557 & 0.613 \\
\hline SV & 0.588 & 0.558 & 0.621 \\
\hline
\end{tabular}

CMF Estimates for Dual Rumble Strips on Tangent and Curved Sections using CMF Combination Methods

As stated previously, there are two methodologies for combining CMFs that were examined in this study. The results from the HSM multiplication method and the NCHRP Project 17-63 method are found Table 29 on the next page. In the HSM method, the total crashes CMF is the only value seen to be higher than the values determined by the NCHRP Project 17-63 methods. This could be caused by the greater than $1.00 \mathrm{CMF}$ value for the tangent total crashes for the ELRS which causes the NCHRP Project 17-63 to use the dominant method. All the other CMFs determined by the NCHRP Project 17-63 method used the dominant common residuals formula. Other than this CMF, the trend of the HSM method overestimating the effect when compared to the NCHRP Project 17-63 method continues. To judge the effectiveness of each method, these CMF values need to be compared to the CMFs derived from the dual rumble strip EB calculations. 
Table 29: CMF Estimates for Dual Rumble Strips on Tangent and Curved Sections using CMF Combination Methods

\begin{tabular}{|l|c|c|c|c|}
\hline \multicolumn{1}{|c|}{ Crash type } & CLRS CMF & ELRS CMF & $\begin{array}{c}\text { Combined CMF } \\
\text { Estimate (HSM) }\end{array}$ & $\begin{array}{c}\text { Combined CMF Estimate } \\
\text { (NCHRP Project 17-63) }\end{array}$ \\
\hline \multicolumn{5}{|c|}{ Tangent Sections } \\
\hline Total & 0.787 & 1.013 & 0.797 & 0.787 \\
\hline PDO & 0.780 & 0.730 & 0.569 & 0.663 \\
\hline SV & 0.773 & 0.765 & 0.591 & 0.669 \\
\hline \multicolumn{7}{|c|}{ Curved Sections } \\
\hline Total & 0.735 & 0.524 & 0.385 & 0.607 \\
\hline PDO & 0.704 & 0.584 & 0.411 & 0.595 \\
\hline SV & 0.720 & 0.570 & 0.410 & 0.602 \\
\hline
\end{tabular}

Table 30 on the next page summarizes the results of the CMFs calculated by the EB method and the other two estimation methodologies. There are differences between the estimates and the EB results with the largest difference between the EB method and the other methods occurring for the total crashes on the tangent sections. This difference stems from the ELRS having a CMF greater than 1.00 on the tangent sections for the total crashes. This disrupts the abilities of the estimates to predict the combined safety benefits and caused the NCHRP Project 17-63 methodology to apply the dominant effect method rather than the dominant common residuals method used in the other CMF calculations. The results for the curved sections demonstrate the trend of the HSM method into overestimating the safety benefits through the multiplication method of combining the CMFs. The HSM estimates a reduction of approximately $60 \%$ in the number of crashes for each type and severity. This estimation is a much higher reduction compared to the approximately $45 \%$ reduction seen in the EB results and the $40 \%$ reduction estimated by the NCHRP Project 17-63 method. These numbers also demonstrate how close the estimate from the NCHRP Project 17-63 is to the EB results for the curved sections. The tangent section results from the same methodology have a greater difference between themselves and the EB results but are still similar, especially in the single vehicle crashes category where the reductions in crashes differ by less than one percent. 
Table 30: Comparison of EB Results to Combination Methods on Tangent and Curved Sections

\begin{tabular}{|l|c|c|c|}
\hline \multicolumn{1}{|c|}{ Crash type } & $\begin{array}{c}\text { Empirical-Bayes } \\
\text { Dual Rumble Strips CMFs }\end{array}$ & $\begin{array}{c}\text { Combined CMF } \\
\text { Estimate (HSM) }\end{array}$ & $\begin{array}{c}\text { Combined CMF Estimate } \\
\text { (NCHRP Project 17-63) }\end{array}$ \\
\hline \multicolumn{5}{|c|}{ Tangent Sections } \\
\hline Total & 0.596 & 0.797 & 0.787 \\
\hline PDO & 0.586 & 0.569 & 0.663 \\
\hline SV & 0.677 & 0.591 & 0.669 \\
\hline \multicolumn{5}{|c|}{ Curved Sections } \\
\hline Total & 0.526 & 0.385 & 0.607 \\
\hline PDO & 0.550 & 0.411 & 0.595 \\
\hline SV & 0.536 & 0.410 & 0.602 \\
\hline
\end{tabular}




\section{Results from Validation of the Highway Safety Manual Crash Prediction Algorithm}

The HSM includes a number of SPFs that require calibration in order for them to be used by studies. This calibration is specific to the SPFs that are being studied and the regions that the studies are taking place in. Once the calibration is complete, the SPFs can be used in a number of scenarios including CMF generation. The use of the SPFs is reliant upon this calibration and the results of this calibration should be examined to determine their accuracy. Appendix Tables 18 and 19 show the data for the sites that were used in the HSM SPF calibration.

The results for the calibration factors for each of the crash types can be found in Table 31 below. Only the total and single vehicle crashes were examined due to restrictions with the overlap of crash types and severities for the predictive models and those examined in the tangent sections. These factors were created using the reference sites that did not experience any form of treatment to create the calibration based on what would occur if no treatment had been applied. These reference sites were also tangential since information in curvature was not available to apply the CMF for curved alignment.

Table 31: Calibration Factors

\begin{tabular}{|r|c|c|}
\cline { 2 - 3 } \multicolumn{1}{c|}{ Crash Type } & Total & SV \\
\hline Calibration Factor & 0.47 & 0.63 \\
\hline Observed Crashes & 2710 & 2139 \\
\hline Predicted Crashes & 5778 & 3387 \\
\hline
\end{tabular}

Assessment through CMF Generation for Rumble Strips

Using the calibration factors in Table 31, the predictive method can be used to generate CMFs as the model can output the expected crashes if the treatment had not been applied. As such, the only change between the predicted and observed crashes will be the application of the treatment options. Table 32 on the next page outlines the CMFs generated . These CMFs were developed for the tangent sites with the treatments applied. 
Table 32: CMFs Generated Through Predictive Model on Tangent Sections

\begin{tabular}{|r|c|c|c|c|c|c|}
\cline { 2 - 6 } \multicolumn{1}{c|}{} & $\begin{array}{c}\text { Expected } \\
\text { Total } \\
\text { Crashes }\end{array}$ & $\begin{array}{c}\text { Observed } \\
\text { Total } \\
\text { Crashes }\end{array}$ & $\begin{array}{c}\text { CMF Total } \\
\text { Crashes }\end{array}$ & $\begin{array}{c}\text { Expected SV } \\
\text { Crashes }\end{array}$ & $\begin{array}{c}\text { Observed } \\
\text { SV Crashes }\end{array}$ & $\begin{array}{c}\text { CMF SV } \\
\text { Crashes }\end{array}$ \\
\hline CLRS & 128 & 81 & 0.631 & 100 & 62 & 0.621 \\
\hline ELRS & 237 & 180 & 0.761 & 162 & 98 & 0.607 \\
\hline $\begin{array}{r}\text { Dual Rumble } \\
\text { Strips }\end{array}$ & 97 & 49 & 0.505 & 67 & 35 & 0.525 \\
\hline
\end{tabular}

Through this method, the values for the implied CMFs calculated through the use of the predictive model show a considerable reduction in crashes due to the application of these rumble strip treatments. All three treatment options had CMFs that indicated the improvement due to the rumble strips as all the values are below 1.00 for the total and single vehicle crashes. The combination of CLRS and ELRS also had lower CMFs than either treatment option individually. The values for the CMFs determined through this methodology should be compared to other methods in order to test its viability. The results for all the previously calculated CMFs for each of the treatment options and crash types can be found in Table 33 below.

Table 33: Empirical-Bayes CMF Comparison with Highway Safety Manual Prediction Methods on Tangent Sections

\begin{tabular}{|r|c|c|c|c|}
\cline { 2 - 5 } \multicolumn{1}{c|}{} & HSM Total & EB Total & HSM SV & EB SV \\
\hline CLRS & 0.631 & 0.787 & 0.621 & 0.773 \\
\hline ELRS & 0.761 & 1.013 & 0.607 & 0.765 \\
\hline $\begin{array}{r}\text { Dual Rumble } \\
\text { Strips }\end{array}$ & 0.505 & 0.596 & 0.525 & 0.677 \\
\hline
\end{tabular}

All the CMF values determined through this methodology are considerably different than the CMF values determined through the EB method. The closest value was the CMFs for the total crashes and dual rumble strip treatment where the HSM only overpredicted the reduction in by crashes by $9 \%$. The differences could be attributed to possible errors in the development of the calibration factors which resulted in the higher number of expected crashes for the sites without rumble strips than 
determined through the EB study. This attests to the fact that the multiplicative method for applying CMFs are the HSM prescribes may not be valid for application in Ontario.

\section{Assessment Through CMF Generation for Shoulder Width}

As stated earlier, there are specific CMFs that are applied to the SPFs generated for use in the HSM. These CMFs allow for the calibration of the SPFs through the generation of the calibration factor for the specific study. With the SPFs calibrated for use in this study, the results from this calibration can be examined by removing the given CMFs and attempting to solve for the implied values for the CMFs.

Ideally, the values for the implied CMFs generated by the SPFs will match the CMFs that are specified for the SPFs. As seen in Table 34 below, this was not the case as the specified CMFs were all higher than the implied CMFs estimated for shoulder width as an example. There are also differences in the CMFs calculated using the total crashes or single vehicle crashes whereas the HSM specifies singular values that are not dependent on the crash types. These results further attest to the fact that the multiplicative method for applying CMFs as prescribed in the HSM may not be valid, although they may also imply that the HSM specified CMF may be overestimating the CMFs for shoulder width. As stated earlier, the acronym PTPV represents partially paved.

Table 34: HSM SPF Specified CMF Comparison

\begin{tabular}{|c|c|c|c|}
\hline $\begin{array}{c}\text { Shoulder Type } \\
\text { and Width (ft) }\end{array}$ & $\begin{array}{c}\text { HSM Specified } \\
\text { Value }\end{array}$ & $\begin{array}{c}\text { CMF Calculated using Total } \\
\text { Crashes }\end{array}$ & $\begin{array}{c}\text { CMF Calculated using SV } \\
\text { Crashes }\end{array}$ \\
\hline PTPV, 8 & 0.87 & 0.543 & 0.655 \\
\hline PTPV, 10 & 0.77 & 0.476 & 0.490 \\
\hline
\end{tabular}




\section{Discussion of Results}

This section of the study examined the validity of the HSM crash prediction algorithm to Ontario provincial highways. This applicability was tested through the methods that are used to estimate the combined effect of multiple safety treatments and through the predictive ability of the algorithm in implying CMFs.

The combined CMF estimation methodologies examined in this study were the HSM and NCHRP Project 17-63 methodologies. The HSM methodology used the multiplication method of combining CMFs to estimate the effect that multiple treatments will have on the roadway. The NCHRP project 1763 methodology uses a number of methods that depend upon a number of factors including the amount of overlap between the treatments and the magnitudes of the individual CMFs. Some of the methods that could be selected include the multiplication method, the dominant effect method and the dominant common residuals method.

These combination methods produced results that differed from the results generated from the EB method. However, it was seen that the HSM method tended to overestimate the safety benefits of the multiple treatments. The HSM method also had bigger differences between its values and the EB results than the NCHRP Project 17-63 method. The NCHRP Project 17-63 method had some values that the closely matched the EB results, but the biggest differences between its results and the EB results occurred when the dominant effect formula was used instead of the dominant common residuals formula. This formula used the lowest CMF as the value for the combined treatment and does not combine the different effects due to CMFs in any fashion.

The results from the HSM methodology show that it has a tendency to overestimate the safety benefits of multiple treatments. The NCHRP Project 17-63 methodology provides more accuracy than the HSM method, but still has flaws that can be clearly seen when the methodology calls for the 
dominant effect method. The examination of the combination methods showed that while the combination methods can provide glimpses into the effects of multiple treatments, the ideal method is to have the real-world data for the effect of the combination treatments rather than an estimation model.

The HSM crash prediction algorithm validity was also examined through the use of the SPFs in the implied CMFs. In the HSM algorithm, CMFs are applied for the different road features such as lane width, rumble strip presence, shoulder width and shoulder type. These SPFs are then calibrated for the local regions and can be used to generate implied CMFs for the road safety treatments by comparing predicted crashes without the CMF applied to observed crashes.

These implied CMFs for rumble strips were compared to the results from the EB study for each of the possible crash types and severities that were common. The CMFs from this method were considerably lower than the EB method results. This was caused by the overestimation in the predicted number of crashes without the treatments being applied. The values for these predicted crash counts were meaningfully higher than the EB method predictions. This indicates that there could be an error in the calibration of the HSM SPFs as this would lead to the overestimation of the predicted crashes. Most importantly, the results suggest that the multiplicative method for applying CMFs as prescribed in the HSM may not be valid for application to Ontario two-lane rural roads.

This is not the only method for testing validity of the HSM algorithm as there are CMFs prescribed in the HSM that can be recalculated using the SPFs. With the calibrated SPFs, the values for the CMFs given by the HSM for road features can be redeveloped to check that the calibration worked as intended. This is done by omitting a CMF and re-estimating it by comparing predicted crashes without the CMF applied to observed crashes. 
The CMF recalculation for shoulder width did not perform as expected as there are differences between the calculated values and the HSM provided values, further confirmation of the earlier finding that the multiplicative method for applying CMFs as prescribed in the HSM may not be valid for application in Ontario. 


\section{Chapter 4: Summary and Conclusions}

This thesis explored the different methods of representing the safety effects of different treatments. In the case study of this research, the treatments were the centreline rumble strips (CLRS), edgeline rumble strips (ELRS) and dual rumble strips. The different methods included the development of Crash Modification Factors (CMFs), the exploration of CMF variability through CMF development on tangent and curved sites and CMFunction generation and the assessment of the Highway Safety Manual's crash prediction algorithm.

One of this study's objectives was to provide definitive results on the safety effect of the CLRS, ELRS and dual rumble strip treatments through the development of CMFs. These results were obtained with the use of the Empirical-Bayes (EB) method. The EB calculations were done on two distinct sets of data including aggregated segments that had tangent and curved sections mixed within the segments, and smaller tangent and curved sections, where each site was mainly tangent or curved and did not have the mixture. The results found using the tangent and curved sections provided increased accuracy for the CMF values due to each alignment type having their own distinct Safety Performance Functions (SPFs) for the estimation of crashes in the EB methodology. Between the tangent and curved sections, all the treatment options were significantly more effective on the curved road sections. This can be attributed to the fact that the rumble strips alert drivers to deviations from normal road operations and the curved sections feature crashes that occur when drivers deviate from their lanes. This was reflected in the CMFs for all three types of treatment, but the greatest changes could be seen in total crashes CMFs for the ELRS. Between the tangent and curved sections, the CMFs indicate approximately $50 \%$ more reductions in crashes on the curved sections. The CMFs for the dual rumble strips also demonstrated that the combination of the two treatment types had a greater safety benefit than either 
treatment on their own. This result was expected as the two treatment types primarily target different crashes.

The CMF variability was then further explored through the development of the CMFunctions. CMFunctions provide more accuracy than CMFs as they vary based upon the independent variables used in the function and thus allow for the different scenarios in the treatment groups to be represented. For this study, the independent variable was set as a combination of the crashes, the length of the road segments and the number of years of data before the treatment. This normalizes the crashes that are experienced by the road sections and accounts for the variation in crash numbers caused by having shorter segments as well as the number of years of data. The CMFunctions all follow the same trends as they show a decrease in the CMF with increases in the expected crashes/km/year before. This indicates that the treatments are more effective when there are higher crash counts which may be caused by the higher opportunities to reduce crashes. Weighted CMFunctions were examined for application, but the CMF values these functions produced were unrealistically low because of outlier weights. This issue could be resolved by grouping sites but the relatively small number of sites did not allow for this option to be explored.

There were two CMF combination methodologies used in this study, the multiplication method that is used in the HSM and the methodology outlined in NCHRP Project 17-63 which defines different equations based on the CMFs examined. The HSM multiplication method tended to overestimate the safety benefit of the dual rumble strips, i.e. have a lower CMF, when compared to the other method. When compared to the results from the dual rumble strips applied to the Ontario rural two-lane highways, the HSM method overestimated most of the CMF values. The methods recommended by NCHRP Project 17-63 give CMF values that are closer to the CMF values using the dual rumble strips treated sites. Some of the largest differences between the NCHRP Project 17-63 method and the EB results occurred when the report's recommendation was to use the dominant effect method. This 
method states that the higher crash reduction dominates the effect that the combination of the treatment options will have and the effect of the combined treatment is this value. The results from these methods show that, while the newer methods may have improved upon the HSM method, there is no substitution for collecting data from sites that have been treated with the combination treatment option and doing a robust before-after study.

The predictive model from the HSM was used in order to evaluate its effectiveness when predicting the future crashes. The first and most critical step of this method is the development of the calibration factor for local conditions. To be truly accurate, this factor requires extensive data. As shown, any errors in the calibration factor can cause the predictive model to overestimate the predicted crashes. The overestimation of the crashes can lead to an overestimation of the CMF values, which happened in this study when CMFs were estimated by comparing observed crashes to crashes predicted by the algorithm without applying the CMF of interest. This overestimation was the most likely cause for the differences in the CMF values from the HSM algorithm and the EB study. With more research, the calibration of the HSM predictive models should give CMF results similar to the ones developed by the EB study.

There were also limitations on the crash types and severities that were examined due to the limited overlap of the crash types and severities in the predictive model and those studied by the tangent sites. Other limitations throughout this study included the use of the single vehicle crashes as the targeted crashes for the ELRS treatment option. In reality, the ELRS target run-off-road crashes which are counted as single vehicle crashes, but are not the only crashes as wildlife crashes are also among the single vehicle crashes category. However, the single vehicle crashes were the best representatives of the run-off-road crashes that were available in the MTO datasets. The low number of sites that had been treated with dual rumble strips also limited this study as it prevent the development of CMFunctions and increased the standard errors. 
Appendix

Appendix Table 1: CLRS Locations

\begin{tabular}{|l|l|l|l|l|l|l|l|}
\hline & \multicolumn{3}{|l|}{ From } & \multicolumn{2}{l}{ To } & & \\
\hline Reference & Highway & LHRS & Offset & LHRS & Offset & Build year & Length (km) \\
\hline CLRS 1 & 17 & 21000 & 0 & 21010 & 2 & 2010 & 12 \\
\hline CLRS 2 & 11 & 17285 & 4.9 & 17285 & 19.5 & 2010 & 14.6 \\
\hline CLRS 3 & 17 & 21210 & 8.9 & 21220 & 4.2 & 2011 & 13.7 \\
\hline CLRS 4 & 17 & 21210 & 1.6 & 21210 & 3.5 & 2011 & 1.9 \\
\hline CLRS 5 & 11 & 17280 & 0 & 17283 & 13.7 & 2015 & 27.6 \\
\hline CLRS 6 & 11 & 17285 & 1 & 17285 & 4.9 & 2015 & 3.9 \\
\hline CLRS 7 & 11 & 17285 & 20.6 & 17285 & 28.3 & 2015 & 7.7 \\
\hline CLRS 8 & 11 & 17293 & 2.3 & 17310 & 0 & 2015 & 15.6 \\
\hline CLRS 9 & 17 & 20751 & 0.1 & 20761 & 1.6 & 2014 & 11.3 \\
\hline CLRS 10 & 17 & 21041 & 0.92 & 21041 & 12.37 & 2015 & 11.45 \\
\hline CLRS 11 & 17 & 21410 & 29.95 & 21420 & 9.87 & 2012 & 9.9 \\
\hline CLRS 12 & 17 & 21410 & 4.9 & 21410 & 20.9 & 2012 & 16 \\
\hline CLRS 13 & 17 & 21036 & 0 & 21036 & 11 & 2012 & 11 \\
\hline CLRS 14 & 17 & 20990 & 7.5 & 20990 & 7.9 & 2012 & 0.4 \\
\hline CLRS 15 & 138 & 45430 & 0 & 45450 & 0 & 2015 & 16.9 \\
\hline
\end{tabular}

Appendix Table 2: ELRS Locations

\begin{tabular}{|l|l|l|l|l|l|l|l|}
\hline & \multicolumn{3}{|l|}{ From } & \multicolumn{2}{l|}{ To } & & \\
\hline Reference & Highway & LHRS & Offset & LHRS & Offset & Build Year & Length $(\mathrm{km})$ \\
\hline ELRS 1 & 41 & 29710 & 4.1 & 29710 & 10.1 & 2015 & 6 \\
\hline ELRS 2 & 17 & 20761 & 1.4 & 20771 & 0 & 2012 & 8.6 \\
\hline ELRS 3 & 17 & 20708 & 0 & 20722 & 0 & 2011 & 14 \\
\hline ELRS 4 & 17 & 20703 & 2.7 & 20708 & 0 & 2008 & 2.3 \\
\hline ELRS 5 & 17 & 20683 & 0 & 20688 & 0 & 2008 & 11.2 \\
\hline ELRS 6 & 15 & 20030 & 4.9 & 20030 & 6.4 & 2006 & 1.5 \\
\hline
\end{tabular}


Appendix Table 3: Dual Rumble Strip Location

\begin{tabular}{|l|l|l|l|l|l|l|l|}
\hline & \multicolumn{3}{|l|}{ From } & \multicolumn{2}{l|}{ To } & & \\
\hline Reference & Highway & LHRS & Offset & LHRS & Offset & Build Year & Length (km) \\
\hline Dual 1 & 17 & 20746 & 0 & 20751 & 0 & 2014 & 5 \\
\hline Dual 2 & 17 & 20730 & 1.3 & 20746 & 0 & 2014 & 14.7 \\
\hline Dual 3 & 17 & 20722 & 0 & 20722 & 1.4 & 2013 & 1.4 \\
\hline Dual 4 & 17 & 20722 & 1.4 & 20722 & 8.9 & 2014 & 7.5 \\
\hline Dual 5 & 17 & 20688 & 0 & 20701 & 1.2 & 2014 & 14.2 \\
\hline
\end{tabular}

Appendix Table 4: Reference Locations

\begin{tabular}{|l|l|l|l|l|l|l|l|}
\hline & & \multicolumn{2}{|l|}{ From } & To & & \\
\hline Reference & Highway & LHRS & Offset & LHRS & Offset & Build Year & $\begin{array}{l}\text { Length } \\
(\mathrm{km})\end{array}$ \\
\hline Ref 1 & 10 & 16550 & 0 & 16550 & 4 & N/A & 4 \\
\hline Ref 2 & 10 & 16557 & 0 & 16557 & 8.3 & N/A & 8.3 \\
\hline Ref 3 & 10 & 16570 & 1 & 16570 & 6 & N/A & 5 \\
\hline Ref 4 & 89 & 38670 & 3.2 & 38670 & 10 & N/A & 6.8 \\
\hline Ref 5 & 89 & 38685 & 0 & 38685 & 10 & N/A & 10 \\
\hline Ref 6 & 89 & 38690 & 1 & 38690 & 11.2 & N/A & 10.2 \\
\hline Ref 7 & 17 & 20840 & 1 & 20840 & 17.4 & N/A & 16.4 \\
\hline Ref 8 & 26 & 25665 & 0 & 29690 & 0 & N/A & 25.3 \\
\hline Ref 9 & 21 & 24170 & 6 & 24190 & 0 & N/A & 29.3 \\
\hline Ref 10 & 21 & 24120 & 0 & 24160 & 0 & N/A & 50.9 \\
\hline Ref 11 & 23 & 25620 & 0 & 25640 & 0 & N/A & 27.1 \\
\hline Ref 12 & 23 & 24590 & 1.3 & 24600 & 0 & N/A & 19.9 \\
\hline
\end{tabular}


Appendix Table 5: CLRS Tangent and Curved Sections

\begin{tabular}{|c|c|c|c|c|c|c|}
\hline & & & From & & To & \\
\hline Reference & Length (km) & Road Type & LHRS & Offset & LHRS & Offset \\
\hline CLRS 1 & 8 & Curved & 17285 & 4.9 & 17285 & 19.5 \\
\hline CLRS 2 & 1.1 & Tangent & 17285 & 4.9 & 17285 & 19.5 \\
\hline CLRS 3 & 0.7 & Curved & 17285 & 4.9 & 17285 & 19.5 \\
\hline CLRS 4 & 0.4 & Tangent & 17285 & 4.9 & 17285 & 19.5 \\
\hline CLRS 5 & 0.6 & Curved & 17285 & 4.9 & 17285 & 19.5 \\
\hline CLRS 6 & 0.4 & Tangent & 17285 & 4.9 & 17285 & 19.5 \\
\hline CLRS 7 & 0.4 & Curved & 17285 & 4.9 & 17285 & 19.5 \\
\hline CLRS 8 & 1.1 & Tangent & 17285 & 4.9 & 17285 & 19.5 \\
\hline CLRS 9 & 1.9 & Curved & 17285 & 4.9 & 17285 & 19.5 \\
\hline CLRS 10 & 0.2 & Curved & 20990 & 7.5 & 20990 & 7.9 \\
\hline CLRS 11 & 0.2 & Tangent & 20990 & 7.5 & 20990 & 7.9 \\
\hline CLRS 12 & 2.5 & Curved & 21000 & 0 & 21010 & 2 \\
\hline CLRS 13 & 1.6 & Tangent & 21000 & 0 & 21010 & 2 \\
\hline CLRS 14 & 0.6 & Curved & 21000 & 0 & 21010 & 2 \\
\hline CLRS 15 & 0.7 & Tangent & 21000 & 0 & 21010 & 2 \\
\hline CLRS 16 & 0.3 & Curved & 21000 & 0 & 21010 & 2 \\
\hline CLRS 17 & 0.4 & Tangent & 21000 & 0 & 21010 & 2 \\
\hline CLRS 18 & 0.8 & Curved & 21000 & 0 & 21010 & 2 \\
\hline CLRS 19 & 3 & Tangent & 21000 & 0 & 21010 & 2 \\
\hline CLRS 20 & 0.7 & Curved & 21000 & 0 & 21010 & 2 \\
\hline CLRS 21 & 0.6 & Tangent & 21000 & 0 & 21010 & 2 \\
\hline CLRS 22 & 0.6 & Curved & 21000 & 0 & 21010 & 2 \\
\hline CLRS 23 & 0.7 & Tangent & 21000 & 0 & 21010 & 2 \\
\hline CLRS 24 & 0.5 & Curved & 21036 & 0 & 21036 & 11 \\
\hline CLRS 25 & 1 & Tangent & 21036 & 0 & 21036 & 11 \\
\hline CLRS 26 & 1.3 & Curved & 21036 & 0 & 21036 & 11 \\
\hline CLRS 27 & 1.7 & Tangent & 21036 & 0 & 21036 & 11 \\
\hline CLRS 28 & 6.5 & Curved & 21036 & 0 & 21036 & 11 \\
\hline CLRS 29 & 0.9 & Curved & 21210 & 1.6 & 21210 & 3.5 \\
\hline CLRS 30 & 1 & Tangent & 21210 & 1.6 & 21210 & 3.5 \\
\hline CLRS 31 & 0.9 & Curved & 21210 & 8.9 & 21220 & 4.2 \\
\hline CLRS 32 & 1.7 & Tangent & 21210 & 8.9 & 21220 & 4.2 \\
\hline CLRS 33 & 9.7 & Curved & 21210 & 8.9 & 21220 & 4.2 \\
\hline CLRS 34 & 16 & Curved & 21410 & 4.9 & 21410 & 20.9 \\
\hline CLRS 35 & 3.5 & Curved & 21410 & 29.95 & 21420 & 9.87 \\
\hline CLRS 36 & 0.8 & Tangent & 21410 & 29.95 & 21420 & 9.87 \\
\hline CLRS 37 & 5.6 & Curved & 21410 & 29.95 & 21420 & 9.87 \\
\hline
\end{tabular}


Appendix Table 6: ELRS Tangent and Curved Sections

\begin{tabular}{|l|l|l|l|l|l|l|}
\hline & & & From & To & & \\
\hline Reference & Length $(\mathrm{km})$ & Road Type & LHRS & Offset & LHRS & Offset \\
\hline ELRS 1 & 1.5 & Tangent & 20030 & 4.9 & 20030 & 6.4 \\
\hline ELRS 2 & 0.5 & Curved & 20683 & 0 & 20688 & 0 \\
\hline ELRS 3 & 1 & Tangent & 20683 & 0 & 20688 & 0 \\
\hline ELRS 4 & 1.5 & Curved & 20683 & 0 & 20688 & 0 \\
\hline ELRS 5 & 3.7 & Tangent & 20683 & 0 & 20688 & 0 \\
\hline ELRS 6 & 2.5 & Curved & 20683 & 0 & 20688 & 0 \\
\hline ELRS 7 & 0.8 & Tangent & 20683 & 0 & 20688 & 0 \\
\hline ELRS 8 & 1.2 & Curved & 20683 & 0 & 20688 & 0 \\
\hline ELRS 9 & 2.7 & Tangent & 20703 & 2.7 & 20708 & 0 \\
\hline ELRS 10 & 0.3 & Curved & 20703 & 2.7 & 20708 & 0 \\
\hline ELRS 11 & 1.4 & Tangent & 20703 & 2.7 & 20708 & 0 \\
\hline ELRS 12 & 0.6 & Tangent & 20708 & 0 & 20722 & 0 \\
\hline ELRS 13 & 5.6 & Curved & 20708 & 0 & 20722 & 0 \\
\hline ELRS 14 & 1.8 & Tangent & 20708 & 0 & 20722 & 0 \\
\hline ELRS 15 & 0.4 & Curved & 20708 & 0 & 20722 & 0 \\
\hline ELRS 16 & 0.8 & Tangent & 20708 & 0 & 20722 & 0 \\
\hline ELRS 17 & 1.7 & Tangent & 20761 & 1.4 & 20771 & 0 \\
\hline ELRS 18 & 1.1 & Curved & 20761 & 1.4 & 20771 & 0 \\
\hline ELRS 19 & 3 & Tangent & 20761 & 1.4 & 20771 & 0 \\
\hline & & & & & & \\
\hline
\end{tabular}

Appendix Table 7: Dual Rumble Strip Tangent and Curved Sections

\begin{tabular}{|l|l|l|l|l|l|l|}
\hline & \multicolumn{4}{|l|}{ From } & To \\
\hline Reference & Length $(\mathrm{km})$ & Road Type & LHRS & Offset & LHRS & Offset \\
\hline Dual 1 & 3 & Tangent & 20688 & 0 & 20701 & 1.2 \\
\hline Dual 2 & 5 & Curved & 20688 & 0 & 20701 & 1.2 \\
\hline Dual 3 & 3.6 & Tangent & 20688 & 0 & 20701 & 1.2 \\
\hline Dual 4 & 1.4 & Curved & 20722 & 0 & 20722 & 1.4 \\
\hline Dual 5 & 7.5 & Tangent & 20722 & 1.4 & 20722 & 8.9 \\
\hline Dual 6 & 0.4 & Tangent & 20730 & 1.3 & 20746 & 0 \\
\hline Dual 7 & 1.2 & Curved & 20730 & 1.3 & 20746 & 0 \\
\hline Dual 8 & 2.7 & Tangent & 20730 & 1.3 & 20746 & 0 \\
\hline Dual 9 & 0.9 & Curved & 20730 & 1.3 & 20746 & 0 \\
\hline Dual 10 & 7.4 & Tangent & 20730 & 1.3 & 20746 & 0 \\
\hline Dual 11 & 2.8 & Curved & 20730 & 1.3 & 20746 & 0 \\
\hline Dual 12 & 3.4 & Curved & 20746 & 0 & 20751 & 0 \\
\hline Dual 13 & 2.3 & Tangent & 20746 & 0 & 20751 & 0 \\
\hline
\end{tabular}


Appendix Table 8: Site Traffic Volumes (2000-2007)

\begin{tabular}{|c|c|c|c|c|c|c|c|c|}
\hline Reference & 2000 & 2001 & 2002 & 2003 & 2004 & 2005 & 2006 & 2007 \\
\hline ELRS 1 & 3650 & 3700 & 3750 & 3750 & 3850 & 3750 & 3950 & 3850 \\
\hline ELRS 2 & 6600 & 6650 & 6800 & 6650 & 7100 & 7250 & 7550 & 7500 \\
\hline Dual 1 & 5700 & 5700 & 5800 & 5850 & 5900 & 6000 & 6050 & 6100 \\
\hline Dual 2 & 7000 & 7100 & 7200 & 7300 & 7400 & 7550 & 7650 & 7750 \\
\hline Dual 3 & 7600 & 7750 & 7850 & 7700 & 8050 & 8150 & 8250 & 8350 \\
\hline Dual 4 & 8550 & 8600 & 8600 & 8650 & 8700 & 8800 & 8750 & 8900 \\
\hline ELRS 3 & 7000 & 7000 & 7200 & 7350 & 7500 & 7650 & 7850 & 8000 \\
\hline ELRS 4 & 8500 & 8850 & 9150 & 9450 & 9750 & 10000 & 10400 & 10200 \\
\hline Dual 5 & 10500 & 10800 & 11100 & 11600 & 11700 & 12000 & 12300 & 12600 \\
\hline ELRS 5 & 11200 & 11400 & 11600 & 11800 & 12000 & 12200 & 12400 & 12700 \\
\hline ELRS 6 & 5250 & 5150 & 5200 & 5000 & 5200 & 5000 & 5050 & 5050 \\
\hline CLRS 1 & 5800 & 5800 & 5950 & 6000 & 6050 & 6150 & 6200 & 6250 \\
\hline CLRS 2 & 3950 & 4000 & 4000 & 4050 & 4100 & 4100 & 4200 & 4300 \\
\hline CLRS 3 & 3800 & 3850 & 3850 & 3850 & 3800 & 3800 & 3800 & 3750 \\
\hline CLRS 4 & 3800 & 4450 & 4450 & 4450 & 4350 & 4350 & 4300 & 4300 \\
\hline Ref 1 & 5650 & 5750 & 6300 & 5900 & 5800 & 5950 & 5900 & 6100 \\
\hline Ref 2 & 5650 & 5750 & 6300 & 5900 & 5800 & 5950 & 5900 & 6100 \\
\hline Ref 3 & 5900 & 6050 & 6300 & 6650 & 6600 & 6650 & 6600 & 6700 \\
\hline Ref 4 & 3100 & 3200 & 3500 & 3600 & 3500 & 3500 & 3500 & 3500 \\
\hline Ref 5 & 2500 & 2550 & 2700 & 3300 & 2700 & 2800 & 2850 & 2900 \\
\hline Ref 6 & 2750 & 2800 & 2800 & 2800 & 2850 & 2900 & 2950 & 3000 \\
\hline Ref 7 & 2250 & 2250 & 2300 & 2300 & 2350 & 2350 & 2500 & 2400 \\
\hline CLRS 5 & 3150 & 3150 & 3150 & 3150 & 3200 & 3200 & 3200 & 3200 \\
\hline CLRS 6 & 3950 & 4000 & 4000 & 4050 & 4100 & 4100 & 4200 & 4300 \\
\hline CLRS 7 & 3950 & 4000 & 4000 & 4050 & 4100 & 4100 & 4200 & 4300 \\
\hline CLRS 8 & 3650 & 3800 & 4200 & 4150 & 4600 & 4400 & 4400 & 4600 \\
\hline CLRS 9 & 5700 & 5700 & 5800 & 5850 & 5900 & 6000 & 6050 & 6100 \\
\hline CLRS 10 & 4350 & 4650 & 4800 & 5000 & 5250 & 5450 & 5800 & 5900 \\
\hline CLRS 11 & 2050 & 2050 & 2050 & 2100 & 2050 & 2150 & 2000 & 2000 \\
\hline CLRS 12 & 2250 & 2250 & 2300 & 2200 & 2300 & 2450 & 2200 & 2200 \\
\hline CLRS 13 & 5600 & 5800 & 6000 & 6200 & 6300 & 6600 & 6800 & 6850 \\
\hline CLRS 14 & 4950 & 4950 & 5050 & 5100 & 5150 & 5250 & 5250 & 5350 \\
\hline CLRS 15 & 4600 & 4650 & 4700 & 4600 & 4800 & 5000 & 5200 & 5350 \\
\hline Ref 8 & 7950 & 8100 & 8450 & 8650 & 8550 & 8550 & 8550 & 8750 \\
\hline Ref 9 & 4050 & 4050 & 4100 & 4100 & 4150 & 4200 & 4200 & 4250 \\
\hline Ref 10 & 4000 & 4100 & 4050 & 4100 & 4050 & 4100 & 4150 & 4150 \\
\hline Ref 11 & 6200 & 6350 & 6500 & 6650 & 6800 & 6950 & 7300 & 7150 \\
\hline Ref 12 & 7300 & 7400 & 7500 & 7700 & 7700 & 7800 & 7900 & 8000 \\
\hline
\end{tabular}


Appendix Table 9: Site Traffic Volumes (2008-2016)

\begin{tabular}{|c|c|c|c|c|c|c|c|c|c|}
\hline Reference & 2008 & 2009 & 2010 & 2011 & 2012 & 2013 & 2014 & 2015 & 2016 \\
\hline ELRS 1 & 3900 & 3600 & 3950 & 4000 & 3400 & 3400 & 3850 & 5300 & 5300 \\
\hline ELRS 2 & 7650 & 7800 & 7950 & 8050 & 8200 & 8350 & 8500 & 7750 & 7900 \\
\hline Dual 1 & 6200 & 6250 & 6300 & 6400 & 6800 & 6600 & 6650 & 6650 & 6700 \\
\hline Dual 2 & 7900 & 8000 & 8100 & 8200 & 8100 & 8450 & 8500 & 8650 & 8750 \\
\hline Dual 3 & 8450 & 8550 & 8650 & 8750 & 8200 & 8650 & 8850 & 8950 & 9050 \\
\hline Dual 4 & 8950 & 9200 & 9050 & 9100 & 9800 & 10000 & 9500 & 9600 & 9650 \\
\hline ELRS 3 & 8150 & 8300 & 8500 & 8650 & 7900 & 8800 & 8950 & 9100 & 9250 \\
\hline ELRS 4 & 10200 & 10200 & 11000 & 11300 & 10900 & 11100 & 11800 & 12000 & 12300 \\
\hline Dual 5 & 12700 & 13200 & 12500 & 13500 & 12500 & 12300 & 13800 & 14000 & 14200 \\
\hline ELRS 5 & 12900 & 13100 & 13300 & 13500 & 12500 & 12300 & 10000 & 12500 & 16700 \\
\hline ELRS 6 & 5050 & 5050 & 4800 & 5050 & 4800 & 4700 & 4550 & & \\
\hline CLRS 1 & 6300 & 6400 & 6450 & 6500 & 6600 & 6650 & 6700 & 6750 & 6850 \\
\hline CLRS 2 & 4200 & 4450 & 4550 & 4300 & 4450 & 4400 & 4500 & 3950 & 4500 \\
\hline CLRS 3 & 3750 & 3700 & 3700 & 3700 & 3650 & 3650 & 3600 & 4050 & 4050 \\
\hline CLRS 4 & 4150 & 4200 & 4200 & 4150 & 4150 & 4100 & 4100 & 4050 & 4050 \\
\hline Ref 1 & 5900 & 6250 & 6300 & 6300 & 6000 & 6000 & 6350 & & \\
\hline Ref 2 & 5900 & 6250 & 6300 & 6300 & 6000 & 6000 & 6350 & & \\
\hline Ref 3 & 6950 & 6950 & 6300 & 6300 & 6200 & 6200 & 6200 & & \\
\hline Ref 4 & 3500 & 3600 & 3100 & 3100 & 2800 & 2800 & 2700 & 2700 & 2750 \\
\hline Ref 5 & 2850 & 3000 & 2750 & 2750 & 2600 & 2600 & 2500 & & \\
\hline Ref 6 & 3050 & 3050 & 3100 & 3150 & 2750 & 2750 & 2900 & 3200 & 3100 \\
\hline Ref 7 & 2450 & 3500 & 2750 & 2800 & 2500 & 2850 & 2850 & & \\
\hline CLRS 5 & 3200 & 3200 & 3200 & 3200 & 3850 & 3350 & 3400 & 3400 & 3400 \\
\hline CLRS 6 & 4200 & 4450 & 4550 & 4300 & 4450 & 4400 & 4500 & 3950 & 4500 \\
\hline CLRS 7 & 4200 & 4450 & 4550 & 4300 & 4450 & 4400 & 4500 & 3950 & 4500 \\
\hline CLRS 8 & 4750 & 5200 & 5000 & 4100 & 5250 & 5350 & 5500 & 5600 & 5750 \\
\hline CLRS 9 & 6200 & 6250 & 6300 & 6400 & 6800 & 6600 & 6650 & 6750 & 6800 \\
\hline CLRS 10 & 6150 & 6350 & 6600 & 6800 & 7050 & 7250 & 7500 & 12500 & 12800 \\
\hline CLRS 11 & 1950 & 2000 & 1700 & 2000 & 1800 & 2000 & 1700 & 1950 & 1950 \\
\hline CLRS 12 & 2150 & 2200 & 1800 & 2200 & 1950 & 2150 & 1850 & 1950 & 1950 \\
\hline CLRS 13 & 7050 & 7700 & 7550 & 7750 & 7900 & 8100 & 8300 & 8500 & 8700 \\
\hline CLRS 14 & 5400 & 5600 & 5500 & 5600 & 5650 & 5700 & 5750 & 5800 & 5850 \\
\hline CLRS 15 & 5100 & 5150 & 5200 & 5250 & 6000 & 6100 & 5650 & 5450 & 5750 \\
\hline Ref 8 & 8550 & 8950 & 8900 & 8900 & 8300 & 9150 & 8500 & 8600 & 8700 \\
\hline Ref 9 & 4250 & 4300 & 4300 & 4350 & 4000 & 4000 & 4100 & 4250 & 4300 \\
\hline Ref 10 & 4100 & 4200 & 4250 & 4250 & 4300 & 4300 & 4350 & 4350 & 4400 \\
\hline Ref 11 & 7300 & 7400 & 7250 & 7700 & 6750 & 7750 & 7850 & 8000 & 8100 \\
\hline Ref 12 & 8100 & 8200 & 8150 & 8150 & 7700 & 7700 & 7700 & 5700 & 6200 \\
\hline
\end{tabular}


Appendix Table 10: CLRS Crash Data Before Period

\begin{tabular}{|l|l|l|l|l|l|}
\hline Type & Total & FI & PDO & App + SS & SV \\
\hline CLRS 1 & 197 & 57 & 140 & 17 & 163 \\
\hline CLRS 2 & 111 & 30 & 81 & 9 & 95 \\
\hline CLRS 3 & 79 & 26 & 53 & 5 & 62 \\
\hline CLRS 4 & 14 & 4 & 11 & 0 & 13 \\
\hline CLRS 5 & 376 & 100 & 285 & 31 & 308 \\
\hline CLRS 6 & 52 & 13 & 39 & 1 & 42 \\
\hline CLRS 7 & 114 & 22 & 92 & 6 & 101 \\
\hline CLRS 8 & 230 & 40 & 190 & 16 & 164 \\
\hline CLRS 9 & 260 & 64 & 199 & 45 & 161 \\
\hline CLRS 10 & 240 & 85 & 155 & 54 & 141 \\
\hline CLRS 11 & 73 & 19 & 54 & 3 & 55 \\
\hline CLRS 12 & 71 & 18 & 53 & 2 & 62 \\
\hline CLRS 13 & 145 & 45 & 100 & 11 & 118 \\
\hline CLRS 14 & 10 & 4 & 6 & 0 & 7 \\
\hline CLRS 15 & 361 & 83 & 278 & 21 & 264 \\
\hline
\end{tabular}

Appendix Table 11: CLRS Crash Data After Period

\begin{tabular}{|l|l|l|l|l|l|}
\hline Type & Total & FI & PDO & App + SS & SV \\
\hline CLRS 1 & 76 & 21 & 87 & 10 & 65 \\
\hline CLRS 2 & 75 & 16 & 59 & 7 & 53 \\
\hline CLRS 3 & 31 & 6 & 25 & 2 & 21 \\
\hline CLRS 4 & 7 & 1 & 6 & 0 & 7 \\
\hline CLRS 5 & 27 & 3 & 24 & 1 & 23 \\
\hline CLRS 6 & 4 & 2 & 2 & 0 & 4 \\
\hline CLRS 7 & 3 & 0 & 3 & 1 & 2 \\
\hline CLRS 8 & 10 & 3 & 7 & 0 & 8 \\
\hline CLRS 9 & 31 & 2 & 29 & 2 & 23 \\
\hline CLRS 10 & 11 & 2 & 9 & 0 & 6 \\
\hline CLRS 11 & 24 & 1 & 12 & 6 & 12 \\
\hline CLRS 12 & 14 & 1 & 13 & 1 & 12 \\
\hline CLRS 13 & 52 & 12 & 36 & 6 & 30 \\
\hline CLRS 14 & 26 & 1 & 5 & 0 & 5 \\
\hline CLRS 15 & 25 & 0 & 25 & 0 & 25 \\
\hline
\end{tabular}


Appendix Table 12: ELRS Crashes Before Period

\begin{tabular}{|l|l|l|l|l|l|}
\hline Type & Total & FI & PDO & App + SS & SV \\
\hline ELRS 1 & 73 & 17 & 56 & 7 & 48 \\
\hline ELRS 2 & 110 & 39 & 71 & 26 & 67 \\
\hline ELRS 3 & 143 & 34 & 109 & 9 & 104 \\
\hline ELRS 4 & 45 & 11 & 34 & 2 & 31 \\
\hline ELRS 5 & 3 & 0 & 3 & 0 & 1 \\
\hline ELRS 6 & 12 & 5 & 7 & 0 & 7 \\
\hline
\end{tabular}

Appendix Table 13: ELRS Crashes After Period

\begin{tabular}{|l|l|l|l|l|l|}
\hline Type & Total & FI & PDO & App + SS & SV \\
\hline ELRS 1 & 3 & 1 & 2 & 1 & 2 \\
\hline ELRS 2 & 23 & 2 & 21 & 2 & 12 \\
\hline ELRS 3 & 37 & 7 & 30 & 0 & 25 \\
\hline ELRS 4 & 87 & 27 & 60 & 6 & 37 \\
\hline ELRS 5 & 8 & 2 & 6 & 3 & 4 \\
\hline ELRS 6 & 19 & 6 & 13 & 1 & 15 \\
\hline
\end{tabular}

Appendix Table 14: Dual Rumble Strips Crashes Before Period

\begin{tabular}{|l|l|l|l|l|l|}
\hline Type & Total & FI & PDO & App + SS & SV \\
\hline Dual 1 & 118 & 31 & 87 & 10 & 87 \\
\hline Dual 2 & 246 & 72 & 174 & 24 & 154 \\
\hline Dual 3 & 45 & 8 & 37 & 2 & 32 \\
\hline Dual 4 & 139 & 31 & 108 & 12 & 94 \\
\hline Dual 5 & 163 & 36 & 127 & 10 & 130 \\
\hline
\end{tabular}

Appendix Table 15: Dual Rumble Strips Crashes After Period

\begin{tabular}{|l|l|l|l|l|l|}
\hline Type & Total & FI & PDO & App + SS & SV \\
\hline Dual 1 & 14 & 3 & 11 & 2 & 12 \\
\hline Dual 2 & 25 & 6 & 19 & 4 & 17 \\
\hline Dual 3 & 1 & 1 & 0 & 0 & 1 \\
\hline Dual 4 & 15 & 4 & 11 & 1 & 13 \\
\hline Dual 5 & 45 & 6 & 39 & 6 & 38 \\
\hline
\end{tabular}


Appendix Table 16: Tangent Sections Before and After Crash Data

\begin{tabular}{|c|c|c|c|c|c|c|c|c|}
\hline $\begin{array}{l}\text { Tangent } \\
\text { Reference }\end{array}$ & $\begin{array}{l}\text { Treatment } \\
\text { Type }\end{array}$ & $\begin{array}{l}\text { Tangent } \\
\text { or Curved }\end{array}$ & $\begin{array}{l}\text { Total } \\
\text { Before }\end{array}$ & $\begin{array}{l}\text { PDO } \\
\text { Before }\end{array}$ & $\begin{array}{l}\text { SV } \\
\text { Before }\end{array}$ & $\begin{array}{l}\text { Total } \\
\text { After }\end{array}$ & $\begin{array}{l}\text { PDO } \\
\text { After }\end{array}$ & $\begin{array}{l}\text { SV } \\
\text { After }\end{array}$ \\
\hline 13 & CLRS & Tangent & 16 & 12 & 14 & 7 & 6 & 6 \\
\hline 15 & CLRS & Tangent & 2 & 2 & 2 & 3 & 3 & 3 \\
\hline 17 & CLRS & Tangent & 3 & 3 & 3 & 2 & 1 & 2 \\
\hline 19 & CLRS & Tangent & 4 & 3 & 4 & 3 & 3 & 3 \\
\hline 33 & ELRS & Tangent & 11 & 6 & 7 & 23 & 11 & 11 \\
\hline 35 & ELRS & Tangent & 10 & 8 & 6 & 12 & 2 & 0 \\
\hline 37 & ELRS & Tangent & 64 & 51 & 53 & 25 & 23 & 24 \\
\hline 39 & ELRS & Tangent & 10 & 7 & 8 & 17 & 0 & 0 \\
\hline 41 & Dual & Tangent & 54 & 40 & 42 & 9 & 6 & 8 \\
\hline 43 & Dual & Tangent & 46 & 25 & 35 & 0 & 0 & 0 \\
\hline 44 & ELRS & Tangent & 24 & 17 & 15 & 24 & 34 & 30 \\
\hline 46 & ELRS & Tangent & 11 & 8 & 10 & 25 & 6 & 7 \\
\hline 47 & ELRS & Tangent & 23 & 18 & 18 & 23 & 6 & 6 \\
\hline 49 & ELRS & Tangent & 15 & 12 & 12 & 6 & 5 & 6 \\
\hline 51 & ELRS & Tangent & 11 & 10 & 8 & 10 & 2 & 4 \\
\hline 53 & Dual & Tangent & 146 & 88 & 111 & 20 & 15 & 14 \\
\hline 54 & Dual & Tangent & 3 & 2 & 2 & 1 & 1 & 1 \\
\hline 56 & Dual & Tangent & 29 & 13 & 17 & 6 & 4 & 5 \\
\hline 58 & Dual & Tangent & 67 & 43 & 49 & 10 & 6 & 5 \\
\hline 61 & Dual & Tangent & 31 & 29 & 22 & 3 & 3 & 3 \\
\hline 68 & ELRS & Tangent & 27 & 18 & 22 & 9 & 7 & 7 \\
\hline 70 & ELRS & Tangent & 32 & 22 & 23 & 6 & 5 & 3 \\
\hline 81 & CLRS & Tangent & 5 & 3 & 4 & 6 & 6 & 3 \\
\hline 83 & CLRS & Tangent & 11 & 5 & 10 & 10 & 8 & 7 \\
\hline 85 & CLRS & Tangent & 11 & 7 & 10 & 2 & 2 & 2 \\
\hline 87 & CLRS & Tangent & 3 & 3 & 3 & 4 & 2 & 4 \\
\hline 89 & CLRS & Tangent & 41 & 34 & 39 & 16 & 10 & 11 \\
\hline 91 & CLRS & Tangent & 17 & 11 & 13 & 0 & 0 & 0 \\
\hline 93 & CLRS & Tangent & 33 & 23 & 23 & 11 & 6 & 9 \\
\hline 95 & CLRS & Tangent & 13 & 9 & 11 & 2 & 2 & 1 \\
\hline 97 & CLRS & Tangent & 21 & 11 & 19 & 7 & 4 & 5 \\
\hline 101 & CLRS & Tangent & 3 & 3 & 3 & 2 & 2 & 2 \\
\hline 103 & CLRS & Tangent & 13 & 7 & 8 & 6 & 5 & 4 \\
\hline 107 & CLRS & Tangent & 2 & 1 & 1 & 0 & 0 & 0 \\
\hline
\end{tabular}


Appendix Table 17: Curved Sections Before and After Crash Data

\begin{tabular}{|c|c|c|c|c|c|c|c|c|}
\hline $\begin{array}{l}\text { Tangent } \\
\text { Reference }\end{array}$ & $\begin{array}{l}\text { Treatment } \\
\text { Type }\end{array}$ & $\begin{array}{l}\text { Tangent } \\
\text { or Curved }\end{array}$ & $\begin{array}{l}\text { Total } \\
\text { Before }\end{array}$ & $\begin{array}{l}\text { PDO } \\
\text { Before }\end{array}$ & $\begin{array}{l}\text { SV } \\
\text { Before }\end{array}$ & $\begin{array}{l}\text { Total } \\
\text { After }\end{array}$ & $\begin{array}{l}\text { PDO } \\
\text { After }\end{array}$ & $\begin{array}{l}\text { SV } \\
\text { After }\end{array}$ \\
\hline 12 & CLRS & Curved & 67 & 59 & 47 & 18 & 8 & 12 \\
\hline 14 & CLRS & Curved & 7 & 5 & 6 & 13 & 5 & 8 \\
\hline 16 & CLRS & Curved & 5 & 4 & 4 & 10 & 4 & 6 \\
\hline 18 & CLRS & Curved & 1 & 0 & 1 & 2 & 2 & 2 \\
\hline 20 & CLRS & Curved & 7 & 7 & 5 & 3 & 21 & 23 \\
\hline 34 & ELRS & Curved & 10 & 5 & 8 & 10 & 7 & 6 \\
\hline 36 & ELRS & Curved & 22 & 12 & 17 & 3 & 4 & 3 \\
\hline 38 & ELRS & Curved & 28 & 25 & 23 & 2 & 3 & 3 \\
\hline 40 & ELRS & Curved & 13 & 11 & 11 & 32 & 21 & 23 \\
\hline 42 & Dual & Curved & 84 & 68 & 64 & 5 & 5 & 4 \\
\hline 45 & ELRS & Curved & 4 & 68 & 64 & 6 & 5 & 5 \\
\hline 48 & ELRS & Curved & 57 & 3 & 3 & 2 & 2 & 2 \\
\hline 50 & ELRS & Curved & 9 & 50 & 46 & 11 & 8 & 7 \\
\hline 52 & Dual & Curved & 35 & 26 & 24 & 2 & 1 & 2 \\
\hline 55 & Dual & Curved & 36 & 21 & 29 & 26 & 24 & 18 \\
\hline 57 & Dual & Curved & 9 & 7 & 5 & 1 & 1 & 1 \\
\hline 59 & Dual & Curved & 56 & 36 & 38 & 1 & 1 & 1 \\
\hline 60 & Dual & Curved & 56 & 49 & 44 & 1 & 1 & 1 \\
\hline 69 & ELRS & Curved & 10 & 8 & 4 & 8 & 7 & 7 \\
\hline 80 & CLRS & Curved & 5 & 4 & 3 & 2 & 2 & 1 \\
\hline 82 & CLRS & Curved & 38 & 34 & 27 & 13 & 3 & 11 \\
\hline 84 & CLRS & Curved & 6 & 5 & 4 & 2 & 1 & 2 \\
\hline 86 & CLRS & Curved & 2 & 2 & 2 & 23 & 14 & 17 \\
\hline 88 & CLRS & Curved & 5 & 5 & 4 & 1 & 1 & 0 \\
\hline 90 & CLRS & Curved & 15 & 15 & 12 & 4 & 4 & 2 \\
\hline 92 & CLRS & Curved & 11 & 9 & 7 & 19 & 17 & 13 \\
\hline 94 & CLRS & Curved & 13 & 9 & 9 & 13 & 12 & 12 \\
\hline 96 & CLRS & Curved & 7 & 5 & 4 & 5 & 5 & 5 \\
\hline 98 & CLRS & Curved & 74 & 61 & 49 & 1 & 1 & 1 \\
\hline 100 & CLRS & Curved & 11 & 9 & 7 & 24 & 20 & 22 \\
\hline 102 & CLRS & Curved & 5 & 5 & 5 & 12 & 6 & 7 \\
\hline 104 & CLRS & Curved & 59 & 48 & 42 & 4 & 3 & 4 \\
\hline 105 & CLRS & Curved & 63 & 57 & 48 & 0 & 0 & 0 \\
\hline 106 & CLRS & Curved & 30 & 24 & 24 & 6 & 6 & 5 \\
\hline 108 & CLRS & Curved & 41 & 35 & 28 & 17 & 12 & 12 \\
\hline
\end{tabular}


Appendix Table 18: Tangent Sections SPF Calibration Table

\begin{tabular}{|c|c|c|c|c|c|c|c|}
\hline $\begin{array}{l}\text { Tangent } \\
\text { Reference }\end{array}$ & AADT & \begin{tabular}{|l|}
$\begin{array}{l}\text { Length } \\
\text { (mi) }\end{array}$ \\
\end{tabular} & $\begin{array}{l}\text { Shoulder } \\
\text { Type }\end{array}$ & \begin{tabular}{|l|} 
Shoulder \\
Width (ft) \\
\end{tabular} & $\begin{array}{l}\text { Lane Width } \\
\text { (ft) }\end{array}$ & $\begin{array}{l}\text { Total } \\
\text { Crashes }\end{array}$ & SV Crashes \\
\hline 1 & 6076 & 6.4 & 2 & 10 & 12 & 70 & 55 \\
\hline 2 & 6497 & 13.4 & 2 & 8 & 12 & 140 & 118 \\
\hline 3 & 3203 & 8.1 & 2 & 10 & 12 & 93 & 66 \\
\hline 4 & 4174 & 44.4 & 2 & 7 & 12 & 104 & 89 \\
\hline 6 & 4174 & 44.4 & 2 & 7 & 12 & 42 & 38 \\
\hline 8 & 4174 & 44.4 & 2 & 7 & 12 & 59 & 51 \\
\hline 10 & 4174 & 44.4 & 2 & 7 & 12 & 24 & 22 \\
\hline 11 & 4188 & 6.3 & 2 & 6 & 11 & 43 & 38 \\
\hline 21 & 7176 & 12.4 & 3 & 8 & 11 & 12 & 12 \\
\hline 23 & 7806 & 25.1 & 2 & 10 & 12 & 28 & 19 \\
\hline 25 & 7806 & 25.1 & 2 & 10 & 12 & 6 & 6 \\
\hline 27 & 7806 & 25.1 & 2 & 10 & 12 & 8 & 5 \\
\hline 29 & 7806 & 25.1 & 2 & 10 & 12 & 88 & 65 \\
\hline 31 & 7806 & 25.1 & 2 & 10 & 12 & 10 & 9 \\
\hline 63 & 3771 & 18.2 & 2 & 6 & 12 & 59 & 44 \\
\hline 65 & 3771 & 18.2 & 2 & 6 & 12 & 55 & 45 \\
\hline 67 & 3771 & 18.2 & 2 & 6 & 12 & 25 & 20 \\
\hline 68 & 3771 & 18.2 & 2 & 6 & 12 & 1 & 1 \\
\hline 71 & 8594 & 26.4 & 2 & 8 & 12 & 48 & 42 \\
\hline 73 & 8594 & 26.4 & 2 & 8 & 12 & 5 & 4 \\
\hline 75 & 8594 & 26.4 & 2 & 8 & 12 & 4 & 4 \\
\hline 77 & 8594 & 26.4 & 2 & 8 & 12 & 27 & 25 \\
\hline 79 & 8594 & 26.4 & 2 & 8 & 12 & 9 & 8 \\
\hline 109 & 6226 & 81.9 & 2 & 10 & 12 & 219 & 174 \\
\hline 111 & 6226 & 81.9 & 2 & 10 & 12 & 167 & 126 \\
\hline 113 & 6226 & 81.9 & 2 & 10 & 12 & 167 & 120 \\
\hline 115 & 4724 & 47.2 & 2 & 8 & 12 & 166 & 143 \\
\hline 117 & 5209 & 32.0 & 3 & 10 & 12 & 125 & 92 \\
\hline 120 & 6150 & 43.6 & 2 & 10 & 12 & 57 & 40 \\
\hline 122 & 6150 & 43.6 & 2 & 10 & 12 & 8 & 6 \\
\hline 124 & 6150 & 43.6 & 2 & 10 & 12 & 19 & 14 \\
\hline 126 & 6150 & 43.6 & 2 & 10 & 12 & 112 & 77 \\
\hline 128 & 6150 & 43.6 & 2 & 10 & 12 & 27 & 21 \\
\hline 130 & 6150 & 43.6 & 2 & 10 & 12 & 95 & 48 \\
\hline 132 & 6076 & 9.7 & 2 & 10 & 12 & 51 & 40 \\
\hline 135 & 2735 & 10.9 & 3 & 7 & 11 & 68 & 59 \\
\hline 136 & 2935 & 16.1 & 2 & 8 & 12 & 110 & 97 \\
\hline 137 & 2603 & 16.4 & 1 & 8 & 12 & 68 & 54 \\
\hline 138 & 4235 & 27.2 & 2 & 0 & 12 & 291 & 242 \\
\hline
\end{tabular}


Appendix Table 19: Rumble Strip Treated Site data for HSM Study

\begin{tabular}{|c|c|c|c|c|c|c|c|c|}
\hline $\begin{array}{l}\text { Tangent } \\
\text { reference }\end{array}$ & $\begin{array}{l}\text { RS } \\
\text { Type }\end{array}$ & $\begin{array}{l}\text { Average } \\
\text { AADT }\end{array}$ & $\begin{array}{l}\text { Years } \\
\text { After }\end{array}$ & $\begin{array}{l}\text { Shoulder } \\
\text { Type }\end{array}$ & $\begin{array}{l}\text { Shoulder } \\
\text { Width (ft) }\end{array}$ & $\begin{array}{l}\text { Length } \\
\text { (mi) }\end{array}$ & Total & SV \\
\hline 13 & CLRS & 4317 & 6 & 2 & 0 & 1.8 & 7 & 6 \\
\hline 15 & CLRS & 4317 & 6 & 2 & 0 & 0.6 & 3 & 3 \\
\hline 17 & CLRS & 4317 & 6 & 2 & 0 & 0.6 & 2 & 2 \\
\hline 19 & CLRS & 4317 & 6 & 2 & 0 & 1.8 & 3 & 3 \\
\hline 33 & ELRS & 4550 & 10 & 1 & 8 & 2.4 & 23 & 11 \\
\hline 35 & ELRS & 13067 & 8 & 2 & 10 & 1.6 & 12 & 0 \\
\hline 37 & ELRS & 13067 & 8 & 2 & 10 & 6.0 & 25 & 24 \\
\hline 39 & ELRS & 13067 & 8 & 2 & 10 & 1.3 & 17 & 0 \\
\hline 41 & BOTH & 14000 & 2 & 2 & 10 & 4.8 & 9 & 6 \\
\hline 43 & BOTH & 14000 & 2 & 2 & 10 & 5.8 & 0 & 0 \\
\hline 44 & ELRS & 12033 & 8 & 2 & 10 & 4.3 & 24 & 30 \\
\hline 46 & ELRS & 12033 & 8 & 2 & 10 & 2.3 & 25 & 7 \\
\hline 47 & ELRS & 9100 & 5 & 2 & 10 & 1.0 & 23 & 6 \\
\hline 49 & ELRS & 9100 & 5 & 2 & 10 & 2.9 & 6 & 6 \\
\hline 51 & ELRS & 9100 & 5 & 2 & 10 & 1.3 & 10 & 4 \\
\hline 53 & BOTH & 9583 & 2 & 1 & 10 & 12.1 & 20 & 15 \\
\hline 54 & BOTH & 8633 & 2 & 2 & 10 & 0.6 & 1 & 1 \\
\hline 56 & BOTH & 8633 & 2 & 2 & 10 & 4.3 & 6 & 4 \\
\hline 58 & BOTH & 8633 & 2 & 2 & 10 & 11.9 & 10 & 6 \\
\hline 61 & ВOTH & 6667 & 2 & 2 & 10 & 3.7 & 3 & 3 \\
\hline 68 & ELRS & 8050 & 4 & 2 & 10 & 2.7 & 9 & 7 \\
\hline 70 & ELRS & 8050 & 4 & 2 & 10 & 4.8 & 6 & 3 \\
\hline 81 & CLRS & 10933 & 4 & 2 & 8 & 0.3 & 6 & 3 \\
\hline 83 & CLRS & 6767 & 6 & 2 & 8 & 2.6 & 10 & 7 \\
\hline 85 & CLRS & 6767 & 6 & 2 & 8 & 1.1 & 2 & 2 \\
\hline 87 & CLRS & 6767 & 6 & 2 & 8 & 0.6 & 4 & 4 \\
\hline 89 & CLRS & 6767 & 6 & 2 & 8 & 4.8 & 16 & 11 \\
\hline 91 & CLRS & 6767 & 6 & 2 & 8 & 1.0 & 0 & 0 \\
\hline 93 & CLRS & 6767 & 6 & 2 & 8 & 1.1 & 11 & 9 \\
\hline 95 & CLRS & 10933 & 4 & 2 & 8 & 1.6 & 2 & 1 \\
\hline 97 & CLRS & 10933 & 4 & 2 & 8 & 2.7 & 7 & 5 \\
\hline 101 & CLRS & 4067 & 5 & 2 & 8 & 1.6 & 2 & 2 \\
\hline 103 & CLRS & 3900 & 5 & 2 & 8 & 2.7 & 6 & 4 \\
\hline 107 & CLRS & 10933 & 4 & 2 & 8 & 1.3 & 0 & 0 \\
\hline
\end{tabular}




\section{References}

American Association of State Highway and Transportation Officials (AASHTO). (2010). Highway Safety Manual, First Edition. Washington, D.C.

Bahar, G., Wales, J., \& Longtin-Nobel, L. (2001). Best Practices for the Implementation of Shoulder and Centreline Rumble Strips. Ottawa: Transportation Association of Canada (TAC).

Carter, D., Srinivasan, R., Gross, F., Himes, S., Le, T., Bonneson, J., \& Hauer, E. (2017). Guidance for the Development and Application of Crash Modification Factors. Chapel Hill: University of North Carolina - Chapel Hill.

Chen, Y., \& Persaud, B. (2014). Methodology to develop crash modification functions for road safety treatments with fully specified and hierarchical models. Accident Analysis \& Prevention, 70, 131139.

Eskandar, M. (2018). Case Studies on Estimating Crash Modification Factors for Treatment Combinations with Empirical Investigation of Dual Rumble Strip Application in Onatrio. Toronto: Ryerson University.

Faisal. (2011). Calibration of Highway Safety Manual Predictive Models and Validation of Safety Performance Functions for Canadian Urban/Suburban Intersections. Toronto: Ryerson University.

Federal Highway Administration (FHWA). (2019, 03 15). Retrieved from CMF Clearinghouse: http://www.cmfclearinghouse.org/index.cfm

Gross, F., Persaud, B., \& Lyon, C. (2010). A Guide to Developing Quality Crash Modification Factors. Washington D.C. 
Hauer, E. (1997). Observational Before-After Studies in Road Safety. Estimating the Effect of Highway and Traffic Engineering Measures on Road Safety. Elsevier Science.

Hauer, E. (2015). The Art of Regression Modelling in Road Safety. Springer .

IBM. (2017). IBM SPSS Statistics V25.0.

Ivan, J. N., Mamun, S. A., Ravishanker, N., Persaud, B., Lyon, C., Srinivasan, R., . . Wang, J.-H. (2018). Improved Prediction Models for Crash Types and Crash Severities. NCHRP.

Lyon, C., Persaud, B., \& Donnell, E. (2018). Safety Evaluation of the SafetyEdge Treatment for Pavement Edge Drop-Offs on Two-Lane Rural Roads. Transportation Research Record 2672(30), pp. 1-8.

Lyon, C., Persaud, B., \& Gross, F. (2016, November 29). Calibrator.

Microsoft. (n.d.). Excel 2016. Microsoft.

Osama, A., Sayed, T., \& Sacchi, E. (2016). Crash Modification Functions for Installation of Left-Turn Lanes at Signalized Intersection Approaches. Transportation Research Record: Journal of the Transporation Research Board, 2583(1), 42-49.

Park, J., \& Abdel-Aty, M. A. (2017). Alternative Approach for Combining Multiple Crash Modification Factors Using Adjustment Function and Analytic Hierarchy Process. Transportation Research Record, 2636(1), 15-22.

Persaud, B., Lyon, C., Eccles, K., \& Soika, J. (2016). Safety Effectiveness of Centerline Plus Shoulder Rumble Strips on Two-Lane Rural Roads. Journal of Transportation Engineering, 142(5).

SAS Institute. (2014). SAS. SAS Institute. 
Sayed, T., DeLeur, P., \& Pump, J. (2010). Impact of rumble strips on collision reduction on highways in british columbia, canada: Comprehensive before-and-after safety study. Transportation Research Record: Journal of the Transportation Research Board, 2148(1), 9-15.

Torbic, D. J., Hutton, J. M., Bokenkroger, C. D., Bauer, K. M., Harwood, D. W., Gilmore, D. K., . . Lyon, C. (2009). Guidance for the design and application of shoulder and centerline rumble strips . Transportation Research Board.

Transport Canada. (2019, February 27). Canadian Motor Vehicle Traffic Collsion Statistics: 2017. Retrieved from Government of Canada: https://www.tc.gc.ca/eng/motorvehiclesafety/canadian-motor-vehicle-traffic-collisionstatistics-2017.html

World Health Organization. (2019). Global Status Report on Road Safety. World Health Organization. 